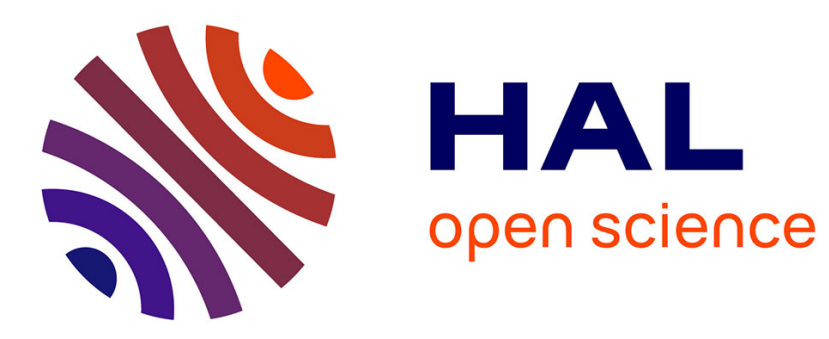

\title{
Antiarrhythmics for maintaining sinus rhythm after cardioversion of atrial fibrillation
}

Lucie Valembois, Etienne Audureau, Andrea Takeda, Witold Jarzebowski, Joël Belmin, Carmelo Lafuente-Lafuente

\section{To cite this version:}

Lucie Valembois, Etienne Audureau, Andrea Takeda, Witold Jarzebowski, Joël Belmin, et al.. Antiarrhythmics for maintaining sinus rhythm after cardioversion of atrial fibrillation. Cochrane database of systematic reviews (Online), 2020, 10.1002/14651858.cd005049.pub4 . hal-02985938

\section{HAL Id: hal-02985938 \\ https: / hal.sorbonne-universite.fr/hal-02985938}

Submitted on 2 Nov 2020

HAL is a multi-disciplinary open access archive for the deposit and dissemination of scientific research documents, whether they are published or not. The documents may come from teaching and research institutions in France or abroad, or from public or private research centers.
L'archive ouverte pluridisciplinaire HAL, est destinée au dépôt et à la diffusion de documents scientifiques de niveau recherche, publiés ou non, émanant des établissements d'enseignement et de recherche français ou étrangers, des laboratoires publics ou privés. 


\section{Antiarrhythmics for maintaining sinus rhythm after cardioversion of atrial fibrillation}

\section{Review information}

\section{Review number: 0331}

\section{Authors}

Lucie Valembois ${ }^{1}$, Etienne Audureau ${ }^{2}$, Andrea Takeda ${ }^{3}$, Witold Jarzebowski ${ }^{4}$, Joël Belmin ${ }^{5}$, Carmelo Lafuente-Lafuente ${ }^{1}$

${ }^{1}$ Service de Gériatrie à Orientation Cardiologique et Neurologique, Groupe Hospitalier PitiéSalpêtrière-Charles Foix, AP-HP, Université Pierre et Marie Curie, Ivry-sur-Seine, France

${ }^{2}$ Service de Santé Publique, Hôpital Henri-Mondor, APHP, Université Paris 12 UPEC,

Créteil, France

${ }^{3}$ Institute of Health Informatics Research, University College London, London, UK

${ }^{4}$ Gériatrie à orientation Cardiologique, Hôpitaux universitaires Pitié-Salpêtrière-Charles Foix, APHP, Ivry-sur-Seine, France

${ }^{5}$ La Triade - Service Hospitalo-Universitaire de Gérontologie, Université Pierre et Marie Curie (Paris 6), Paris, France

Citation example: Valembois L, Audureau E, Takeda A, Jarzebowski W, Belmin J, LafuenteLafuente C. Antiarrhythmics for maintaining sinus rhythm after cardioversion of atrial fibrillation. Cochrane Database of Systematic Reviews 2015, Issue 3. Art. No.: CD005049. DOI: 10.1002/14651858.CD005049.pub4.

\section{Contact person}

\section{Carmelo Lafuente-Lafuente}

Service de Gériatrie à Orientation Cardiologique et Neurologique

Groupe Hospitalier Pitié-Salpêtrière-Charles Foix, AP-HP, Université Pierre et Marie Curie

7 Avenue de la République

94205 Ivry-sur-Seine

Ile-de-France

France

E-mail: c.lafuente@nodo3.net

E-mail 2: carmelo.lafuente@cfx.ap-hop.paris.fr

\section{Abstract}




\section{Background}

Atrial fibrillation is the most frequent sustained arrhythmia. Atrial fibrillation frequently recurs after restoration of normal sinus rhythm. Antiarrhythmic drugs have been widely used to prevent recurrence, but the effect of these drugs on all-cause mortality and other clinical outcomes is unclear. This is an update of a review previously published in 2007, 2012 and 2015.

\section{Objectives}

To determine in patients who have recovered sinus rhythm after having atrial fibrillation, the effects of long-term treatment with antiarrhythmic drugs on death, stroke, embolism, drug adverse effects and recurrence of atrial fibrillation.

\section{Search methods}

We updated the searches of CENTRAL in the Cochrane Library, MEDLINE, Embase in January 2019 and ClinicalTrials.gov and WHO ICTRP in February 2019. The reference lists of retrieved articles, recent reviews and meta-analyses were checked.

\section{Selection criteria}

Two authors independently selected randomised controlled trials (RCTs) comparing any antiarrhythmic drug with a control (no treatment, placebo, drugs for rate control) or with another antiarrhythmic drug in adults who had atrial fibrillation and in whom sinus rhythm was restored, spontaneously or by any intervention. Post-operative atrial fibrillation was excluded.

\section{Data collection and analysis}

Two authors independently assessed quality and extracted data. Studies were pooled, if appropriate, using Mantel-Haenszel Risk Ratios (RR). All results were calculated at one year of follow-up or the nearest time point.

\section{Main results}

In this update one new study (100 patients) was included and one study previously included was excluded because of double publication. Finally, a total of 59 randomised controlled trials comprising 20,981 patients were included. Overall, mean follow-up was 10.2 months.

\section{All-cause mortality}

High-quality evidence from five RCTs indicated that treatment with sotalol was associated with a higher all-cause mortality rate, compared with placebo or no treatment (RR 2.23, 95\% CI 1.03 to 4.81; participants $=1882$ ). The NNTH for sotalol was 102 patients treated for one year to have one excess death. Low-quality evidence from six RCTs strongly suggested that 
risk of mortality was higher in people taking quinidine, although the confidence interval also includes the possibility of no difference (RR $2.01,95 \%$ CI 0.84 to 4.77 ; participants $=1646$ ).

No effect on mortality was apparent with the remaining drugs studied, but less data was available for them and it could be underpowered to detect small increases in mortality. In particular, very few data was available for flecainide (no death reported in any treatment arm in 4 RCTs studying flecainide, participants $=511$ ) and propafenone (only 2 deaths reported in 5 included RCTs, participants $=998$ ).

\section{Withdrawals due to adverse events, Proarrhythmia}

All analysed drugs increased withdrawals due to adverse effects compared to placebo or no treatment (Quinidine, RR 1,56; Dronedarone, RR 1,58; Propafenone, RR 1,62; Sotalol, RR 1,95; Metoprolol, RR 3,47; Amiodarone, RR 6,7; Flecainide, RR 15,41). Certainty of the evidence for this outcome was low for amiodarone, dofetilide and flecainide; moderate to high for the remaining drugs.

Virtually all studied antiarrhythmics showed increased pro-arrhythmic effects (counting both tachyarrhythmias and bradyarrhythmias attributable to treatment) (Propafenone, RR 1,32; Dronedarone, RR 1,95; Quinidine, RR 2,05; Amiodarone, RR 2,22; Sotalol, RR 3,55; Flecainide, RR 4,80; Metoprolol, RR 18,14). Certainty of the evidence for this outcome was moderate to high, except for propafenone, which was very low because of small sample size and unclear risk of bias.

\section{Prevention of recurrences of atrial fibrillation}

Moderate to high-quality evidence showed that all analysed drugs, including metoprolol, reduced recurrence of atrial fibrillation (Amiodarone, RR 0,52; Flecainide, RR 0,65; Propafenone, RR 0,67; Quinidine, RR 0,83; Sotalol, RR 0,83; Metoprolol, RR 0,83; Dronedarone, RR 0,85).

\section{Clinical outcomes}

Only 11 studies reported stroke outcomes. Low to very-low quality evidence showed no apparent effect on stroke rates of antiarrhythmic treatment, with the only exception of dronedarone. High-quality evidence from two RCTs suggested that dronedarone may be associated with reduced risk of stroke (RR 0.66, 95\% CI 0.47 to 0.95 ; participants $=5872$ ). This result, however, is due to a single large study and to date have not be reproduced in other studies.

Seven trials reported data on the incidence of heart failure, which was low. There were no differences in those trials between patients receiving antiarrhythmics and patients receiving placebo or no treatment (Low-quality evidence).

\section{Authors' conclusions}

There is high-quality evidence of increased mortality associated with sotalol treatment, and low-quality evidence strongly suggesting increased mortality also with quinidine, when employed for maintaining sinus rhythm in patients with atrial fibrillation. These drugs should 
not be employed for this indication, or used with extreme caution. Caution should also be taken when using flecainide, as very few data on mortality is available for this drug when employed for maintaining sinus rhythm, making impossible any reliable estimation, and there is moderate-quality evidence of marked increases in pro-arrhythmia and adverse effects.

Overall, there is evidence showing that antiarrhythmic drugs increase adverse events, increase pro-arrhythmic events and some of them may increase mortality. Conversely, although they reduce recurrences of atrial fibrillation, there is no evidence of any benefit on clinical outcomes. In the light of these results, chronic treatment with antiarrhythmics drugs should not be considered as a first-line treatment for maintaining sinus rhythm in patients with atrial fibrillation.

\section{Plain language summary}

\section{Antiarrhythmics for maintaining sinus rhythm after reversing atrial fibrillation}

\section{Review question}

We reviewed the evidence about the effect of various specific medications (called "antiarrhythmics") on mortality, stroke rate, withdrawals due to adverse effects and recurrences, in people who had recovered normal heart rythm after suffering atrial fibrillation (a type of heart arrhythmia).

\section{Background}

Atrial fibrillation is a disease where the heart rhythm is irregular (this is called arrhythmia) and often, but not always, too fast. Atrial fibrillation may produce complications, either in the heart (heart failure, syncope) or in other organs by causing embolisms, this is, the formation of blood clots in the cavities of the heart that may then travel to other places, for example the brain.

Atrial fibrillation can be reverted, restoring normal heart rhythm, by using medications or a controlled electrical shock. However, a major problem is that atrial fibrillation frequently recurs. A variety of medications have been employed to avoid these recurrences and keep the normal heart rhythm.

\section{Study characteristics}

This is an update of a review previously published in 2007, 2012 and 2015, with results of a search in January 2018 incorporated. We found 59 studies testing various antiarrhythmic drugs and involving 20,981 patients. The mean age of patients was 65 years. The most frequent diseases were hypertension and diseases of the arteries and valves of the heart.

\section{Key results and quality of the evidence}


The cumulative data from these studies showed that some of these medications (quinidine, disopyramide and sotalol) may cause a small increase in the number of deaths in treated patients (moderate-quality evidence).

The data also showed that several drugs are effective at preventing recurrences of atrial fibrillation (quinidine, disopyramide, flecainide, propafenone, amiodarone, dofetilide, dronedarone, metoprolol and sotalol) but that all of them increased adverse effects (the evidence was of moderate quality for both outcomes).

Less data were available on the risk of embolic stroke (only 11 studies) and no consistent evidence of an effect on this outcome was apparent (low-quality evidence: not enough data and results not similar across studies). Finally, too few studies reported data on heart failure and the use of anticoagulants to be able to analyse the findings.

Thus, it is unclear if the long-term benefits obtained with antiarrhythmic medications in this use outweigh their risks.

\section{Background}

\section{Description of the condition}

Atrial fibrillation is the most common sustained arrhythmia and its incidence increases substantially with age (Go 2001; Knuiman 2014; Ruigomez 2002). Atrial fibrillation is associated with increased morbidity and mortality, due to stroke, other embolic complications and heart failure (Benjamin 1998; Heeringa 2006; Krahn 1995; Stewart 2002). In developed countries, atrial fibrillation has grown progressively in the last few decades as a contributing cause of hospitalisation and death (Chugh 2014; MMWR 2003; Wattigney 2003).

In people who have atrial fibrillation, normal sinus rhythm is interrupted by periods of atrial fibrillation that may be either symptomatic or asymptomatic. Symptoms can be mild (for example palpitations, breathlessness or reduced effort capacity) or severe, causing syncope, heart failure or acute coronary syndrome. Many of the symptoms caused by atrial fibrillation are related to the degree of tachycardia and can be improved by either controlling heart rate (rate control strategy) or converting atrial fibrillation to normal sinus rhythm by electrical or pharmacological means (rhythm control strategy).

Most patients alternate between atrial fibrillation and sinus rhythm. The frequency and duration of atrial fibrillation are highly variable, both within patients and between patients, and are employed to classify this arrhythmia (ESC 2016; ACC/AHA/ESC 2014; NICE 2014). If the arrhythmia terminates spontaneously, atrial fibrillation is designated as 'paroxysmal', and it may recur afterwards or not. When atrial fibrillation is sustained beyond seven days it is designated as 'persistent'. Termination with pharmacological or electrical intervention does not change the designation. When atrial fibrillation is first detected, and it is not known if it will resolve or persist, it is designated 'recent onset' or simply 'first detected' atrial fibrillation. Finally, 'permanent' atrial fibrillation refers to persistent atrial fibrillation where cardioversion has failed or has not been attempted because it is considered that there is no possibility to restore sinus rhythm. An individual patient can show different classes of atrial fibrillation over time. 


\section{Description of the intervention}

Many patients recover sinus rhythm spontaneously after an episode of recent onset atrial fibrillation, as many as 70\% in some studies (Geleris 2001). Electrical and pharmacological cardioversion are very effective in restoring sinus rhythm, even in long-standing persistent atrial fibrillation. However, a major problem is that recurrence of atrial fibrillation occurs frequently. The risk of recurrence of atrial fibrillation is dependent on age, duration of the atrial fibrillation and the existence and severity of underlying heart disease (Flaker 1995; Frick 2001). The overall rate of recurrence of atrial fibrillation without treatment is high; of patients who have converted to sinus rhythm, only $20 \%$ to $30 \%$ will remain in sinus rhythm one year later (Gelder 1996; Golzari 1996; AFFIRM 2002).

Long-term antiarrhythmic therapy has been widely used to prevent the recurrence of atrial fibrillation. Antiarrhythmic drugs are usually grouped into four classes following the classification by Vaughan Williams (Vaughan Williams 1984). Class I drugs are those with a direct membrane action (sodium ( $\mathrm{Na}$ ) channel blockade), subdivided to Ia, Ib and Ic depending on specific effects on conduction and repolarization; class II drugs are betablockers; class III drugs are those that prolong repolarization; and class IV drugs are calcium channel blockers. There is evidence that several class I, class III and maybe class II antiarrhythmic drugs are more effective than placebo for maintaining sinus rhythm (Miller 2000; Nichol 2002). However, some questions remain concerning the long term use of antiarrhythmic drugs.

\section{How the intervention might work}

It has been assumed that keeping patients in sinus rhythm would improve their quality of life and reduce the risks of embolism, stroke, heart failure or increased mortality that are associated with atrial fibrillation (Anter 2009). However, this has not been proven and, unfortunately, many of the trials with antiarrhythmic drugs have focused only on maintenance of sinus rhythm and have not assessed other relevant outcomes (Connolly 2000). Overall, the rhythm control strategy, using antiarrhythmics to maintain sinus rhythm, has not shown any clear benefit on clinical outcomes (for example mortality or stroke) in randomised controlled trials compared to a rate control strategy (Caldeira 2012; Chatterjee 2013; Cordina 2005; Denus 2005; Testa 2005).

Chronic treatment with antiarrhythmic drugs can be associated with severe adverse effects, including the potential induction of life-threatening arrhythmias (a phenomenon called "proarrhythmia"). Adverse effects could compromise any benefits of maintaining sinus rhythm, or even outweigh them, leading to worse outcomes overall. In fact, the results of some trials show increased mortality associated with the long-term use of some antiarrhythmics, as in the case with quinidine (Coplen 1990; SPAF 1992) or flecainide (CAST 1991). Finally, it is not known if all antiarrhythmic drugs are equivalent in their effectiveness and safety in the treatment of atrial fibrillation.

\section{Why it is important to do this review}

Many trials have studied long-term treatment with diverse antiarrhythmic drugs for maintaining sinus rhythm, sometimes compared to placebo and sometimes compared to other 
antiarrhythmic drugs. Attempts to summarise this evidence in systematic reviews of trials or meta-analyses have been incomplete. They were combined in a narrative review (Golzari 1996); trials using different antiarrhythmics and with very dissimilar lengths of treatment were pooled together (Nichol 2002); and outcomes other than sinus rhythm maintenance were not evaluated (Miller 2000). Consequently, we planned to conduct a more exhaustive systematic review of randomised controlled trials studying the long-term use of antiarrhythmic drugs to maintain sinus rhythm and aimed to determine their effects not only on the recurrence of atrial fibrillation but also on other important clinical outcomes.

After the first publication of this review, another meta-analysis on the same subject was published by Freementle et al (Freemantle 2011). This meta-analysis employed a mixed treatment comparison method, combining the estimates obtained from direct and indirect comparisons in a network of trials. Network meta-analysis represents an interesting extension of traditional pairwise meta-analyses and can potentially provide a more complete overview of a health set. However, appropriate use of these methods requires strict assumptions and standardization (Caldwell 2015). Although assumptions underlying classical pairwise metaanalyses are well understood, those concerning network meta-analysis are more complex and prone to misinterpretation. The conduction of network meta-analysis still poses multiple challenges that should be carefully considered when utilizing such methods (Cipriani 2013; Tonin 2017).

In any case, after the first publication of this review in 2007 and the publication of the metaanalysis by Freemantle et al, several new randomised controlled trials have been published. We have systematically searched, assessed and, when found adequate, included any new trial in this domain in the successive updates of this review.

\section{Objectives}

To determine in patients who have recovered sinus rhythm after having atrial fibrillation, the effects of long-term treatment with antiarrhythmic drugs on death, stroke, embolism, drug adverse effects and recurrence of atrial fibrillation.

The primary aim was to assess the effects of any antiarrhythmic drug compared with no antiarrhythmic treatment, that is no treatment, placebo, or treatment for rate control. If several antiarrhythmic drugs appeared to be effective the secondary aim was to compare them.

\section{Methods}

\section{Criteria for considering studies for this review}

\section{Types of studies}

Randomised controlled trials with concealed allocation of participants to intervention or placebo. We excluded studies that were not randomised or that used an overt allocation method, where future assignments could be anticipated (e.g. by date, by entry number, alternating or rotating). We also excluded cross-over studies (as the recurrence rate of AF is not uniform over time), cluster-randomized studies (more prone to selection bias and to local 
variations in other intervention applied to AF patients) and studies where duration of follow up was less than six months.

\section{Types of participants}

Adults (> 16 years) who had atrial fibrillation of any type and duration and in whom sinus rhythm had been restored, spontaneously or by any therapeutic intervention.

We excluded patients with atrial fibrillation following cardiac surgery as well as patients with any condition causing a life expectancy of less than 12 months.

\section{Types of interventions}

To be included, studies must have randomly allocated patients to an intervention group and a control group. The intervention group must have received oral long-term treatment with any available antiarrhythmic drug, at an appropriate dosing regime, aimed at preventing new episodes of atrial fibrillation and maintaining sinus rhythm.

For the primary comparison of the review the control group was no active treatment, this is, any of the following: placebo, no treatment, or drugs for rate control (digoxin, calcium channel blockers, beta-blockers).

For the secondary objective of evaluating differences between antiarrhythmic drugs, the control group could be any of the other antiarrhythmic drugs that have shown effectiveness compared to no antiarrhythmic treatment.

Both groups, intervention and control, had to be similar with regard to cardiac disease (frequency, type and severity) and type of atrial fibrillation (especially duration). Also, both groups must have been treated similarly apart from the experimental therapy, that is:

1. the guidelines used to manage initiation, discontinuation, dose and surveillance of anticoagulation had to be the same in both the intervention and control groups;

2. management and drugs used for hypertension and heart failure had to be similar.

\section{Types of outcome measures}

\section{Primary outcomes}

1. Mortality, all-cause

2. Stroke, all types

3. Adverse effects: Withdrawals from taking the study drug caused by adverse events

4. Adverse effects: Pro-arrhythmia, including any of the following: sudden death, any new symptomatic arrhythmia (including symptomatic bradycardia), aggravation of existing arrhythmias (i.e. rapid atrial fibrillation) and new appearance on electrocardiogram of QRS or QT widening that leads to stopping treatment (Friedman $\underline{1998)})$

\section{Secondary outcomes}


1. Recurrence of atrial fibrillation (number of patients who had a recurrence of atrial fibrillation during follow up)

2. Use of anticoagulation (number of patients started on long-term treatment with anticoagulants at the end of follow up)

3. Heart failure

We analysed all outcomes at 12 months. If a trial did not measure outcomes at these exact time point then the nearest measure point was used (e.g. at 6,9 or 15 months instead of 12 months).

\section{Search methods for identification of studies}

\section{Electronic searches}

The searches from 2005 (Appendix 1), 2010 (Appendix 2) and 2014 (Appendix 3) have been updated and were re-run on 31 January 2019 (Appendix 4).

We searched the Cochrane Central Register of Controlled Trials (CENTRAL) in the Cochrane Library (2019, Issue 1 of 12), MEDLINE (Ovid, 1946 to 28 January 2019) and Embase (Ovid, 1980 to 2019 week 4).

We also searched two clinical trials registers; ClinicalTrials.gov (www.clinicaltrials.gov) (up to 7 February 2019) and the World Health Organisation International Clinical Trials Registry Platform (ICTRP) (http://apps.who.int/trialsearch/) (up to 7 February 2019).

The RCT filter for MEDLINE is the Cochrane sensitivity-maximising RCT filter, and for EMBASE, terms as recommended in the Cochrane Handbook have been applied (Lefebvre $\underline{2011)}$.

\section{Searching other resources}

In addition, we checked the reference lists of retrieved studies as well as the reference lists of recent guidelines, meta-analyses and general reviews on atrial fibrillation.

We applied no language restrictions.

\section{Data collection and analysis}

\section{Selection of studies}

The titles (and abstracts where available) were read by the any of the authors and any publication that seemed to possibly meet the above criteria was retrieved. Two independent authors read the full texts of the studies that were retrieved and selected the trials that met the criteria for inclusion. A predefined form was developed and used for this task. The selected trials were compared and any discrepancy resolved by discussion and consensus between the authors. The articles that were finally selected for the review were checked to avoid duplication of data. Records of the selection process were kept and a PRISMA flowchart was prepared (PRISMA 2009). 


\section{Data extraction and management}

Two authors (LV, WJ, JB, CLL) extracted data independently using a data collection form specifically developed for this task. When necessary, we contacted the authors of primary studies for additional information. We checked the completed data forms for agreement and resolved any differences by discussion and consensus.

In addition to data relating to the outcomes of the review, we collected information on the following.

1. Study methods and design (randomisation, allocation concealment and blinding).

2. Baseline characteristics of patients (age, gender, frequency and type of heart disease, echocardiographic measures, duration and type of atrial fibrillation, as defined in each study and knowing that definitions employed have not been always consistent).

3. Details of treatments (method of cardioversion employed, time interval between conversion to sinus rhythm and initiation of intervention, antiarrhythmic drugs used and dose, treatment used in control group, concomitant treatments (beta-blockers, angiotensin converting enzyme inhibitors, antiplatelets and warfarin)).

4. Follow-up duration, patients lost to follow up and withdrawals.

\section{Assessment of risk of bias in included studies}

Two authors (LV, EA, WJ, JB, CLL) independently assessed the risk of bias of the selected studies across the main domains of risk of bias, as recommended in the Cochrane Handbook for Systematic Reviews of Interventions (Higgins 2017): random sequence generation, blinding of participants and personnel, blinding of outcome assessment, incomplete outcome data and selective reporting.

Any differences of opinion were resolved by discussion and consensus.

\section{Measures of treatment effect}

Risk ratio (RR) was determined for all outcomes as they are all dichotomous variables. If evidence of an effect appeared for any outcome and the control group rates of the outcomes were broadly similar, we calculated the number needed to treat to benefit (NNTB) or number needed to treat to harm (NNTH) to prevent or produce, respectively, one adverse outcome for the specified duration of treatment. We used the pooled RR and the pooled rate from the control groups.

\section{Unit of analysis issues}

There was no cross-over trial or cluster randomised trial included in this review. For trials with multiple timepoints, only data at one year (or the nearest timepoint) was included. For trials comparing two antiarrhythmics and placebo/no treatment, the placebo (or no treatment) group was spliced into two groups with smaller sample size, to include two different comparisons.

\section{Dealing with missing data}


We analysed the data on the basis of intention to treat. By default, missing patients were considered not to have experienced an event and we used the randomized number of patients as the denominator. Nevertheless, the worst-case scenario intention-to-treat-analysis was also carried out for all outcomes as a sensitivity analysis.

\section{Assessment of heterogeneity}

Heterogeneity was tested using the Mantel-Haenszel $\mathrm{Chi}^{2}$ test and the $\mathrm{I}^{2}$ statistic (Higgins 2011). If important heterogeneity was found, we searched for an explanation based on the differences in clinical characteristics of the included studies. If the studies were found to be clinically very dissimilar they were not statistically combined.

\section{Assessment of reporting biases}

Funnel plots were used to test for the presence of publication bias, based on the data for each primary and secondary outcome.

\section{Data synthesis}

Data were pooled using RevMan software (Version 5.3). If no heterogeneity was found, Mantel-Haenszel RRs were calculated for all outcomes using a fixed-effect model. If heterogeneity between studies was observed, RRs were calculated using a random-effects model.

Data for all antiarrhythmic drugs were pooled and analysed individually (for each specific drug).

\section{Summary of findings}

We created a Summary of findings table using the following outcomes: all-cause mortality, withdrawals due to adverse effects, pro-arrhythmia, stroke and recurrence of AF. We used the five GRADE considerations (study limitations, consistency of effect, imprecision, indirectness and publication bias) to assess the quality of a body of evidence as it relates to the studies which contribute data to the meta-analyses for the prespecified outcomes. We used methods and recommendations described in Section 8.5 and Chapter 12 of the Cochrane Handbook for Systematic Reviews of Interventions (Higgins 2011) using GRADEpro software (https://gradepro.org/). Each comparison - a) antiarrhythmics compared with placebo / no treatment; b) antiarrhythmics compared between themselves - got a separate Summary of findings table. We justified all decisions to downgrade the quality of studies using footnotes and we made comments to aid reader's understanding of the review where necessary.

Judgements about evidence quality were made by two review authors ( $\mathrm{LV}, \mathrm{EA}, \mathrm{WJ}, \mathrm{JB}$, CLL) working independently, with disagreements resolved by discussion or involving a third author (JB or CLL). Judgements were justified, documented and incorporated into reporting of results for each outcome.

\section{Subgroup analysis and investigation of heterogeneity}


Predefined subgroup analyses were:

1. paroxysmal atrial fibrillation and persistent atrial fibrillation;

2. patients with heart failure opposed to patients who had never developed heart failure;

3. studies where warfarin was mandatory versus those where warfarin was discretionary; and

4. patients with a structurally normal heart ('lone' atrial fibrillation).

\section{Sensitivity analysis}

Sensitivity analyses were performed by selectively pooling:

1. studies having the lower risk of bias, defined as low risk of bias at least in the following domains: allocation concealment, blinding and incomplete outcome data, for all outcomes.

2. studies including the greatest number of patients (i.e. > 200 patients).

In addition, the worst-case scenario intention-to-treat-analysis (this is, considering all missing patients as having events) was also carried out for all outcomes to test if any potential difference might have arisen due to losses to follow up.

\section{Results}

\section{Description of studies}

\section{Results of the search}

We found a total of 6,332 references and assessed 205 articles in more detail for the previous publication of this review (Lafuente-Lafuente 2015. We retrieved, translated, when needed, and assessed articles in Chinese, English, French, German, Italian, Spanish and Swedish. Finally, 59 studies fulfilled the inclusion criteria and had useable data. They comprised 20,981 patients in total.

Compared with the previous publication of this review in 2015, which searched the medical literature until January 2014, we read 2185 additional references (LV, CLL, AT), assessed in detail 21 new articles (LV, EA, CLL, WJ), included one new randomised controlled trial (Chun 2014) and identified one ongoing study (Park 2017). The new included trial compared dronedarone and propafenone, added 100 more patients and reported only AF recurrence rates, but not mortality or adverse events.

On the contrary, during our process of checking papers for double publication we became aware that the data from one study we had previously included, SVA-4 2008a, was already reported in another included publication (

Figure 1 illustrates the selection of articles, following the PRISMA model. Agreement between authors was good for both selecting studies and extracting the data. Details of each included study are shown in the Characteristics of included studies table, and the reasons for exclusion are shown in the Characteristics of excluded studies table. 


\section{Included studies}

\section{Patients}

Entry criteria differed between studies in several aspects. In some trials atrial fibrillation was documented in the past history but patients were in sinus rhythm at the time of inclusion, while in other trials patients were in atrial fibrillation and needed to be converted to sinus rhythm (only those converted were included in the review). The duration of atrial fibrillation when persistent, or the time from the last documented episode of atrial fibrillation when paroxysmal, were highly variable (from one month to one year, or no time limit in some studies). Some of the studies required atrial fibrillation to be symptomatic while others did not. A few studies (six in total) enrolled both patients with atrial fibrillation or atrial flutter. When available, only data from patients with atrial fibrillation were used.

Regarding the type of atrial fibrillation, 8 studies included exclusively paroxysmal or recent onset atrial fibrillation, 28 studies included only persistent atrial fibrillation (i.e. lasting more than 7 days), and the remaining 23 studies included both types. Overall, $48 \%$ of the pooled population had persistent or permanent atrial fibrillation.

The mean age of patients varied from 46 to 72 years in the included studies and was 64.8 years in the pooled population. The proportion of patients having underlying heart disease varied widely, from $29 \%$ to $100 \%$, with only one study selectively including patients without structural heart disease (FAPIS 1996). The most frequent diseases were coronary artery disease (5\% to $50 \%$ of patients), hypertension, and valvular abnormalities (less frequent in recent studies). The mean left ventricle ejection fraction was greater than $50 \%$ in almost all trials but with five exceptions (DIAMOND 2001; Kalusche 1994; Nergardh 2007; Plewan 2001; Vijayalaskshmi 2006).

\section{Interventions}

Twenty nine trials (accumulating 13,443 patients) compared an antiarrhythmic with a control, 12 trials (4536 patients) compared two different antiarrhythmics and a control, and 18 trials (3,002 patients) compared two or more antiarrhythmics with each other. The comparator used in the 41 trials with control groups was a placebo in 32 trials, a beta-blocker in 2 trials (DAPHNE 2008; Plewan 2001), digoxin in 1 trial (Steinbeck 1988) and no treatment in 6 trials (Flec-SL 2012; Hillestad 1971; Santas 2012; Sodermark 1975; Van Gelder 1989; Vijayalaskshmi 2006).

Drugs included in this review, for which at least one well designed randomised controlled trial was found, were (a) class Ia: quinidine, disopyramide; (c) class Ic: flecainide, propafenone; (d) class II (beta-blockers): metoprolol; (e) class III: amiodarone, dofetilide, dronedarone and sotalol.

\section{Follow up}

The most frequent length of follow up was one year. It was shorter in 17 trials (6 to 9 months) and longuer in 6 trials (15 to 19 months). Five trials followed patients for two years or more (AFFIRM Substudy 2003; ATHENA 2009; Kochiadakis 2000; Kochiadakis 2004a;

Kochiadakis 2004b). We extracted and pooled all outcomes at one year of follow up or the nearest time point available. For studies with shorter duration of follow up the last 
observation available was employed. Overall, the mean follow-up of the pooled population analysed was 10.2 months.

\section{Excluded studies}

Main reasons for exclusion of studies were not being actually controlled or randomized (43 studies), having a follow-up shorter than 6 months (16 studies) and including in the control group patients who did not revert to sinus ryhtm (10 studies). Additionnal details on excluded studies are given in the Characteristics of excluded studies table.

\section{Risk of bias in included studies}

Asymmetry was found in the funnel plot of withdrawals beacuse of adverse effects on treatment with sotalol (Figure 2). It showed fewer small studies on the left side (this is, there were more small studies showing a trend to more withdrawals on active treatment). However, funnel plots for other outcomes with sotalol were symmetric, so we think the risk of substantial publication bias is low. Funnel plots for the remaining drugs were symmetric.

The results of the assessment of the risk of bias of included studies across different domains are showed in Figure 3 and Figure 4.

\section{Allocation (selection bias)}

All included studies were described as randomised controlled trials. However, only a minority detailed how the random number sequence was generated (18 studies, 30.5\%) or how the allocation of patients was concealed (17 studies, 28.8\%). Because of lack of details, the risk of bias on these items is unclear for the remaining studies.

\section{Blinding (performance bias and detection bias)}

The majority of trials comparing an antiarrhythmic versus a control were described as blinded (of 41 trials: 25 were double-blind and 5 single-blind, the remaining 11 were open-label). In contrast, most trials comparing two or more different antiarrhythmics were open-label (15 out of 18 ). However, only 17 of the 25 studies said to be double-blind adequately reported the method of blinding (and it was adequate in all cases). Nonetheless, we think that the risk of bias associated to this lack of adequate blinding is not very high because: (a) most outcomes assessed in this review are objective ones: recurrence of AF and pro-arrhythmia were established by ECG records, mortality and stroke are hard outcomes; (b) results from adequately double-blind studies and open-label studies are very consistent; (c) well described, adequate blinding was more frequent in studies comparing an active drug with no active treatment, which is the main comparison of the review.

\section{Incomplete outcome data (attrition bias)}

Withrawals and dropouts were adequately reported in the majority of studies. The percentage of patients lost to follow up was detailed in 47 out of the 59 included trials and was small (5\% to $10 \%$ ). However, virtually all studies followed patients until atrial fibrillation recurred or until treatment was stopped for any reason, and no longer. Data for some outcomes, like mortality, were therefore not extensive. 


\section{Selective reporting (reporting bias)}

All studies but three (Chun 2014; DAPHNE 2008; Santas 2012) had data on all-cause mortality, all but two (ASAP 2003; PITAGORA 2008) on atrial fibrillation recurrence rates, and all but three (AFIB 1997; Chun 2014; Santas 2012) presented data for adverse effects, either withdrawals or pro-arrhythmia (Table 1). Other outcomes were less frequently reported: in studies with a placebo or no treatment arm, stroke was reported in 11 trials, heart failure in 2 trials and actual frequency of anticoagulation in none. All studies reported the outcomes they have prespecified in the way they had prespecified.

\section{Other potential sources of bias}

Conflict of interest could exist as almost all the studies included in the review were funded by the company manufacturing the antiarrhythmic drug tested.

\section{Effects of interventions}

All outcomes were calculated at one year of follow up or the nearest time point (overall mean follow-up was 10.2 months).

Imputing missing patients as events (the worst-case intention-to-treat scenario) generally did not modify the results, so the best-case intention-to-treat analysis (missing patients counted as being free of events) was reported as the default; where differences existed details are given.

\section{All-cause mortality}

The all-cause mortality rate was low ( $0 \%$ to $5.1 \%$ at 1 year). The only exception to this generally low mortality rate was the DIAMOND study (DIAMOND 2001). This trial recruited patients with advanced heart failure and had an overall all-cause mortality of $31 \%$ at 1 year.

The quantity and quality of data on mortality varied markedly between drugs. We could not find any data on mortality with flecainide and very few data with disopyramide and propafenone.

More data was available for other drugs. We found evidence suggesting an increase in the risk of death with two drugs, quinidine and sotalol. For the remaining drugs studied, available evidence did not show any apparent effect in mortality.

No important heterogeneity between studies was detected for this outcome with any of the drugs studied.

\section{Drugs with very few or no data on mortality}

\section{Disopyramide}

Only one study reported all-cause mortality in people taking disopyramide compared with placebo/no treatment. It included only 92 participants and had a very wide confidence 
interval for mortality that includes both possible benefits and harms (Analysis 2.1: RR 5.00, $95 \%$ CI 0.25 to $101.37 ; \mathrm{I}^{2}=0 \%$, low-quality evidence).

Counting missing participants as having died did not change this finding (Analysis 2.2). No other sensitivity analysis could be carried out.

\section{Propafenone}

Of the five included trials (998 patients), only two studies reported any death, one each. The confidence interval was wide, including both possible benefits and harms, and the results varied markedly between the main analysis (Analysis 3.1) (RR 0.19, 95\% CI 0.02 to 1.68 ; participants $=212 ;$ studies $\left.=2 ; \mathrm{I}^{2}=0 \%\right)$ and the sensitivity analysis which treated missing participants as having died (Analysis 3.2) (RR 1.28, 95\% CI 0.45 to 3.62; participants $=406$; studies $=3 ; \mathrm{I}^{2}=19 \%$ ). Restriciting the analysis to the only study at low risk of bias (Analysis 3.3) did not differ from the main analysis.

Overall, the evidence for this outcome is very low-quality, meaning that we are uncertain of the effect of propafenone on mortality.

\section{Flecainide}

None of the four trials we found studying flecainide (511 patients in total) reported any death from any cause. Thus, this outcome could not be analysed.

\section{Drugs associated with an increase in mortality}

\section{Quinidine}

All-cause mortality was reported by six studies which compared quinidine with placebo or no treatment (Analysis 1.1). The GRADE rating was low-quality for this outcome. The pooled RR suggested that risk of mortality was higher in people taking quinidine compared with placebo or no treatment, although the confidence interval also includes the possibility of a lower or similar mortality rate (RR 2.01, 95\% CI 0.84 to 4.77 ; participants = 1646; studies = $6 ; \mathrm{I}^{2}=0 \%$ ). This corresponds to eight deaths per 1,000 in the control group and 15 per 1,000 (95\% CI 6 to 36 per 1,000) in the quinidine group.

Sensitivity analysis which treated missing patients as having died (Analysis 1.2) increased the RR slightly, but was not substantially different to the main analysis (RR $2.12,95 \%$ CI 0.96 to 4.67; participants $=1646 ;$ studies $=6 ; I^{2}=0 \%$ ).

Conversely, sensitivity analysis of quinidine studies at low risk of bias (Analysis 1.5), or studies with more than 200 participants (Analysis 1.6), left only two studies (PAFAC 2004; SOPAT 2004) in which no difference in all-cause mortality was apparent compared with controls (RR 1.29, 95\% CI 0.34 to 4.92; participants $=1234$; studies $=2$; $\mathrm{I}^{2}=0 \%$ ). These two trials were more recent, employed a lower dose of quinidine (320 to $480 \mathrm{mg} / \mathrm{day}$ ) than other studies (800 to $1800 \mathrm{mg} /$ day) and combined quinidine with verapamil. However, when comparing those two studies against older, higher dose studies (Analysis 1.3), the test for subgroup differences did not indicate that the effect differed between those two groups $(\mathrm{P}=0.4)$. 
Other sensitivity analysis did not differ from the main analysis (Analysis 1.4: persistent atrial fibrillation).

\section{Sotalol}

High-quality evidence from five RCTs indicated that people taking sotalol had a higher allcause mortality rate than those with placebo or no treatment (Analysis 9.1; RR 2.23, 95\% CI 1.03 to 4.81; participants $=1882 ;$ studies $\left.=5 ; \mathrm{I}^{2}=0 \%\right)($ Figure 7). This corresponds to eight deaths per 1,000 in the control group and 19 (95\% $\mathrm{Ci} 9$ to 40) in the sotalol group. The NNTH for sotalol was 102 patients treated for one year to have one excess death, with a wide $95 \%$ CI of 33 to 4167.

This association with increased mortality persisted in all sensitivity analyses undertaken, either counting missing patients as deaths (Analysis 9.2) (RR 2.02, 95\% CI 1.28 to 3.20; participants $=2757$; studies $\left.=10 ; \mathrm{I}^{2}=0 \%\right)$, restricting to those studies at low risk of bias (Analysis 9.4) or which included only persistent atrial fibrillation (Analysis 9.3), analysis which were identical since they both contained the same studies (RR 2.51, 95\% CI 1.06 to 5.98 ; participants $=1311$; studies $\left.=3 ; \mathrm{I}^{2}=0 \%\right)$. An even larger effect was seen when restricting the analysis to just those studies with at least 200 participants (Analysis 9.5) (RR $2.65,95 \%$ CI 1.16 to 6.09 ; participants $=1826$; studies $=4 ; \mathrm{I}^{2}=0 \%$ ).

\section{Drugs with no apparent effect on mortality}

For the remaining drugs studied, available evidence did not show any apparent difference in mortality with respect to placebo / no treatment. However, data for mortality was rarely extensive and the data obtained could be underpowered to detect mild differences in mortality for several of the drugs studied.

\section{Metoprolol}

Two studies (moderate-quality evidence) were pooled that compared metoprolol with placebo or no treatment. The main analysis obtained very wide confidence intervals (Analysis 5.1) $\left(\right.$ RR 2.02, 95\% CI 0.37 to 11.05; participants $=562$; studies $=2 ; \mathrm{I}^{2}=47 \%$ ). Results did not change in any of the sensitivity analyses (Analysis 5.2; Analysis 5.3; Analysis 5.4; Analysis $\underline{5.5}$ ).

\section{Amiodarone}

Moderate-quality evidence from two studies comparing amiodarone with placebo or no treatment (Analysis 6.1) produced wide confidence intervals (RR 1.66, 95\% CI 0.55 to 4.99; participants $=444$; studies $\left.=2 ; \mathrm{I}^{2}=10 \%\right)$. This finding did not change in any of the sensitivity analyses (Analysis 6.2; Analysis 6.3).

\section{Dofetilide}

Moderate-quality evidence from three RCTs Analysis 7.1 (RR 0.98, 95\% CI 0.76 to 1.27; participants $=1183$; studies $=3 ; \mathrm{I}^{2}=0 \%$ ) gave no evidence of a difference in all-cause mortality rate between dofetilide and placebo/ no treatment groups. Sensitivity analyses did not differ substantially from the main analysis (Analysis 7.2; Analysis 7.4; Analysis 7.3; Analysis 7.5). 


\section{Dronedarone}

High-quality evidence from three RCTs (Analysis 8.1) showed no clear difference in allcause mortality between dronedarone and placebo/ no treatment (RR $0.86,95 \%$ CI 0.68 to 1.09; participants $=6071 ;$ studies $=3 ; \mathrm{I}^{2}=0 \%$ ). The ATHENA 2009 study dominates this analysis, taking $97 \%$ of the weight in the meta-analysis.

There was very little difference between this main result and the different sensitivity analyses (Analysis 8.2; Analysis 8.3; Analysis 8.4; Analysis 8.5).

\section{Head to head comparisons}

In direct comparisons between antiarrhythmics, no differences in mortality was observed (Table 2).

\section{Withdrawals due to adverse effects}

Withdrawals due to adverse effects were more frequent with all studied drugs:

\section{Quinidine}

Moderate-quality evidence suggested a higher number of withdrawals due to adverse events in the quinidine group than in the placebo/no treatment controls (Analysis 1.7), although the confidence interval does include the possibilities of a slightly smaller number of withdrawals and also of no difference between groups (RR 1.56, 95\% CI 0.87 to 2.78; participants $=1669$; studies $=7 ; \mathrm{I}^{2}=67 \%$ ). This corresponds to 163 withdrawals per 1,000 people in the control group and 254 (95\% CI 142 to 452 ) in the quinidine group.

There was high heterogeneity in the main analysis, which seemed to be related to two more recent studies (PAFAC 2004; SOPAT 2004) which employed lower doses of quinidine and combined it with verapamil. A subgroup analysis based in the age/dose of the studies (Analysis 1.8) suggested there is a real difference between these two studies and older studies which employed a higher dose of quinidine (test for subgroup differences, $\mathrm{p}=0.009$ ). In older, higher-dose studies, approximately three times more people withdrew due to adverse effects, compared to placebo/no treatment (RR 3.05, 95\% CI 1.29 to 7.22; participants $=435$; studies $=5 ; \mathrm{I}^{2}=29 \%$ ). In more recent, lower-dose studies, there was no evidence of a difference in withdrawals (RR $0.88,95 \%$ CI 0.61 to 1.27 ; participants $=1234$; studies $=2 ; \mathrm{I}^{2}=51 \%$ ).

The results of sensitivity analysis varied depending on whether they included mostly older studies, as the analysis of studies on permanent atrial fibrillation, which showed an increase of withdrawals with quinidine (Analysis 1.9); or whether they included mainly the two more recent studies, which showed no difference with controls (Analysis 1.10, Analysis 1.11).

\section{Disopyramide}

Low-quality evidence from two RCTs indicated a more than three-fold higher risk of withdrawal due to adverse events among people taking disopyramide compared with placebo or no treatment, although the confidence interval also includes the possibility of similar risks of withdrawal due to adverse events (Analysis 2.4 RR 3.68, 95\% CI 0.95 to 14.24; participants $=146 ;$ studies $\left.=2 ; \mathrm{I}^{2}=0 \%\right)$. This corresponds to 28 withdrawals per 1,000 
people in the control group and 104 (95\% CI 27 to 401) per 1,000 in the disopyramide group. The result of sensitivity Analysis 2.5 is identical to the main analysis. No further sensitivity analyses were possible.

\section{Propafenone}

Moderate-quality evidence indicated a higher risk of withdrawals due to adverse events in people taking propafenone compared with those in placebo/ no treatment groups (Analysis 3.4; RR 1.62, 95\% CI 1.07 to 2.46; participants $=1098$; studies $=5 ; \mathrm{I}^{2}=0 \%$ ). Corresponding numbers of withdrawals due to adverse events were 61 per 1,000 in the control group and 99 (95\% CI 65 to 150) per 1,000 in the propafenone group. The NNTH for propafenone was 26 patients treated for one year to have one excess withdrawal (95\%CI 11 to 234).

Restricting the analysis to the only study with more than 200 participants indicated a lack of evidence for a difference between groups (Analysis 3.5; RR 1.29, 95\% CI 0.79 to 2.11; participants $=523$; studies $=1$ ).

\section{Flecainide}

Only one very small RCT (Van Gelder 1989) reported withdrawals due to adverse events (Analysis 4.3) (RR 15.41, 95\% CI 0.91 to 260.19; participants $=73$; studies $=1$; low-quality evidence). Seven people taking flecainide withdrew due to adverse events, compared with none in the control arm. The RR reflects a higher risk of withdrawal due to adverse events when taking flecainide, but the confidence interval is wide enough to include no difference between groups and even a small chance of a lower risk, but the very few people in this analysis limit the usefulness of this result. As there was just one study, all possible sensitivity analyses were identical to the main results.

\section{Metoprolol}

High-quality evidence from two RCTs found that the risk of withdrawing due to adverse events was more than three times higher among people taking metoprolol than people on placebo/ no treatment (Analysis 5.6; RR 3.47, 95\% CI 1.48 to 8.15; participants $=562$; studies $=2 ; \mathrm{I}^{2}=0 \%$ ). This represents 21 per 1,000 people on placebo/ no treatment withdrawing due to adverse effects, compared with 74 (95\% CI 31 to 173 per 1,000 people on metoprolol. The NNTH was 19 patients treated for one year to have one excess withdrawal (95\% CI 7 to 99$)$.

All sensitivity analysis were similar to the main results (Analysis 5.7; Analysis 5.8; $\underline{\text { Analysis }}$ $\underline{5.9}$ ).

\section{Amiodarone}

Pooled analysis of four RCTs found low-quality evidence that the risk of withdrawing due to an adverse event was more than six times higher for people taking amiodarone than for people taking placebo/ no treatment (Analysis 6.4; RR 6.70, 95\% CI 1.91 to 23.45; participants $=319 ;$ studies $\left.=4 ; \mathrm{I}^{2}=0 \%\right)$. This corresponds to seven people out of 1,000 taking placebo/ no treatment withdrawing, compared with 49 per 1,000 (95\% CI 14 to 172) taking amiodarone. The NNTH for amiodarone was 25 patients treated for one year to have one excess withdrawal (95\%CI 6 to 157). 
Sensitivity analysis restricted to the only study at low risk of bias (Analysis 6.6) had a very wide confidence interval (RR 4.98, 95\% CI 0.65 to 38.29; participants $=99$; studies $=1$ ).

\section{Dofetilide}

Low-quality evidence from two RCTs suggested withdrawals due to adverse effects may be higher in people taking dofetilide, but the wide confidence interval also includes the possibility that there is the same risk (or a lower risk) as for people taking placebo/ no treatment (Analysis 7.6; RR 1.77, 95\% CI 0.75 to 4.18; participants $=677$; studies $=2 ; \mathrm{I}^{2}=$ $0 \%)$. The risk is 34 per 1,000 in the placebo/ no treatment group compared with $61(95 \% \mathrm{CI}$ 26 to 144 ) per 1,000 people taking dofetilide. Sensitivity analyses were identical to the main result (Analysis 7.7; Analysis 7.8).

\section{Dronedarone}

Three RCTs showed moderate-quality evidence of a higher risk of withdrawals due to adverse effects among people taking dronedarone (Analysis 8.6; RR 1.58, 95\% CI 1.34 to 1.85 ; participants $=6071 ;$ studies $=3 ; \mathrm{I}^{2}=31 \%$ ). This corresponds to a risk of 77 withdrawals per 1,000 people in the placebo/ no treatment group and of 122 withdrawals per 1,000 people taking dronedarone (95\% CI 104 to 143). The NNTH was 22 patients treated for one year to have one excess withdrawal (95\%CI 15 to 38 ).

The ATHENA 2009 study had $82.5 \%$ of the weight in the main meta-analysis, so the sensitivity analyses are heavily influenced by this large study. When it was included, they were very similar to the main analysis (Analysis 8.8; Analysis 8.9). The analysis of studies on permanent atrial fibrillation did not include the ATHENA trial and and had a very wide confidence interval (Analysis 8.7; RR 14.51, 95\% CI 0.90 to 234.74).

\section{Sotalol}

Results from 12 RCTs were pooled in Analysis 9.6 (RR 1.95, 95\% CI 1.23 to 3.11; participants $=2688$; studies $=12 ; \mathrm{I}^{2}=56 \%$ ). The risk of withdrawing due to an adverse event is almost twice as high in people taking sotalol as in people taking placebo or no treatment, with a risk of 94 withdrawals per 1,000 in the control group and 183 (95\% CI 116 to 293) per 1,000 in the sotalol group. The corresponding NNTH was 11 patients treated for one year to have one excess withdrawal (95\%CI 5 to 46).

Evidence was rated as moderate-quality due to suspected publication bias. Although there was an $\mathrm{I}^{2}$ of $56 \%$ we did not downgrade for heterogeneity, because subgroup analysis Analysis 9.7 showed a difference between a subgroup containing the PAFAC 2004 and SOPAT 2004 studies, and a subgroup containing the other studies ( $\mathrm{p}=0.009$ from test for subgroup differences).

Sensitivity analyses all showed all an increase in withdrawals on sotalol, giving estimates which were very similar to the main analysis (permanent atrial fibrillation, Analysis 9.8), lower (low risk of bias studies, Analysis 9.9; RR 1.27, 95\% CI 1.00 to 1.60; participants = 1686; studies $=4 ; \mathrm{I}^{2}=78 \%$ ), or slightly lower (studies with at least 200 participants, $\underline{\text { Analysis }}$ 9.10; RR 1.81, 95\% CI 0.97 to 3.35; participants $=1900 ;$ studies $=5 ; \mathrm{I}^{2}=79 \%$ )

\section{Head to head comparisons}


In direct comparisons between antiarrhythmics (Table 3), quinidine appeared to caused more withdrawals than flecainide or oher class I drugs. Amiodarone seemed to produce fewer withdrawals than class I drugs combined, but did not show any difference compared with dronedarone or sotalol. Sotalol, in turn, caused more withdrawals than dofetilide or betablockers.

\section{Pro-arrhythmia}

Virtually all studied antiarrhythmics showed increased pro-arrhythmic effects (counting both bradyarrhythmias and tachyarrhythmias attributable to treatment).

Ventricular arrhythmias (torsades, ventricular tachycardia (VT), ventricular fibrillation (VF), widening QRS or QT leading to stopping treatment, sudden death or unexplained syncope) were the most frequent pro-arrhythmic events reported with dofetilide (100\% of all proarrhythmic events), quinidine (94\%) and flecainide (69\%), while symptomatic bradyarrhythmias (sinus bradycardia leading to stopping treatment, atrio-ventricular block) were more frequent with metoprolol (94\% of all events) and amiodarone (69\%). Others drugs demonstrated both types of pro-arrhythmic events: propafenone $(63 \%$ ventricular events, $39 \%$ bradycardia), sotalol (61\% ventricular events, $39 \%$ bradycardia) and dronedarone (41\% ventricular events, $59 \%$ bradycardia).

\section{Quinidine}

High-quality evidence from seven RCTs (Analysis 1.12) showed that the risk of proarrhythmia was twice as high in people taking quinidine compared with people in placebo/ no treatment groups, although the confidence interval doesn't exclude the possibility of no difference between groups (RR 2.05, 95\% CI 0.95 to 4.41; participants = 1676; studies = 7; $\mathrm{I}^{2}$ $=0 \%$ ). This represents 11 cases per 1,000 in the control group and 22 (95\% CI 10 to 48 ) in the quinidine group.

In a way very similar to the analysis of withdrawals due to adverse effects, the results of sensitivity analysis varied depending wether they included mostly older, higher-dose studies, as the analysis of studies on permanent atrial fibrillation, which showed an increase of proarrhythmia with quinidine (Analysis 1.14); or whether they included mainly the two more recent, lower-dose studies (PAFAC 2004, SOPAT 2004) which showed no difference with controls (Analysis 1.15, Analysis 1.16). However, a subgroup analysis comparing older studies with more recent ones did not find a difference between groups (test for difference between subgroups $\mathrm{P}=0.41)$ for this outcome (Analysis 1.3 $)$.

\section{Disopyramide}

No disopyramide studies reported pro-arrhythmia.

\section{Propafenone}

Three RCTs reported pro-arrhythmia, but the very low-quality evidence and wide confidence intervals means that we are uncertain of the effect of propafenone on this outcome (Analysis 3.6 RR $1.32,95 \%$ CI 0.39 to 4.47 ; participants $=381$; studies $=3 ; \mathrm{I}^{2}=8 \%$ ). Sensitivity analysis restricted to the only study at low risk of bias (Analysis 3.7) shows a lack of 
evidence for a difference between groups (RR 0.49, 95\% CI 0.09 to 2.75; participants $=102$; studies $=1$ ).

\section{Flecainide}

Risk of pro-arrhythmia was over four times higher among people taking flecainide than placebo/ no treatment (Analysis 4.6; RR 4.80, 95\% CI 1.30 to 17.77; participants $=511$; studies $=4 ; I^{2}=0 \%$; moderate-quality evidence). This corresponds to a risk of six per 1,000 among people taking placebo or no treatment, compared with a risk of 30 (95\% CI 8 to 112) for people taking flecainide. The NNTH for flecainide was 44 patients treated for one year to have one excess pro-arrhythmic event (95\%CI 10 to 556).

All sensitivity analysis suggested an increased risk of pro-arrhythmia with flecainide, but their confidence intervals were wider and included the possibility of no difference between groups (Analysis 4.7; Analysis 4.8; Analysis 4.9).

\section{Metoprolol}

High-quality evidence showed and important increase of pro-arrhythmia with metoprolol, compared to placebo (Analysis 5.10; RR 18.14, 95\% CI 2.42 to 135.66; participants $=562$; studies $\left.=2 ; \mathrm{I}^{2}=0 \%\right)$ due mainly to symptomatic bradyarrhythmias $(94 \%$ of all proarrhythmic events). In the pooled population, pro-arrhythmic events were reported in no patient on placebo and in 60 patients per 1,000 on treatment with metoprolol. The corresponding NNTH was 19 patients treated for one year to have one excess bradyarrhythmia (95\% CI 2 to 235).

All sensitivity analyses showed results similar to the main analysis (Analysis 5.11; Analysis 5.12; Analysis 5.13)

\section{Amiodarone}

Moderate quality evidence suggested an increase in pro-arrhythmia with amiodarone compared to placebo/ no treatment, but the confidence interval included the possibility of no difference (or even a reduction) (Analysis 6.7; (RR 2.22, 95\% CI 0.71 to 6.96; participants = 673 ; studies $=4 ; \mathrm{I}^{2}=0 \%$ ). This corresponds to a risk of eight per 1,000 with placebo/ no treatment and of 18 (95\% CI 6 to 57) with amiodarone. Symptomatic bradyarrhythmias represented $69 \%$ of events with amiodarone.

Sensitivity analyses gave similar results, the only difference was that they pooled fewer studies and confidence intervals were larger (Analysis 6.8; Analysis 6.9; Analysis 6.10).

\section{Dofetilide}

Moderate-quality evidence found a five-fold increase in pro-arrhythmic events with dofetilide compared to placebo/no treatment (Analysis 7.9; RR 5.50, 95\% CI 1.33 to 22.76; participants $=1183$; studies $\left.=3 ; \mathrm{I}^{2}=0 \%\right)$. That corresponds to two cases per 1,000 in the control group and 13 (95\%CI 3 to 53) with dofetilide. The NNTH for dofetilide was 111 patients treated for one year to have one excess pro-arrhythmic event (95\% CI 23 to 1515). 
Sensitivity analyses did not differ to the main analysis (Analysis 7.10; Analysis 7.11;

Analysis 7.12)

\section{Dronedarone}

Moderate-quality evidence from two RCTs suggested and increase of pro-arrhythmia with dronedarone compared with placebo, but the confidence interval included the possibility of no difference or even a benefit on this outcome (Analysis 8.6; RR 1.95, 95\% CI 0.77 to 4.98; participants $=5872 ;$ studies $=2 ; \mathrm{I}^{2}=78 \%$ ). This represents 18 cases per 1,000 in the placebo group and 36 (95\% CI 14 to 91) in patients taking dronedarone.

In sensitivity analysis, there was only one study (ATHENA 2009) rated as low risk of bias or including more than 200 patients. This study found an increased risk of pro-arrhythmia with dronedarone compared to placebo (Analysis 8.11; Analysis 8.12; RR 2.94, 95\% CI 2.08 to 4.15 , participants $=4628$ )

\section{Sotalol}

Moderate-quality evidence showed increased pro-arrhythmia rates on sotalol compared to placebo/ no treatment (Analysis 9.11; RR 3.55, 95\% CI 2.16 to 5.83; participants = 2989; studies $\left.=12 ; \mathrm{I}^{2}=20 \%\right)$. This corresponds to 12 cases per 1,000 in the control group and 41 (95\% CI 25 to 68) in patients treated with sotalol. The corresponding NNTH was 33 patients treated for one year to have one excess pro-arrhythmic event (95\% CI 17 to 72 ).

All sensitivity analyses were very similar to the main analysis (Analysis 9.13; Analysis 9.14; Analysis 9.15).

\section{Head to head comparisons}

In direct comparisons between antiarrhythmics (Table 4), amiodarone seemed to produce fewer pro-arrhythmic events than class I drugs combined, but did not show clear differences compared with dronedarone or sotalol. No other differences between drugs were observed.

\section{Stroke}

Data available for this outcome was limited. Only 11 of the 41 studies with a control group (placebo or no treatment arm) reported stroke outcomes (ATHENA 2009; Benditt 1999; Carunchio 1995; EURIDIS ADONIS 2007; Flec-SL 2012; Hillestad 1971; Karlson 1998; Lloyd 1984; SAFE-T 2005; Sodermark 1975; SOPAT 2004) and we were uncertain that reporting of stroke was complete. The reported stroke rate was very low (1\% to $2 \%$ at 1 year).

\section{Drugs with no data on stroke}

No data on stroke was reported in any included study for propafenone, metoprolol and dofetilide.

\section{Drugs with no apparent effect on stroke}


Low to very-low quality evidence showed no apparent effect on stroke rates - compared to placebo or no treatment - with the following drugs:

- Quinidine (Analysis 1.17; RR 0.97, 95\% CI 0.25 to 3.83; participants = 1107; studies $\left.=4 ; I^{2}=0 \%\right)$

- $\quad$ Dysopiramide (Analysis 2.7; RR 0.31, 95\% CI 0.03 to 2.91; participants = 146; studies $\left.=2 ; \mathrm{I}^{2}=0 \%\right)$

- $\quad$ Flecainide (Analysis 4.10; RR 2.04, 95\% CI 0.11 to 39.00; participants $=362$; studies $\left.=1 ; I^{2}=0 \%\right)$

- Amiodarone (Analysis 6.11; RR 1.15, 95\% CI 0.30 to 4.39; participants = 399; studies $\left.=1 ; \mathrm{I}^{2}=0 \%\right)$

- Sotalol (Analysis 9.16; RR 1.47, 95\% CI 0.48 to 4.51; participants $=1161$; studies $=$ $\left.3 ; \mathrm{I}^{2}=0 \%\right)$

The corresponding sensitivity analyses, when these were possible, did not show any notable difference with the main analyses.

\section{Dronedarone}

High-quality evidence from two RCTs suggested that dronedarone may be associated with reduced risk of stroke (Analysis 8.13; RR 0.66, 95\% CI 0.47 to 0.95 ; participants $=5872$; studies $\left.=2 ; \mathrm{I}^{2}=0 \%\right)$. This corresponds to a risk of stroke of 27 per 1,000 on people receiving placebo and 18 per 1,000 (13 to 25) on people taking dronedarone. The corresponding NNTB would be 109 patients treated for one year to prevent one stroke (95\% CI 70 to 741).

This result, however, is due to a single large study, ATHENA 2009, which accounted for $94,6 \%$ of the weight in the meta-analysis. Sensitivity analysis restricted to studies with more than 200 patients included the same two studies and produced identical results (Analysis $\underline{8.14})$.

\section{Atrial fibrillation recurrence}

All antiarrhythmic drugs included in this review, including metoprolol, reduced the risk of recurrence of atrial fibrillation. Recurrence rates of atrial fibrillation at 1 year were high: $69 \%$ to $84 \%$ in controls not receiving antiarrhythmic treatment, reduced to $43 \%$ to $67 \%$ in patients treated with antiarrhythmics.

Details for each individual drug are as follows:

\section{Quinidine}

High-quality evidence showed a reduction in atrial fibrillation recurrences with quinidine (Analysis 1.21; RR $0.83,95 \%$ CI 0.78 to 0.88 ; participants $=1624$; studies $=7 ; \mathrm{I}^{2}=0 \%$ ). Recurrence rates at one year were $80.5 \%$ in patients on placebo or no treatment and $66.8 \%$ (62.8 to 70.8) in patients on quinidine. The NNTB for quinidine was 7 patients treated for one year to avoid one recurrence (95\% CI 6 to 10$)$.

Results of sensitivity analyses did not differ from the main analysis (Analysis 1.22; Analysis 1.23; Analysis 1.24) 


\section{Disopyramide}

Evidence for disopyramide was low-quality because it consisted of two small RCTs with unclear risk of bias. It suggests disopyramide reduces recurrences of atrial fibrillation (Analysis 2.9; RR 0.77, 95\% CI 0.59 to 1.01; participants $=146$; studies $=2 ; \mathrm{I}^{2}=0 \%$ ). This corresponds to a recurrence rate, at 6 months to 1 year, of $69.0 \%$ in the control group and $53.1 \%$ (40.7 to 69.7) in the group treated with disopyramide. Both studies included only patients with permanent atrial fibrillation (Analysis 2.10) and no other sensitivity analysis was possible.

\section{Propafenone}

Moderate-quality evidence from five RCTs indicated that propafenone reduced atrial fibrillation recurrences by about a third (Analysis 3.8; RR 0.67, 95\% CI 0.61 to 0.74 ; participants $=1098 ;$ studies $\left.=5 ; \mathrm{I}^{2}=0 \%\right)$. Recurrence rate was $73.0 \%$ in controls and $48.9 \%$ (44.5 to 54.0) in patients treated with propafenone. The corresponding NNTB was 4 patients treated for one year to avoid one recurrence (95\% CI 3 to 5 ).

Results from sensitivity analyses were very similar (Analysis 3.9; Analysis 3.10).

\section{Flecainide}

High-quality evidence showed that flecainide reduces atrial fibrillation recurrences also by about a third (Analysis 4.14; RR 0.65, 95\% CI 0.55 to 0.77; participants $=511$; studies $=4$; $\mathrm{I}^{2}$ $=29 \%$ ). That corresponded to a recurrence rate of $69.8 \%$ in people not treated or on placebo and of 45.4\% (38.4 to 53.8) in people taking flecainide. The NNTB for flecainide was 4 patients treated for one year to avoid one recurrence (95\% CI 3 to 6).

Results from sensitivity analysis did not differ substantially (Analysis 4.15; Analysis 4.16; Analysis 4.17).

\section{Metoprolol}

Moderate-quality evidence from two RCTs suggests that metoprolol reduces recurrences of atrial fibrillation, compared with placebo, but the confidence interval includes the possibility of no difference (Analysis 5.14; RR $0.83,95 \%$ CI 0.68 to 1.02; participants $=562$; studies $=$ $2 ; \mathrm{I}^{2}=59 \%$ ). The corresponding recurrence rates were $72.0 \%$ in people receiving placebo and $59.7 \%$ (49.0 to 73.4) in people treated with metoprolol. All sensitivity analyses included the same two trials and obtained identical results (Analysis 5.15; Analysis 5.12) except the analysis restricted to studies including more than 200 patients, which included only one study and showed no difference between metoprolol and placebo (Analysis 4.17).

\section{Amiodarone}

High-quality evidence showed a reduction of atrial fibrillation recurrences with amiodarone of about a half, compared to placebo or no treatment (Analysis 6.14; RR 0.52, 95\% CI 0.46 to $0.58 ;$ participants $=812 ;$ studies $=6 ; \mathrm{I}^{2}=33 \%$ ). This corresponded to a recurrence rate of $81.2 \%$ in people not receiving active treatment and of $42.2 \%$ (37.3 to 47.1 ) in people receiving amiodarone. The NNTB for amiodarone was 3 patients treated for one year to avoid one recurrence (95\% CI 2 to 4$)$. 
All sensitivity analyses obtained very similar results (Analysis 6.15; Analysis 6.16; Analysis $\underline{6.17})$.

\section{Dofetilide}

Moderate-quality evidence indicated that dofetilide reduces recurrences of atrial fibrillation, compared to placebo, by about a quarter (Analysis 7.13; RR 0.72, 95\% CI 0.61 to 0.85 ; participants $=1183$; studies $\left.=3 ; \mathrm{I}^{2}=79 \%\right)$. Recurrence rates were $84.2 \%$ in people taking placebo and $60.6 \%$ (51.4 to 71.6 ) in people taking dofetilide. The corresponding NNTB was 4 patients treated for one year to avoid one recurrence (95\% CI 3 to 8 ).

Substantial heterogeneity existed between studies on dofetilide for this outcome $\left(\mathrm{I}^{2}=79 \%, \mathrm{P}\right.$ $=0.008$ ). All studies showed the same direction of effect (that is, a reduction of atrial fibrillation recurrences) and the heterogeneity was probably caused by differences in the characteristics of recruited patients.

Sensitivity analyses did not differ from the main analysis (Analysis 7.14; Analysis 7.15; Analysis 7.16).

\section{Dronedarone}

Moderate-quality evidence from two RCTs showed a reduction of recurrences of atrial fibrillation with dronedarone of about $15 \%$ (Analysis 8.15; RR $0.85,95 \%$ CI 0.80 to 0.91 ; participants $=1443$; studies $=2 ; \mathrm{I}^{2}=0 \%$ ). This corresponded to a recurrence rate of $76.6 \%$ in people treated with placebo and of $65.1 \%$ (61.3 to 69.7) in people treated with dronedarone. The NNTB for dronedarone was 9 patients treated for one year to avoid one recurrence (95\% CI 7 to 15$)$.

Results from sensitivity analyses were quasi identical (Analysis 8.16; Analysis 8.17).

\section{Sotalol}

High-quality evidence found a reduction of atrial fibrillation recurrences of about a fifth with sotalol compared with placebo or no treatment (Analysis 9.20; RR 0.83, 95\% CI 0.80 to 0.87; participants $=3179 ;$ studies $=14 ; \mathrm{I}^{2}=54 \%$ ). The corresponding recurrence rates were $78.8 \%$ in patients not receiving an antiarrhythmic and $65.4 \%$ (63.1 to 68.6) in patients receiving sotalol. The NNTB for sotalol was 7 patients treated for one year to avoid one recurrence (95\% CI 6 to 10$)$.

No substantial difference with the main analysis appeared in any of the sensitivity analyses (Analysis 9.21; Analysis 9.22; Analysis 9.23).

\section{Head to head comparisons}

In direct comparisons between antiarrhythmics (Table 5), amiodarone appeared to reduce the recurrence of atrial fibrillation more than the combined class I drugs, more than dronedarone and more than sotalol. No other differences were apparent in head to head comparisons between antiarrhythmics.

\section{Other outcomes}


Chronic anticoagulation with warfarin was mandatory (that is, every patient received anticoagulation therapy throughout the whole follow-up period) in only three studies (Channer 2004; Hillestad 1971; Van Gelder 1989). In the rest of the studies the decision on anticoagulation use was left to the judgement of the attending physician. Unfortunately, no trial reported the actual frequency of anticoagulation in the different treatment groups during follow up.

Seven trials reported some data on the incidence of heart failure (ATHENA 2009; DYONISOS 2010; FAPIS 1996; Hohnloser 1995; Kuhlkamp 2000; PRODIS 1996; Reimold 1993), which was low. There were no differences in those trials between patients receiving antiarrhythmics and patients receiving placebo or no treatment.

\section{Subgroup analysis}

Twenty-three of the studies with a control group (placebo or no treatment) included only patients with persistent atrial fibrillation. The mean duration of atrial fibrillation in those studies varied greatly, from 3 to 36 months. Only four studies exclusively included patients with paroxysmal atrial fibrillation. The remaining studies included patients with both paroxysmal and persistent atrial fibrillation; none reported outcomes separately by type of atrial fibrillation.

It was not possible to compare subgroups of patients with permanent and paroxysmal atrial fibrillation for any given antiarrhythmic drug. Therefore, we analysed separately patients with permanent atrial fibrillation - for the outcomes and drugs that was possible - but as a sensitivity analysis.

Other planned subgroup analyses (patients with heart failure, studies where warfarin was mandatory versus those where it was discretionary, patients with a structurally normal heart) were not possible as separate data for each group of patients were seldom available. A more detailed analysis by left ventricular function or by the New York Heart Association (NYHA) class was not possible either, for the same reason.

\section{Discussion}

In the third update of this systematic review we have found and included just one new randomised controlled trial which added little additional information (100 patients, reported only AF recurrence rates). Conversely, we excluded a previously included study as we become aware its data were already reported in another included study. Additionnally, we have restructured the analysis of the review to treat each drug separately, in order to present all analysis and results in a clearer way. In the end, some of the results regarding specific antiarrhythmics and conclusions of the review have changed.

\section{Summary of main results}

The primary aim of this review was to determine if long-term treatment with antiarrhythmics carried any clinical benefit to patients in addition to maintenance of sinus rhythm. Consequently, we focused on all-cause mortality, stroke, embolism and also potential adverse effects of treatment as the main outcomes. 
Concerning all-cause mortality, we found that no antiarrhythmic produced a benefit on mortality and that some antiarrhythmics, sotalol and very probably quinidine, actually were associated with an increase in all-cause mortality. Results for sotalol are particularly strong and the certainty of evidence is high: included studies had a low risk of bias for this outcome; results were consistent in all sensitivity analysis, replicating the results of the main analysis and indicating a clear association with increased mortality. The mortality rate in the pooled population was low, $0,8 \%$ in control patients (placebo or no treatment), but it was doubled in patients receiving sotalol. The mean NNTH was estimated at 102 patients treated for one year to have one excess death.

The results suggesting an increase in mortality also with quinidine are less solid. The confidence interval included the possibility of no difference and when the analysis was restricted to more recent, larger and high-quality studies, two studies remained (PAFAC 2004, SOPAT 2004) which showed no increase in all-cause mortality in the active treatment groups. A possible explanation is that both studies used a lower dose of quinidine than earlier trials and that quinidine was combined with verapamil, which has been shown to reduce some of the pro-arrhythmic effects of quinidine, such as accelerated atrio-ventricular conduction. Finally, the proportion of patients having structural heart disease was lower in the PAFAC and SOPAT studies than in earlier trials. Therefore, he certainty of the evidence pointing to increased all-cause mortality with quinidine was rated as low.

It is important to note that our data does not allow us to exclude a small increase in mortality with other antiarrhythmics, similar to those observed with quinidine and sotalol. Pooled data for other drugs included fewer studies and patients than for quinidine or sotalol and could be underpowered to detect effects that are of small size. In particular, we found very few data on mortality with flecainide. This is concerning because this drug has been shown to induce an excess of mortality in some trials (CAST 1991) and it showed a high risk of pro-arrhythmia in our review, similar to that of sotalol. The combined flecainide data had only a fifth of the patients included for sotalol and, despite the fact that several of the included studies stated that they analysed mortality, no death at all was reported in any treatment group. Thus, we are very unsure about what the effect of long-term treatment with flecainide in mortality might be. Similarly, the combined data for amiodarone for this outcome included four times less patients than with sotalol, so our power to detect small increases in mortality was very limited. Amiodarone has a well known high toxicity profile, showed in our analysis one of the highest risk of withdrawing treatment due to adverse effects (RR 6.70, 95\% CI 1.91 to 23.45) and was associated, in other meta-analysis employing different methods, to a possible increase in mortality (Freemantle 2011; Piccini 2009) (See below: Agreements and disagreements with other studies or reviews).

With respect to adverse effects, virtually all the antiarrhythmics showed more withdrawals from treatment due to adverse effects and were associated to increased pro-arrhythmic events, compared with patients receiving placebo or no treatment. It is important to remember that we employed an extended definition of pro-arrhythmia that included severe, symptomatic bradycardia and AV blocks. Metoprolol was associated with an increase in pro-arrhythmia, precisely because an increased incidence of severe bradycardias. Of all antiarrhythmics, quinidine at higher doses and sotalol appeared to be the drugs with more withdrawals because of adverse events both compared to controls and to other antiarrhythmics. Withdrawal rates with quinidine were as high as $25 \%$ in the pooled population anlysed. Amiodarone, even if it compared favourably with class I drugs combined, had a very high RR (6.70) for increasing withdrawals compared to placebo. Moreover, these were the results at one year follow up, 
and the adverse effects of amiodarone are known to increase in frequency over time (Harris 1983; Lafuente-Lafuente 2009).

Regarding other outcomes, our results show that all the antiarrhythmic drugs studied reduce the recurrence of atrial fibrillation. The effectiveness of antiarrhythmics, however, was limited: they reduced recurrences by $20 \%$ to $50 \%$ compared to controls, which means that atrial fibrillation still recurred in many patients (43\% to 67\%) treated with antiarrhythmics, at one year. Amiodarone seemed to be the most effective drug in preventing recurrences as it had the lowest RR and in head to head comparisons it was better than combined class I drugs, dronedarone or sotalol. In spite of this, atrial fibrillation recurred at one year in $43 \%$ of patients treated with amiodarone.

Avobe all, we did not found any evidence of any clinical benefit derived from this reduction of recurrences of atrial fibrillation. The results on mortality showed no benefit with any drug, rather the contrary, as we have already discussed. Much fewer data existed on stroke or heart failure, but what data we found showed no difference between patients receiving active antiarrhythmic treatment and those not receiving it. The only exception was a single study (ATHENA 2009) in which the stroke rate was lower in the dronedarone arm than in the placebo arm. This finding was not confirmed by other studies of dronedarone. This lack of observable clinical benefit from the reduction of atrial fibrillation recurrences can have several explanations: a) any potential benefit obtained with antiarrhythmics might be erased by the associated toxicity and increased pro-arrhythmic events; b) clinical evolution and prognosis might be determined in many patients mostly by their underlying heart disease, rather than by atrial fibrillation itself.

An interesting result of this review is that metoprolol, a beta-blocker, also showed a reduction in atrial fibrillation recurrence, based on the pooled data from two high-quality randomised controlled trials (Kuhlkamp 2000; Nergardh 2007). Besides, no difference in preventing recurrences was found between beta-blockers and sotalol in two other trials (DAPHNE 2008 comparing sotalol against metoprolol or atenolol, and Plewan 2001 against bisoprolol). The effect of beta-blockers in reducing the recurrence of atrial fibrillation could be due to their ability to suppress atrial extrasystoles, known to be a frequent precipitant of paroxysmal atrial fibrillation (Haïssaguerre 1998). Beta-blocker effects might also relate to antihypertensive and anti-Ischaemic actions or to their effect in reducing cardiac remodelling associated with coronary artery disease or heart failure. Metoprolol was associated, however, like most active drugs here studied, to increased withdrawals due to adverse effects and increased cases of severe, symptomatic bradycardia.

\section{Overall completeness and applicability of evidence}

Data on all-cause mortality, recurrence of atrial fibrillation and main adverse drug events was reported by most of the included trials. We also intended to analyse other clinically relevant outcomes such as the frequency of systemic embolism and use of long-term anticoagulation, or the influence of heart failure and structural heart disease in the response to treatment. Unfortunately data on those outcomes were sparse, if reported at all. In the few trials where they were reported, the frequencies of stroke and heart failure were very low, perhaps because the populations that were included were low risk. The frequency of use of anticoagulants during the follow up was not reported in any study. 
Similarly, we wanted to analyse the influence of structural heart disease on effectiveness, specially with respect to left ventricular ejection fraction and left atrial size, and the influence of duration of atrial fibrillation before cardioversion. These are factors well known to influence the risk of recurrence of atrial fibrillation. Unfortunately this analysis was not possible as separate data were not available for those patients subgroups.

This lack of data for some clinical outcomes is the main limitation of our review. Another limitation could be that in many studies patients were followed up until atrial fibrillation recurred, and not thereafter, hence additional events between that point and the complete one year of follow up might have been missed. Also, the populations included in most studies were at low risk of events, the mean age of included patients was 64 years old and most of them had a normal left ventricular ejection fraction. We do not know if our results can be extrapolated to other patient populations, especially older patients and those with a reduced left ventricular ejection fraction.

Finally, it is important to remember that maintaining sinus rhythm by using long-term antiarrhythmic drugs is only one possible step in the more general 'rhythm control' strategy, and antiarrhythmic drugs should be put within the perspective of the global strategy chosen for the patient (ACC/AHA/ESC 2014; NICE 2014). Other therapies have proven to be useful to prevent or reduce recurrence of atrial fibrillation in selected patients, especially catheter ablation (APAF 2006; Oral 2006; Terasawa 2009); and antiarrhythmics have been occasionally used for terminating recurrences (Alboni 2004). However, the effects of these therapies on the important clinical endpoints of all-cause mortality, stroke, incidence of heart failure are still not well known. A different Cochrane review has studied the effectiveness of catheter ablation for paroxysmal and persistent atrial fibrillation (Chen 2012).

\section{Quality of the evidence}

Two areas of concern regarding the risk of bias of included studies were present: (a) a lack of details, in about $70 \%$ of studies, on the procedures followed for randomisation and for concealing the allocation of patients; and (b) a lack of double-blinding in approximately $60 \%$ of studies. The lack of details on the randomisation and concealing procedures can probably be explained, at least partly, by the fact that many of the studies were conducted in the eighties and nineties, when the standards for reporting research methods were less developed. Also, it was very difficult to obtain additional data from authors for studies so old. The lack of blinding concerned specially studies comparing two antiarrhythmics and much less studies comparing an antiarrhythmic with no active treatment. Nevertheless, these concerns did not allow us to consider the evidence as "high quality".

On the other hand, despite the potential sources of bias, there were two other characteristics that increased our confidence in the results of the review: (a) Consistency of results: for each analysis, there were always several studies available and results are very consistent across individual studies, despite their differences in blinding or in the description of the allocation procedures; (b) Objective outcomes: with the only exception of withdrawals because of adverse effects, the outcomes analysed were measured objectively (ECG records) or are hard outcomes (stroke, mortality), which reduces the risk of bias associated to the lack of blinding. 
In the end, we judged the available evidence for most analysed outcomes (all-cause mortality, withdrawals dure to adverse effects, pro-arrhythmia and recurrence of atrial fibrillation) as of moderate quality.

\section{Potential biases in the review process}

We are not aware of any potential bias in the review process. There were very few disagreements between reviewers regarding the inclusion and exclusion of candidate studies. There were also few disagreements regarding the data extracted from included studies. Disagreements were easily resolved by discussion and consensus in all cases.

\section{Agreements and disagreements with other studies or reviews}

A previous meta-analysis by Coplen et al found that quinidine increased all-cause mortality (Coplen 1990). A meta-analysis by Nichol et al found no difference in all-cause mortality with any antiarrhythmic, but most of the trials that they pooled had very short follow-up periods (Nichol 2002).

A more recent network meta-analysis, using a mixed treatment comparison method (where the estimates obtained from direct and indirect comparisons are combined in a network of trials), also found an increase in all-cause mortality associated with sotalol (Freemantle 2011). This meta-analysis, as well as a different meta-analysis that compared amiodarone and dronedarone (Piccini 2009), raised the possibility of an increase in mortality associated with amiodarone treatment compared with placebo. This result, however, appeared in exploratory analysis (restricted to inclusion of larger studies) and not in the main analysis. Quinidine was not studied in the meta-analysis by Freemantle et al.

\section{Authors' conclusions}

\section{Implications for practice}

There is high-quality evidence of increased all-cause mortality associated with sotalol treatment. Consequently, this drug should not be used for this indication (maintaining sinus rhythm in patients who had atrial fibrillation). If employed, it should be with extreme caution and very closely monitored.

Similarly, quinidine should neither be employed for this indication, or used with extreme caution, as there is low-quality evidence suggesting that its use is also associated with increased mortality, as well as moderate-quality evidence of a marked increase in withdrawals due to adverse events and high-quality evidence of increased pro-arrhythmic events.

Caution should also be taken when using flecainide. This drug has been shown to induce an excess of mortality in some trials in other heart conditions (CAST 1991). Very few data on mortality is available for this drug when employed for maintaining sinus rhythm, making impossible any reliable estimation of mortality in patients with atrial fibrillation. It exists, 
however, moderate-quality evidence of an important increase in pro-arrhythmic events with flecainide.

Overall, given: a) the concerns regarding increased mortality with several drugs; b) the modest effectiveness of antiarrhythmic drugs for preventing recurrences of atrial fibrillation; c) the evidence of increased adverse events with all drugs studied; d) the evidence of increased pro-arrhythmic events with most drugs studied, and; e) the absence of evidence of any benefit obtained with these drugs on clinical endpoints; chronic treatment with antiarrhythmics drugs should not be considered as a first-line treatment for maintaining sinus rhythm in patients with atrial fibrillation. Other treatments, or strategies, with fewer associated adverse events, or higher effectiveness, should be considered before: no treatment at all, rate control strategy (Caldeira 2012, Chatterjee 2013), pulmonary veins catheter ablation (Khan 2014, CASTLE-AF 2018) or, in selected patients with paroxysmal atrial fibrillation, episodic, very short-term use of antiarrhythmics (in hospital or as a "pill-in-the pocket" approach, Alboni 2004, Saborido 2010).

\section{Implications for research}

Adequate evidence exists for some outcomes (withdrawals, pro-arrhythmia and atrial fibrillation recurrences) for all drugs included in this review. There is good evidence regarding mortality for several antiarrhythmics, but there is an important lack of data on mortality for some drugs, specially flecainide and propafenone, and limited data for other drugs, like amiodarone, which does not allow to exclude small increases in mortality with them.

Available evidence is limited by the lack of systematic assessment in many studies of important clinical outcomes: stroke, heart failure, and functional measures (exercise capacity, quality of life). Trials studying antiarrhythmic drugs should measure their effects on these outcomes in addition to prevention of arrhythmia recurrences. Pending questions include the effects of antiarrhythmics on these clinical outcomes, and the effects in specific subgroups of patients, specifically patients with heart failure or reduced left ventricular ejection fraction, and older patients.

Finally, new drugs or other procedures that are more effective in preventing atrial fibrillation recurrence or are associated with fewer adverse effects, or both, would be desirable.

\section{Acknowledgements}

We thank all the trial authors who answered our request for additional data; Professor Charles Caulin for his most valuable suggestions; Dr Barbara Stadler for translating articles from German, Lone Gale for helping with articles in Swedish, Dr Qian Zhang for translating from Chinese; Dr Miguel Angel Longas-Tejero, Pr Stéphane Mouly and Pr Jean-François Bergmann for their help in previous versions of this review; and all the staff of Cochrane Heart Group for their most important help and support.

\section{Contributions of authors}


CL-L and JB: prepared and designed the review,

CL-L: searched for primary studies and contacted authors of primary studies when needed.

LV, AT, WJ: screened search results, and retrieved papers.

LV, EA, WJ, JB and CL-L: assessed papers for inclusion and risk of bias.

LV, EA, WJ and CL-L: extracted data.

CL-L and AT performed analysis and interpreted data.

LV and WJ: interpreted data and reviewed the manuscript.

CL-L, AT and JB: wrote the review.

\section{Declarations of interest}

Lucie Valembois: none known.

Etienne Audureau: none known

Andrea Takeda: none known

Witold Jarzebowski: none known

Joël Belmin: none known

Carmelo Lafuente-Lafuente has received consultant fees (less than EUR 5000 total) from Sanofi-Aventis, in 2009 and 2010, for helping to conduct a study (a mixed treatment comparison meta-analysis) on several antiarrhythmic drugs for the management of atrial fibrillation. Sanofi-Aventis is the manufacturer of amiodarone and dronedarone, two of the antiarrhythmics studied in this review. He also received personal fees from Bayer Healthcare and BMS, outside this work.

\section{Differences between protocol and review}

Some of the original planned outcomes and planned subgroup analyses could not be performed because the data needed were not recorded or not reported in the original studies. Some planned outcomes were thus modified:

- All-cause mortality and cardiovascular mortality were virtually identical in all studies, so we chose to report only all-cause mortality.

- We finally analysed only stroke instead the originally planned "embolic complications (stroke and peripheral embolism combined)" as data for peripheral embolism lacked;

- Heart failure was added as a secondary outcome, because it is an important outcome in these patients. 
Other modifications included in the successive updates with respect to the original protocol were:

- Assessment of the risk of bias of included studies was expanded to comply with the new Cochrane MECIR methodological requirements;

- We decided to report risk ratios instead Peto odds ratios, as originally done, because risk ratios are more interpretable by clinicians and non-statisticians.

- Initially, we analysed data not only by each individual drug but also grouped by pharmacological class, following the classification of Vaughan Williams (Vaughan Williams 1984). However, individual antiarrhythmics are very different one from another even inside the same class and it is not clear what would be the clinical implications of grouping them by classes. Consequently, after discussion, we decided to analyze data only by individual drugs.

- We decide to drop out several drugs that have never been marketed for this indication (never proved to be effective) : aprindine (class IB), bidisomide (class IB) and azimilide (class III).

\section{Summary of findings tables}

\section{Quinidine compared to placebo or no treatment for maintaining sinus rhythm after cardioversion of atrial fibrillation}

Quinidine compared to placebo or no treatment for maintaining sinus rhythm after cardioversion of atrial fibrillation

Patient or population: adults in sinus rhythm after cardioversion of atrial fibrillation

Setting: Hospital / community

Intervention: Quinidine

Comparison: placebo or no treatment

\begin{tabular}{|c|c|c|c|c|c|c|}
\hline \multirow[t]{2}{*}{ Outcomes } & \multicolumn{2}{|c|}{$\begin{array}{l}\text { Anticipated absolute } \\
\text { effects }^{*}(95 \% \mathrm{CI})\end{array}$} & \multirow{2}{*}{$\begin{array}{l}\text { Relative } \\
\text { effect } \\
(95 \% \\
\text { CI })\end{array}$} & \multirow{2}{*}{$\begin{array}{l}\text { № of } \\
\text { participants } \\
\text { (studies) }\end{array}$} & \multirow{2}{*}{$\begin{array}{l}\text { Certainty of } \\
\text { the evidence } \\
\text { (GRADE) }\end{array}$} & \multirow[t]{2}{*}{ Comments } \\
\hline & $\begin{array}{l}\text { Risk with } \\
\text { placebo or } \\
\text { no } \\
\text { treatment }\end{array}$ & $\begin{array}{l}\text { Risk with } \\
\text { Quinidine }\end{array}$ & & & & \\
\hline All-cause & \multicolumn{2}{|c|}{ Study population } & \multirow{2}{*}{$\begin{array}{l}\text { RR } 2.01 \\
(0.84 \text { to } \\
4.77)\end{array}$} & \multirow{2}{*}{$\begin{array}{l}1646 \\
\text { (6 RCTs) }\end{array}$} & \multirow{2}{*}{$\begin{array}{l}\bigoplus \bigoplus \Theta \ominus \\
\mathrm{LOW}^{12}\end{array}$} & \\
\hline $\begin{array}{l}\text { mortality - } \\
\text { main analysis } \\
\text { follow up: } \\
\text { median } 12 \\
\text { months }\end{array}$ & $\begin{array}{l}8 \text { per } \\
1,000\end{array}$ & $\begin{array}{l}15 \text { per } \\
1,000 \\
(6 \text { to } 36)\end{array}$ & & & & \\
\hline Withdrawals & \multicolumn{2}{|c|}{ Study population } & 1.56 & 1669 & $\bigoplus \bigoplus \bigoplus \ominus$ & Heterogeneity \\
\hline due to & 163 per & 254 per & $(0.87$ & (7 RCTs) & MODERATE & was high for the \\
\hline
\end{tabular}




\begin{tabular}{|c|c|c|}
\hline $\begin{array}{l}\text { adverse } 1,000 \\
\text { effects - main } \\
\text { analysis } \\
\text { follow up: } \\
\text { median 12 } \\
\text { months }\end{array}$ & $\begin{array}{l}1,000(1422.78) \\
\text { to } 452)\end{array}$ & $\begin{array}{l}\text { main analysis, } \\
\text { but the test for } \\
\text { subgroup } \\
\text { differences } \\
\text { indicated that the } \\
\text { RR was higher in } \\
\text { older studies } \\
\text { which used a } \\
\text { higher dose. }\end{array}$ \\
\hline
\end{tabular}

\begin{tabular}{lllll} 
Pro- & \multicolumn{2}{c}{ Study population } & RR 2.05 1676 & $\oplus \bigoplus \bigoplus \bigoplus$ \\
arrhythmia - & 11 per & 22 per & $(0.95$ to $(7 \mathrm{RCTs})$ & HIGH $^{36}$ \\
main analysis & 1,000 & 1,000 & $4.41)$ & \\
follow up: & \multicolumn{1}{l}{$(10$ to 48$)$} & &
\end{tabular}

median 12

months

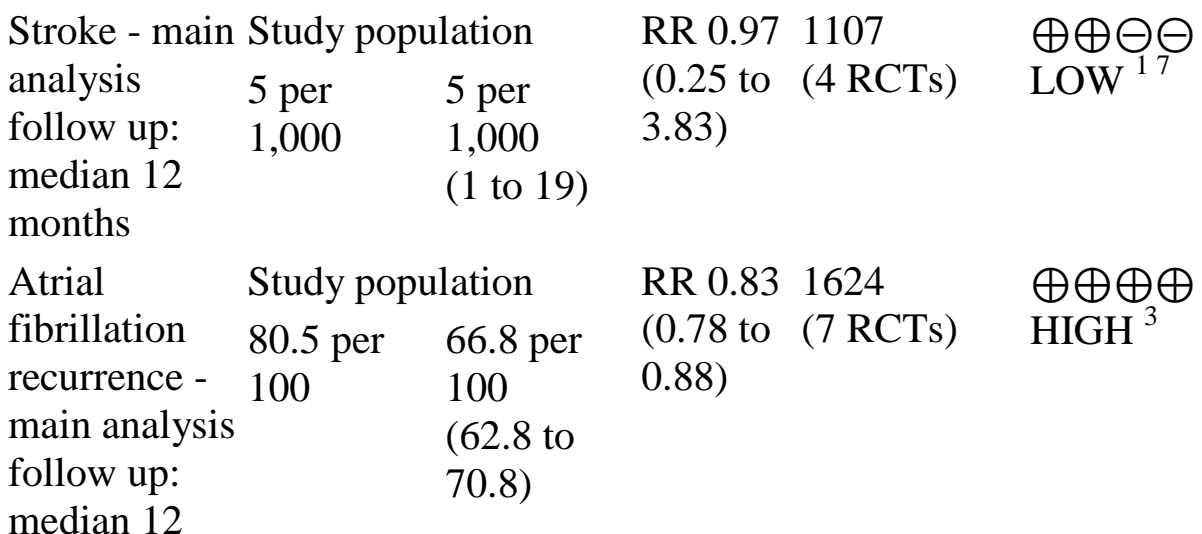

months

*The risk in the intervention group (and its $95 \%$ confidence interval) is based on the assumed risk in the comparison group and the relative effect of the intervention (and its $95 \%$ $\mathrm{CI})$.

CI: Confidence interval; RR: Risk ratio; OR: Odds ratio;

\section{GRADE Working Group grades of evidence}

High certainty: We are very confident that the true effect lies close to that of the estimate of the effect

Moderate certainty: We are moderately confident in the effect estimate: The true effect is likely to be close to the estimate of the effect, but there is a possibility that it is substantially different

Low certainty: Our confidence in the effect estimate is limited: The true effect may be substantially different from the estimate of the effect

Very low certainty: We have very little confidence in the effect estimate: The true effect is likely to be substantially different from the estimate of effect

Footnotes

${ }^{1}$ Downgraded one level for study limitations: majority of studies were at low or unclear risk of bias for at least one of the key domains (allocation concealment, blinding, incomplete outcome data) 
${ }^{2}$ Downgraded one level for imprecision: confidence interval includes no effect, the possibility of a beneficial effect, and a strong harmful effect.

${ }^{3}$ Not downgraded for study limitations, as the 2 studies contributing majority of weight were at low risk for key domains (allocation concealment, blinding, incomplete outcome data)

${ }^{4}$ Not downgraded for inconsistency: although heterogeneity was high for the main analysis, this was partially explained by subgroup analysis.

${ }^{5}$ Downgraded one level for imprecision: confidence interval includes possibility of no effect or small beneficial effect as well as harmful effect.

${ }^{6}$ Not downgraded for imprecision, although CI just includes null

${ }^{7}$ Downgraded one level for imprecision: confidence interval includes both important benefits and harms, and event rate was very low.

\section{Disopyramide compared to placebo or no treatment for maintaining sinus rhythm after cardioversion of atrial fibrillation}

Disopyramide compared to placebo or no treatment for maintaining sinus rhythm after cardioversion of atrial fibrillation

Patient or population: adults in sinus rhythm after cardioversion of atrial fibrillation

Setting: Hospital / community

Intervention: Disopyramide

Comparison: placebo or no treatment

Outcomes Anticipated absolute
effects $^{*}(95 \% \mathrm{CI})$

Relative № of

Certainty Comments

effect participants of the

Risk with Risk with $\quad(95 \% \quad$ (studies) $\quad$ evidence

placebo or Disopyramide CI)

(GRADE)

no

treatment

$\begin{array}{llll}\text { All-cause } & \text { Study population } & \text { RR 5.00 92 } & \oplus \bigoplus \ominus \ominus \\ \text { mortality - main } & 0 \text { per 1,000 0 per 1,000 } & (0.25 \text { to (1 RCT) } & \text { LOW }{ }^{12} \\ \text { analysis } & (0 \text { to } 0) & 101.37) & \\ \text { follow up: mean } & & & \end{array}$

follow up: mean

12 months

Withdrawals due Study population

to adverse

28 per

104 per 1,000

RR 3.68146

effects - main $\quad 1,000$

(27 to 401 )

(0.95 to (2 RCTs)

$\oplus \oplus \ominus \ominus$

analysis

14.24)

follow up: range

6 to 12 months

Pro-arrhythmia - -

not reported

Stroke -

Study population

RR 0.31146

$\oplus \ominus \ominus \ominus$ 


$\begin{array}{llllll}\text { Individual } & 28 \text { per } & 9 \text { per 1,000 } & (0.03 \text { to } & \text { (2 RCTs) } & \text { VERY } \\ \text { antiarrhythmics } & 1,000 & (1 \text { to } 82) & 2.91) & \text { LOW }^{23} \\ \text { follow up: range } & & & & \end{array}$

follow up: range

6 to 12 months

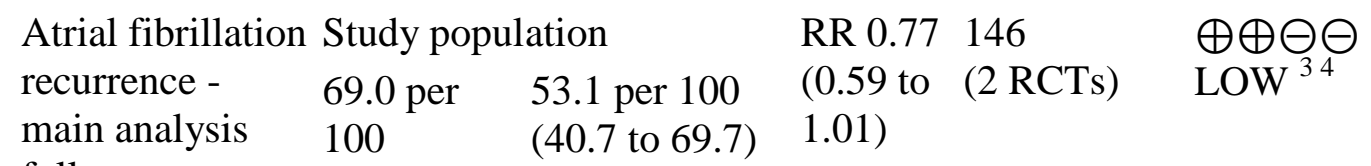

follow up: range

6 to 12 months

*The risk in the intervention group (and its $95 \%$ confidence interval) is based on the assumed risk in the comparison group and the relative effect of the intervention (and its $95 \%$ CI).

CI: Confidence interval; RR: Risk ratio; OR: Odds ratio;

GRADE Working Group grades of evidence

High certainty: We are very confident that the true effect lies close to that of the estimate of the effect

Moderate certainty: We are moderately confident in the effect estimate: The true effect is likely to be close to the estimate of the effect, but there is a possibility that it is substantially different

Low certainty: Our confidence in the effect estimate is limited: The true effect may be substantially different from the estimate of the effect

Very low certainty: We have very little confidence in the effect estimate: The true effect is likely to be substantially different from the estimate of effect

Footnotes

${ }^{1}$ Not downgraded for study limitations: study had unclear blinding but this is less relevant for this outcome.

${ }^{2}$ Downgraded by two levels for imprecision: very small sample size and wide confidence intervals including both important benefits and harms.

${ }^{3}$ Downgraded by one level for study limitations: both studies had unclear risk of bias for one of the key domains.

${ }^{4}$ Downgraded by one level for imprecision: very small sample size

\section{Propafenone compared to placebo or no treatment for maintaining sinus rhythm after cardioversion of atrial fibrillation}

Propafenone compared to placebo or no treatment for maintaining sinus rhythm after cardioversion of atrial fibrillation

Patient or population: adults in sinus rhythm after cardioversion of atrial fibrillation

Setting: Hospital / community

Intervention: Propafenone 
Comparison: placebo or no treatment

\begin{tabular}{|c|c|c|c|c|c|}
\hline \multirow[t]{2}{*}{ Outcomes } & \multicolumn{2}{|c|}{$\begin{array}{l}\text { Anticipated absolute } \\
\text { effects }^{*}(95 \% \mathrm{CI})\end{array}$} & \multirow{2}{*}{$\begin{array}{l}\text { Relative } \\
\text { effect } \\
(95 \% \\
\text { CI })\end{array}$} & \multirow{2}{*}{$\begin{array}{l}\text { № of } \\
\text { participants } \\
\text { (studies) }\end{array}$} & \multirow{2}{*}{$\begin{array}{l}\text { Certainty of } \\
\text { the evidence } \\
\text { (GRADE) }\end{array}$} \\
\hline & $\begin{array}{l}\text { Risk with } \\
\text { placebo or } \\
\text { no } \\
\text { treatment }\end{array}$ & $\begin{array}{l}\text { Risk with } \\
\text { Propafenone }\end{array}$ & & & \\
\hline \multirow[b]{2}{*}{$\begin{array}{l}\text { All-cause } \\
\text { mortality - } \\
\text { main analysis } \\
\text { follow up: } \\
\text { range } 6 \text { to } 15 \\
\text { months }\end{array}$} & \multicolumn{2}{|c|}{ Study population } & \multirow{2}{*}{$\begin{array}{l}\mathrm{RR} 0.19 \\
(0.02 \text { to } \\
1.68)\end{array}$} & \multirow{2}{*}{$\begin{array}{l}212 \\
(2 \mathrm{RCTs})\end{array}$} & \multirow{2}{*}{$\begin{array}{l}\oplus \Theta \Theta \Theta \\
\text { VERY LOW } \\
1\end{array}$} \\
\hline & $\begin{array}{l}26 \text { per } \\
1,000\end{array}$ & $\begin{array}{l}5 \text { per } 1,000 \\
(1 \text { to } 44)\end{array}$ & & & \\
\hline Withdrawals & \multicolumn{2}{|c|}{ Study population } & \multirow{2}{*}{$\begin{array}{l}\text { RR } 1.62 \\
(1.07 \text { to } \\
2.46)\end{array}$} & \multirow{2}{*}{$\begin{array}{l}1098 \\
(5 \mathrm{RCTs})\end{array}$} & \multirow{2}{*}{$\begin{array}{l}\oplus \underset{1}{\operatorname{MODERATE}} \\
\bigoplus \oplus \oplus \ominus\end{array}$} \\
\hline $\begin{array}{l}\text { due to adverse } \\
\text { effects - main } \\
\text { analysis } \\
\text { follow up: } \\
\text { range } 6 \text { to } 15 \\
\text { months }\end{array}$ & $\begin{array}{l}61 \text { per } \\
1,000\end{array}$ & $\begin{array}{l}99 \text { per } 1,000 \\
(65 \text { to } 150)\end{array}$ & & & \\
\hline Pro- & \multicolumn{2}{|c|}{ Study population } & \multirow{2}{*}{$\begin{array}{l}\text { RR } 1.32 \\
(0.39 \text { to } \\
4.47)\end{array}$} & \multirow{2}{*}{$\begin{array}{l}381 \\
(3 \mathrm{RCTs})\end{array}$} & \multirow{2}{*}{$\begin{array}{l}\oplus \ominus \Theta \Theta \\
\text { VERY LOW }\end{array}$} \\
\hline $\begin{array}{l}\text { arrhythmia - } \\
\text { main analysis } \\
\text { follow up: } \\
\text { range } 6 \text { to } 15 \\
\text { months }\end{array}$ & $\begin{array}{l}13 \text { per } \\
1,000\end{array}$ & $\begin{array}{l}17 \text { per } 1,000 \\
(5 \text { to } 56)\end{array}$ & & & \\
\hline $\begin{array}{l}\text { Stroke - not } \\
\text { reported }\end{array}$ & - & - & - & - & - \\
\hline Atrial & \multicolumn{2}{|c|}{ Study population } & \multirow{2}{*}{$\begin{array}{l}\text { RR } 0.67 \\
(0.61 \text { to } \\
0.74)\end{array}$} & \multirow{2}{*}{$\begin{array}{l}1098 \\
(5 \mathrm{RCTs})\end{array}$} & \multirow{2}{*}{$\begin{array}{l}\bigoplus \underset{1}{\oplus} \oplus \bigoplus \Theta \\
\text { MODERATE }\end{array}$} \\
\hline $\begin{array}{l}\text { fibrillation } \\
\text { recurrence - } \\
\text { main analysis } \\
\text { follow up: } \\
\text { range } 6 \text { to } 15 \\
\text { months }\end{array}$ & $\begin{array}{l}73.0 \text { per } \\
100\end{array}$ & $\begin{array}{l}48.9 \text { per } 100 \\
(44.5 \text { to } 54.0)\end{array}$ & & & \\
\hline
\end{tabular}

*The risk in the intervention group (and its $95 \%$ confidence interval) is based on the assumed risk in the comparison group and the relative effect of the intervention (and its 95\% CI).

CI: Confidence interval; RR: Risk ratio; OR: Odds ratio;

GRADE Working Group grades of evidence

High certainty: We are very confident that the true effect lies close to that of the estimate of the effect

Moderate certainty: We are moderately confident in the effect estimate: The true effect is likely to be close to the estimate of the effect, but there is a possibility that it is substantially different

Low certainty: Our confidence in the effect estimate is limited: The true effect may be substantially different from the estimate of the effect 
Very low certainty: We have very little confidence in the effect estimate: The true effect is likely to be substantially different from the estimate of effect

Footnotes

${ }^{1}$ Downgraded by one level for study limitations. All studies had unclear or high risk of bias in at least one of the three key domains (allocation concealment, blinding, incomplete outcome data).

${ }^{2}$ Downgraded by two levels for imprecision due to small sample size and confidence interval wide enough to include both important benefit and harm.

\section{Flecainide compared to placebo or no treatment for maintaining sinus rhythm after cardioversion of atrial fibrillation}

Flecainide compared to placebo or no treatment for maintaining sinus rhythm after cardioversion of atrial fibrillation

Patient or population: adults in sinus rhythm after cardioversion of atrial fibrillation

Setting: Hospital / community

Intervention: Flecainide

Comparison: placebo or no treatment

Outcomes

Anticipated absolute

effects $^{*}(95 \% \mathrm{CI})$

Relative № of

Certainty of Comments

Risk with Risk with

placebo or Flecainide

effect participants the evidence

(95\% (studies) (GRADE)

no

treatment

\begin{tabular}{|c|c|c|c|c|c|}
\hline \multirow{2}{*}{$\begin{array}{l}\text { All-cause } \\
\text { mortality - } \\
\text { main analysis }\end{array}$} & \multicolumn{2}{|c|}{ Study population } & \multirow[t]{2}{*}{-} & \multirow[t]{2}{*}{ (0 RCTs) } & \multirow[t]{2}{*}{ - } \\
\hline & $\begin{array}{l}\text { see } \\
\text { comment }\end{array}$ & $\begin{array}{l}\text { see } \\
\text { comment }\end{array}$ & & & \\
\hline Withdrawals & \multicolumn{2}{|c|}{ Study population } & $\mathrm{RR}$ & & $\oplus \oplus \ominus \ominus$ \\
\hline $\begin{array}{l}\text { due to adverse } \\
\text { effects - main } \\
\text { analysis }\end{array}$ & 0 per 1,000 & $\begin{array}{l}194 \text { per } \\
1,000 \\
\text { (? to ?) }\end{array}$ & $\begin{array}{l}15.41 \\
(0.91 \text { to } \\
260)\end{array}$ & (1 RCT) & $\mathrm{LOW}^{12}$ \\
\hline
\end{tabular}

follow up:

mean 6 months

Pro-arrhythmia

- main analysis

follow up:

Study population

RR $4.80 \quad 511$

6 per 1,00030 per

1,000

(1.30 to (4 RCTs)

$\oplus \oplus \oplus \Theta$

range 6 to 12

(8 to 112 )

months

MODERATE

Stroke - main

analysis

Study population

RR 2.04362

follow up:

0 per 1,000 ? per 1,000

(0.11 to (1 RCT) 3

(0 to 0$)$

39)

$\oplus \oplus \Theta \Theta$
$\operatorname{LOW}^{12}$

mean 6 months 


$\begin{array}{lclll}\text { Atrial } & \text { Study population } & \text { RR 0.65 } 511 & \oplus \bigoplus \bigoplus \bigoplus \\ \text { fibrillation } & 69.8 \text { per } 10045.4 \text { per } & (0.55 \text { to } & \text { (4 RCTs) } & \text { HIGH }^{4} \\ \text { recurrence - } & 100 & 0.77) & & \\ \text { main analysis } & (38.4 \text { to } & & \\ \text { follow up: } & 53.8) & & \\ \text { range 6 to } 12 & & & \\ \text { months } & & & \end{array}$

*The risk in the intervention group (and its $95 \%$ confidence interval) is based on the assumed risk in the comparison group and the relative effect of the intervention (and its $95 \%$ CI).

CI: Confidence interval; RR: Risk ratio; OR: Odds ratio;

GRADE Working Group grades of evidence

High certainty: We are very confident that the true effect lies close to that of the estimate of the effect

Moderate certainty: We are moderately confident in the effect estimate: The true effect is likely to be close to the estimate of the effect, but there is a possibility that it is substantially different

Low certainty: Our confidence in the effect estimate is limited: The true effect may be substantially different from the estimate of the effect

Very low certainty: We have very little confidence in the effect estimate: The true effect is likely to be substantially different from the estimate of effect

Footnotes

${ }^{1}$ Not downgraded for study limitations. the only included study was at high risk of bias for blinding (less relevant for this outcome) but low risk for other key domains.

${ }^{2}$ Downgraded by two levels for imprecision due to small sample size and wide confidence interval that included both possible harm and no effect.

${ }^{3}$ Downgraded by one level for study limitations; all studies were at high or unclear risk of bias in at least one of the key domains.

${ }^{4}$ Not downgraded for study limitations. Majority of weight came from 2 largest studies which were at high risk of bias for blinding (less relevant for this outcome) but low risk for other key domains.

\section{Metoprolol compared to placebo or no treatment for maintaining sinus rhythm after cardioversion of atrial fibrillation}

Metoprolol compared to placebo or no treatment for maintaining sinus rhythm after cardioversion of atrial fibrillation

Patient or population: adults in sinus rhythm after cardioversion of atrial fibrillation

Setting: Hospital / community

Intervention: Metoprolol

Comparison: placebo or no treatment 


\begin{tabular}{|c|c|c|c|c|c|c|}
\hline \multirow[t]{2}{*}{ Outcomes } & \multicolumn{2}{|c|}{$\begin{array}{l}\text { Anticipated absolute } \\
\text { effects }^{*}(95 \% \text { CI })\end{array}$} & \multirow{2}{*}{$\begin{array}{l}\text { Relative } \\
\text { effect } \\
(95 \% \\
\text { CI })\end{array}$} & \multirow{2}{*}{$\begin{array}{l}\text { № of } \\
\text { participants } \\
\text { (studies) }\end{array}$} & \multirow{2}{*}{$\begin{array}{l}\text { Certainty of } \\
\text { the evidence } \\
\text { (GRADE) }\end{array}$} & \multirow[t]{2}{*}{ Comments } \\
\hline & $\begin{array}{l}\text { Risk with } \\
\text { placebo or } \\
\text { no } \\
\text { treatment }\end{array}$ & $\begin{array}{l}\text { Risk with } \\
\text { Metoprolol }\end{array}$ & & & & \\
\hline All-cause & \multicolumn{2}{|c|}{ Study population } & \multirow{2}{*}{$\begin{array}{l}\text { RR } 2.02 \\
(0.37 \text { to } \\
11.1)\end{array}$} & \multirow{2}{*}{$\begin{array}{l}562 \\
(2 \mathrm{RCTs})\end{array}$} & \multirow{2}{*}{$\begin{array}{l}\bigoplus \bigoplus \bigoplus \Theta \\
\text { MODERATE }\end{array}$} & \\
\hline $\begin{array}{l}\text { mortality - } \\
\text { main analysis } \\
\text { follow up: } \\
\text { mean } 6 \text { months }\end{array}$ & 4 per 1,000 & $\begin{array}{l}7 \text { per } 1,000 \\
(1 \text { to } 39)\end{array}$ & & & & \\
\hline \multirow{2}{*}{$\begin{array}{l}\text { Withdrawals } \\
\text { due to adverse } \\
\text { effects - main } \\
\text { analysis } \\
\text { follow up: } \\
\text { mean } 6 \text { months }\end{array}$} & \multicolumn{2}{|c|}{ Study population } & RR 3.47 & \multirow{2}{*}{$\begin{array}{l}562 \\
(2 \mathrm{RCTs})\end{array}$} & \multirow{2}{*}{$\begin{array}{l}\bigoplus \oplus \bigoplus \bigoplus \\
\mathrm{HIGH}\end{array}$} & \\
\hline & $\begin{array}{l}21 \text { per } \\
1,000\end{array}$ & $\begin{array}{l}74 \text { per } 1,000 \\
(31 \text { to } 173)\end{array}$ & $\begin{array}{l}(1.48 \text { to } \\
8.1)\end{array}$ & & & \\
\hline Pro-arrhythmia & \multicolumn{2}{|c|}{ Study population } & \multirow{2}{*}{$\begin{array}{l}\text { RR } 18.14 \\
(2.42 \text { to } \\
135.6)\end{array}$} & \multirow{2}{*}{$\begin{array}{l}562 \\
(2 \mathrm{RCTs})\end{array}$} & \multirow{2}{*}{$\begin{array}{l}\bigoplus \bigoplus \bigoplus \bigoplus \\
\mathrm{HIGH}\end{array}$} & \\
\hline $\begin{array}{l}\text { - main analysis } \\
\text { follow up: } \\
\text { mean } 6 \text { months }\end{array}$ & 0 per 1,000 & $\begin{array}{l}? \text { per } 1,000 \\
(0 \text { to } 0)\end{array}$ & & & & \\
\hline $\begin{array}{l}\text { Stroke - not } \\
\text { reported }\end{array}$ & - & - & - & - & - & \\
\hline Atrial & \multicolumn{2}{|c|}{ Study population } & RR 0.83 & 562 & $\oplus \oplus \oplus \ominus$ & \\
\hline $\begin{array}{l}\text { fibrillation } \\
\text { recurrence - } \\
\text { main analysis } \\
\text { follow up: } \\
\text { mean } 6 \text { months }\end{array}$ & $\begin{array}{l}72.0 \text { per } \\
100\end{array}$ & $\begin{array}{l}59.7 \text { per } 100 \\
(49.0 \text { to } \\
73.4)\end{array}$ & $\begin{array}{l}(0.68 \\
1.02)\end{array}$ & (2 RCTs) & $\underset{2}{\text { MODERATE }}$ & \\
\hline
\end{tabular}
assumed risk in the comparison group and the relative effect of the intervention (and its $95 \%$ $\mathrm{CI})$.

CI: Confidence interval; RR: Risk ratio; OR: Odds ratio;

GRADE Working Group grades of evidence

High certainty: We are very confident that the true effect lies close to that of the estimate of the effect

Moderate certainty: We are moderately confident in the effect estimate: The true effect is likely to be close to the estimate of the effect, but there is a possibility that it is substantially different

Low certainty: Our confidence in the effect estimate is limited: The true effect may be substantially different from the estimate of the effect

Very low certainty: We have very little confidence in the effect estimate: The true effect is likely to be substantially different from the estimate of effect 
${ }^{1}$ Downgraded by one level for imprecision. Confidence interval includes both possible harm and possible benefit.

${ }^{2}$ Downgraded by one level for inconsistency: high $\mathrm{I}^{2}$ indicated heterogeneity and this could not be explored in subgroup analysis due to only 2 studies being included.

\section{Amiodarone compared to placebo or no treatment for maintaining sinus rhythm after cardioversion of atrial fibrillation}

Amiodarone compared to placebo or no treatment for maintaining sinus rhythm after cardioversion of atrial fibrillation

Patient or population: adults in sinus rhythm after cardioversion of atrial fibrillation

Setting: Hospital / community

Intervention: Amiodarone

Comparison: placebo or no treatment

\begin{tabular}{|c|c|c|c|c|c|c|}
\hline \multirow[t]{2}{*}{ Outcomes } & \multicolumn{2}{|c|}{$\begin{array}{l}\text { Anticipated absolute } \\
\text { effects }^{*}(95 \% \mathrm{CI})\end{array}$} & \multirow{2}{*}{$\begin{array}{l}\text { Relative } \\
\text { effect } \\
(95 \% \\
\text { CI })\end{array}$} & \multirow{2}{*}{$\begin{array}{l}\text { № of } \\
\text { participants } \\
\text { (studies) }\end{array}$} & \multirow{2}{*}{$\begin{array}{l}\text { Certainty of } \\
\text { the evidence } \\
\text { (GRADE) }\end{array}$} & \multirow[t]{2}{*}{ Comments } \\
\hline & $\begin{array}{l}\text { Risk with } \\
\text { placebo or } \\
\text { no } \\
\text { treatment }\end{array}$ & $\begin{array}{l}\text { Risk with } \\
\text { Amiodarone }\end{array}$ & & & & \\
\hline All-cause & \multicolumn{2}{|c|}{ Study population } & RR 1.66 & 444 & $\bigoplus \oplus \oplus \ominus$ & \\
\hline $\begin{array}{l}\text { mortality - } \\
\text { Main analysis } \\
\text { follow up: } \\
\text { range } 6 \text { to } 12 \\
\text { months }\end{array}$ & $\begin{array}{l}26 \text { per } \\
1,000\end{array}$ & $\begin{array}{l}43 \text { per } 1,000 \\
(14 \text { to } 129)\end{array}$ & $\begin{array}{l}(0.55 \text { to } \\
4.99)\end{array}$ & (2 RCTs) & $\underset{1}{\text { MODERATE }}$ & \\
\hline $\begin{array}{l}\text { Withdrawals } \\
\text { due to adverse } \\
\text { effects - Main } \\
\text { analysis } \\
\text { follow up: } \\
\text { range } 6 \text { to } 16 \\
\text { months }\end{array}$ & \multicolumn{2}{|c|}{$\begin{array}{l}\text { Study population } \\
7 \text { per } 1,00049 \text { per } 1,000 \\
(14 \text { to } 172)\end{array}$} & $\begin{array}{l}\text { RR } 6.70 \\
(1.91 \text { to } \\
23.45)\end{array}$ & $\begin{array}{l}319 \\
\text { (4 RCTs) }\end{array}$ & $\begin{array}{l}\oplus \oplus \ominus \ominus \\
\mathrm{LOW}^{23}\end{array}$ & \\
\hline $\begin{array}{l}\text { Pro- } \\
\text { arrhythmia - } \\
\text { Main analysis } \\
\text { follow up: } \\
\text { range } 6 \text { to } 16 \\
\text { months }\end{array}$ & \multicolumn{2}{|c|}{$\begin{array}{l}\text { Study population } \\
8 \text { per } 1,00018 \text { per } 1,000 \\
\quad(6 \text { to } 57)\end{array}$} & $\begin{array}{l}\text { RR } 2.22 \\
(0.71 \text { to } \\
6.96)\end{array}$ & $\begin{array}{l}673 \\
\text { (4 RCTs) }\end{array}$ & $\begin{array}{l}\bigoplus \bigoplus \bigoplus \Theta \\
\text { MODERATE }\end{array}$ & \\
\hline Stroke - Main & \multicolumn{2}{|c|}{ Study population } & RR 1.15 & 399 & $\oplus \oplus \ominus \ominus$ & \\
\hline $\begin{array}{l}\text { analysis } \\
\text { follow up: } \\
\text { mean } 12 \\
\text { months }\end{array}$ & $\begin{array}{l}23 \text { per } \\
1,000\end{array}$ & $\begin{array}{l}26 \text { per } 1,000 \\
(7 \text { to } 100)\end{array}$ & $\begin{array}{l}(0.30 \text { to } \\
4.39)\end{array}$ & (1 RCT) & I $O W$ & \\
\hline Atrial & \multicolumn{2}{|c|}{ Study population } & RR 0.52 & 812 & $\oplus \oplus \oplus \oplus$ & \\
\hline
\end{tabular}




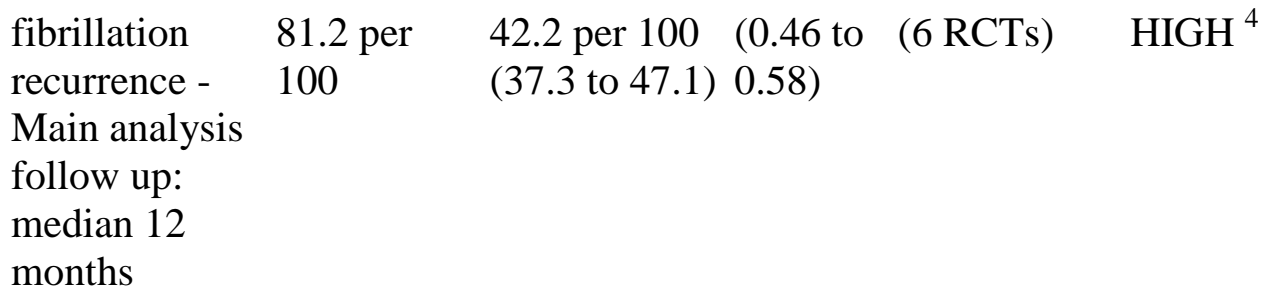

*The risk in the intervention group (and its $95 \%$ confidence interval) is based on the assumed risk in the comparison group and the relative effect of the intervention (and its 95\% $\mathrm{CI})$.

CI: Confidence interval; RR: Risk ratio; OR: Odds ratio;

GRADE Working Group grades of evidence

High certainty: We are very confident that the true effect lies close to that of the estimate of the effect

Moderate certainty: We are moderately confident in the effect estimate: The true effect is likely to be close to the estimate of the effect, but there is a possibility that it is substantially different

Low certainty: Our confidence in the effect estimate is limited: The true effect may be substantially different from the estimate of the effect

Very low certainty: We have very little confidence in the effect estimate: The true effect is likely to be substantially different from the estimate of effect

Footnotes

${ }^{1}$ Downgraded by one level for imprecision: confidence interval includes both possible benefit and harm

${ }^{2}$ Downgraded by one level for study limitations: majority of weight was from studies with unclear or high risk of bias in key domains.

${ }^{3}$ Downgraded by one level for imprecision: small sample size

${ }^{4}$ Not downgraded for study limitations, as the majority weight was from studies at low risk of bias in all key domains.

${ }^{5}$ Downgraded by two levels for imprecision: small sample size and wide confidence interval which includes both possible benefit and harm.

\section{Dofetilide compared to placebo or no treatment for maintaining sinus rhythm after cardioversion of atrial fibrillation}

Dofetilide compared to placebo or no treatment for maintaining sinus rhythm after cardioversion of atrial fibrillation

Patient or population: adults in sinus rhythm after cardioversion of atrial fibrillation

Setting: Hospital / community

Intervention: Dofetilide

Comparison: placebo or no treatment 


\begin{tabular}{|c|c|c|c|c|c|c|}
\hline \multirow[t]{2}{*}{ Outcomes } & \multicolumn{2}{|c|}{$\begin{array}{l}\text { Anticipated absolute } \\
\text { effects }{ }^{*}(95 \% \mathrm{CI})\end{array}$} & \multirow{2}{*}{$\begin{array}{l}\text { Relative } \\
\text { effect } \\
(95 \% \\
\text { CI })\end{array}$} & \multirow{2}{*}{$\begin{array}{l}\text { № of } \\
\text { participants } \\
\text { (studies) }\end{array}$} & \multirow{2}{*}{$\begin{array}{l}\text { Certainty of } \\
\text { the evidence } \\
\text { (GRADE) }\end{array}$} & \multirow[t]{2}{*}{ Comments } \\
\hline & $\begin{array}{l}\text { Risk with } \\
\text { placebo or } \\
\text { no } \\
\text { treatment }\end{array}$ & $\begin{array}{l}\text { Risk with } \\
\text { Dofetilide }\end{array}$ & & & & \\
\hline All-cause & \multicolumn{2}{|c|}{ Study population } & RR 0.98 & 1183 & $\oplus \oplus \oplus \ominus$ & \\
\hline $\begin{array}{l}\text { mortality - } \\
\text { Main analysis } \\
\text { follow up: } \\
\text { mean } 12 \\
\text { months }\end{array}$ & $\begin{array}{l}193 \text { per } \\
1,000\end{array}$ & $\begin{array}{l}189 \text { per } \\
1,000 \\
(146 \text { to } \\
245)\end{array}$ & $\begin{array}{l}(0.76 \text { to } \\
1.27)\end{array}$ & (3 RCTs) & $\underset{1}{\text { MODERATE }}$ & \\
\hline $\begin{array}{l}\text { Withdrawals } \\
\text { due to adverse } \\
\text { effects - Main } \\
\text { analysis } \\
\text { follow up: } \\
\text { mean } 12 \\
\text { months }\end{array}$ & \multicolumn{2}{|c|}{$\begin{array}{l}\text { Study population } \\
34 \text { per } 1,00061 \text { per } \\
1,000 \\
(26 \text { to } 144)\end{array}$} & $\begin{array}{l}\text { RR } 1.77 \\
(0.75 \text { to } \\
4.2)\end{array}$ & $\begin{array}{l}677 \\
(2 \text { RCTs) }\end{array}$ & $\begin{array}{l}\bigoplus \oplus \mathrm{LOW}^{12} \\
\mathrm{LO}^{2}\end{array}$ & \\
\hline $\begin{array}{l}\text { Pro-arrhythmia } \\
\text { - Main analysis } \\
\text { follow up: } \\
\text { mean } 12 \\
\text { months }\end{array}$ & $\begin{array}{l}\text { Study popul } \\
2 \text { per } 1,000\end{array}$ & $\begin{array}{l}\text { ation } \\
13 \text { per } \\
1,000 \\
(3 \text { to } 53 \text { ) }\end{array}$ & $\begin{array}{l}\text { RR } 5.50 \\
(1.33 \text { to } \\
22.8)\end{array}$ & $\begin{array}{l}1183 \\
\text { (3 RCTs) }\end{array}$ & $\begin{array}{l}\bigoplus \bigoplus{ }_{1} \oplus \bigoplus \ominus \\
\bigoplus \text { ODERATE }\end{array}$ & \\
\hline $\begin{array}{l}\text { Stroke - not } \\
\text { reported }\end{array}$ & - & - & - & - & - & \\
\hline $\begin{array}{l}\text { Atrial } \\
\text { fibrillation } \\
\text { recurrence - } \\
\text { Main analysis } \\
\text { follow up: } \\
\text { mean } 12 \\
\text { months }\end{array}$ & \multicolumn{2}{|c|}{$\begin{array}{l}\text { Study population } \\
84.2 \text { per } 10060.6 \text { per } \\
\qquad \begin{aligned} 100 \\
(51.4 \text { to } \\
71.6)\end{aligned}\end{array}$} & $\begin{array}{l}\text { RR } \\
0.0 .72 \\
(0.61 \\
0.85)\end{array}$ & $\begin{array}{l}1183 \\
\text { (3 RCTs) }\end{array}$ & 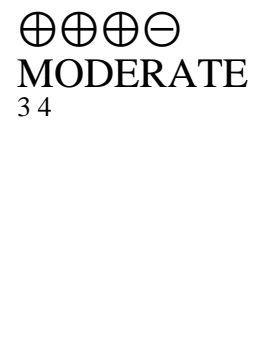 & \\
\hline
\end{tabular}

*The risk in the intervention group (and its $95 \%$ confidence interval) is based on the assumed risk in the comparison group and the relative effect of the intervention (and its $95 \%$ $\mathrm{CI})$.

CI: Confidence interval; RR: Risk ratio; OR: Odds ratio;

GRADE Working Group grades of evidence

High certainty: We are very confident that the true effect lies close to that of the estimate of the effect

Moderate certainty: We are moderately confident in the effect estimate: The true effect is likely to be close to the estimate of the effect, but there is a possibility that it is substantially different

Low certainty: Our confidence in the effect estimate is limited: The true effect may be substantially different from the estimate of the effect

Very low certainty: We have very little confidence in the effect estimate: The true effect is likely to be substantially different from the estimate of effect 
${ }^{1}$ Downgraded by one level for study limitations: majority of studies had unclear risk of selection bias.

${ }^{2}$ Downgraded by one level for imprecision: confidence interval includes both possible benefit and harm.

${ }^{3}$ Not downgraded for study limitations as $51 \%$ of weight came from a study with low risk of bias across all domains (but other 2 studies had unclear risk of selection bias).

${ }^{4}$ Downgraded by one level for heterogeneity due to very high $\mathrm{I}^{2}$ value $(79 \%)$

\section{Dronedarone compared to placebo or no treatment for maintaining sinus rhythm after cardioversion of atrial fibrillation}

Dronedarone compared to placebo or no treatment for maintaining sinus rhythm after cardioversion of atrial fibrillation

Patient or population: adults in sinus rhythm after cardioversion of atrial fibrillation

Setting: Hospital / community

Intervention: Dronedarone

Comparison: placebo or no treatment

\begin{tabular}{|c|c|c|c|c|c|c|}
\hline \multirow[t]{2}{*}{ Outcomes } & \multicolumn{2}{|c|}{$\begin{array}{l}\text { Anticipated absolute } \\
\text { effects }^{*}(95 \% \mathrm{CI})\end{array}$} & \multirow{2}{*}{$\begin{array}{l}\begin{array}{l}\text { Relative } \\
\text { effect } \\
(95 \% \\
\text { CI })\end{array}\end{array}$} & \multirow{2}{*}{$\begin{array}{l}\text { № of } \\
\text { participants } \\
\text { (studies) }\end{array}$} & \multirow{2}{*}{$\begin{array}{l}\text { Certainty of } \\
\text { the evidence } \\
\text { (GRADE) }\end{array}$} & \multirow[t]{2}{*}{ Comments } \\
\hline & $\begin{array}{l}\text { Risk with } \\
\text { placebo or } \\
\text { no } \\
\text { treatment }\end{array}$ & $\begin{array}{l}\text { Risk with } \\
\text { Dronedarone }\end{array}$ & & & & \\
\hline All-cause & \multicolumn{2}{|c|}{ Study population } & \multirow{2}{*}{$\begin{array}{l}\text { RR } 0.86 \\
(0.68 \text { to } \\
1.09)\end{array}$} & \multirow{2}{*}{$\begin{array}{l}6071 \\
(3 \mathrm{RCTs})\end{array}$} & \multirow{2}{*}{$\begin{array}{l}\bigoplus \bigoplus \bigoplus \bigoplus \\
\mathrm{HIGH}\end{array}$} & \\
\hline $\begin{array}{l}\text { mortality - } \\
\text { Main analysis } \\
\text { follow up: } \\
\text { range } 6 \text { to } 12 \\
\text { months }\end{array}$ & $\begin{array}{l}51 \text { per } \\
1,000\end{array}$ & $\begin{array}{l}44 \text { per } 1,000 \\
(35 \text { to } 56)\end{array}$ & & & & \\
\hline Withdrawals & \multicolumn{2}{|c|}{ Study population } & \multirow{2}{*}{$\begin{array}{l}\text { RR } 1.58 \\
(1.34 \text { to } \\
1.85)\end{array}$} & \multirow{2}{*}{$\begin{array}{l}6071 \\
(3 \mathrm{RCTs})\end{array}$} & \multirow{2}{*}{$\begin{array}{l}\bigoplus \bigoplus \bigoplus \bigoplus \\
\text { MODERATE }\end{array}$} & \\
\hline $\begin{array}{l}\text { due to adverse } \\
\text { effects - Main } \\
\text { analysis } \\
\text { follow up: } \\
\text { range } 6 \text { to } 12 \\
\text { months }\end{array}$ & $\begin{array}{l}77 \text { per } \\
1,000\end{array}$ & $\begin{array}{l}122 \text { per } 1,000 \\
(104 \text { to } 143)\end{array}$ & & & & \\
\hline Pro- & \multicolumn{2}{|c|}{ Study population } & RR 1.95 & 5872 & $\oplus \oplus \oplus \ominus$ & \\
\hline $\begin{array}{l}\text { arrhythmia - } \\
\text { main analysis } \\
\text { follow up: }\end{array}$ & $\begin{array}{l}18 \text { per } \\
1,000\end{array}$ & $\begin{array}{l}36 \text { per } 1,000 \\
(14 \text { to } 91)\end{array}$ & $\begin{array}{l}(0.77 \\
4.98)\end{array}$ & (2 RCTs) & $\underset{2}{\text { MODERATE }}$ & \\
\hline
\end{tabular}


mean 12

months

\begin{tabular}{|c|c|c|c|c|c|}
\hline \multirow{2}{*}{$\begin{array}{l}\text { Stroke - Main } \\
\text { analysis } \\
\text { follow up: } \\
\text { mean } 12 \\
\text { months }\end{array}$} & \multicolumn{2}{|c|}{ Study population } & \multirow{2}{*}{$\begin{array}{l}\mathrm{RR} 0.66 \\
(0.47 \text { to } \\
0.95)\end{array}$} & \multirow{2}{*}{$\begin{array}{l}5872 \\
(2 \mathrm{RCTs})\end{array}$} & \multirow{2}{*}{$\begin{array}{l}\bigoplus \bigoplus \bigoplus \bigoplus \\
\mathrm{HIGH}\end{array}$} \\
\hline & $\begin{array}{l}27 \text { per } \\
1,000\end{array}$ & $\begin{array}{l}18 \text { per } 1,000 \\
(13 \text { to } 25)\end{array}$ & & & \\
\hline Atrial & \multicolumn{2}{|c|}{ Study population } & RR 0.85 & 1443 & $\bigoplus \bigoplus \bigoplus \ominus$ \\
\hline $\begin{array}{l}\text { fibrillation } \\
\text { recurrence - } \\
\text { Main analysis } \\
\text { follow up: } \\
\text { range } 6 \text { to } 12 \\
\text { months }\end{array}$ & $\begin{array}{l}76.6 \text { per } \\
100\end{array}$ & $\begin{array}{l}65.1 \text { per } 100 \\
(61.3 \text { to } 69.7)\end{array}$ & $\begin{array}{l}(0.80 \text { to } \\
0.91)\end{array}$ & (2 RCTs) & $\underset{3}{\text { MODERATE }}$ \\
\hline
\end{tabular}

*The risk in the intervention group (and its $95 \%$ confidence interval) is based on the assumed risk in the comparison group and the relative effect of the intervention (and its $95 \%$ CI).

CI: Confidence interval; RR: Risk ratio; OR: Odds ratio;

GRADE Working Group grades of evidence

High certainty: We are very confident that the true effect lies close to that of the estimate of the effect

Moderate certainty: We are moderately confident in the effect estimate: The true effect is likely to be close to the estimate of the effect, but there is a possibility that it is substantially different

Low certainty: Our confidence in the effect estimate is limited: The true effect may be substantially different from the estimate of the effect

Very low certainty: We have very little confidence in the effect estimate: The true effect is likely to be substantially different from the estimate of effect

Footnotes

${ }^{1}$ Downgraded by one level for study limitations: $83 \%$ of weight came from a study with unclear blinding, which could be relevant to this outcome.

${ }^{2}$ Downgraded by one level for inconsistency due to very high $\mathrm{I}^{2}$ of $78 \%$.

${ }^{3}$ Downgraded by one level for study limitations: most weight came from a study with unclear allocation concealment.

\section{Sotalol compared to placebo or no treatment for maintaining sinus rhythm after cardioversion of atrial fibrillation}

Sotalol compared to placebo or no treatment for maintaining sinus rhythm after cardioversion of atrial fibrillation

Patient or population: adults in sinus rhythm after cardioversion of atrial fibrillation 
Setting: Hospital / community

Intervention: Sotalol

Comparison: placebo or no treatment

\begin{tabular}{|c|c|c|c|c|c|c|}
\hline \multirow[t]{2}{*}{ Outcomes } & \multicolumn{2}{|c|}{$\begin{array}{l}\text { Anticipated } \\
\text { absolute effects } \\
(95 \% \text { CI })\end{array}$} & \multirow{2}{*}{$\begin{array}{l}\text { Relative } \\
\text { effect } \\
(95 \% \\
\text { CI) }\end{array}$} & \multirow[t]{2}{*}{$\begin{array}{l}\text { № of } \\
\text { participants } \\
\text { (studies) }\end{array}$} & \multirow[t]{2}{*}{$\begin{array}{l}\text { Certainty of } \\
\text { the evidence } \\
\text { (GRADE) }\end{array}$} & \multirow[t]{2}{*}{ Comments } \\
\hline & $\begin{array}{l}\text { Risk with } \\
\text { placebo or } \\
\text { no } \\
\text { treatment }\end{array}$ & $\begin{array}{l}\text { Risk } \\
\text { with } \\
\text { Sotalol }\end{array}$ & & & & \\
\hline $\begin{array}{l}\text { All-cause } \\
\text { mortality - } \\
\text { Main analysis } \\
\text { follow up: } \\
\text { range } 6 \text { to } 12 \\
\text { months }\end{array}$ & $\begin{array}{l}\text { Study popu } \\
8 \text { per } 1,000\end{array}$ & $\begin{array}{l}\text { lation } \\
19 \text { per } \\
1,000 \\
(9 \text { to } \\
40)\end{array}$ & $\begin{array}{l}\text { RR } 2.23 \\
(1.03 \text { to } \\
4.81)\end{array}$ & $\begin{array}{l}1882 \\
\text { (5 RCTs) }\end{array}$ & $\begin{array}{l}\bigoplus \bigoplus \bigoplus \bigoplus \\
\mathrm{HIGH}\end{array}$ & \\
\hline $\begin{array}{l}\text { Withdrawals } \\
\text { due to } \\
\text { adverse } \\
\text { effects - Main } \\
\text { analysis } \\
\text { follow up: } \\
\text { range } 6 \text { to } 19 \\
\text { months; } \\
\text { median } 12\end{array}$ & $\begin{array}{l}\text { Study popu } \\
94 \text { per } \\
1,000\end{array}$ & $\begin{array}{l}\text { lation } \\
183 \text { per } \\
1,000 \\
(116 \text { to } \\
293)\end{array}$ & $\begin{array}{l}\text { RR 1.95 } \\
(1.23 \\
3.11)\end{array}$ & $\begin{array}{l}2688 \\
\text { (12 RCTs) }\end{array}$ & $\begin{array}{l}\bigoplus \underset{123}{\bigoplus} \oplus \bigoplus \Theta \\
\underset{\text { MODERATE }}{\bigoplus}\end{array}$ & $\begin{array}{l}\text { Heterogeneity was } \\
\text { high for the main } \\
\text { analysis, but the } \\
\text { test for subgroup } \\
\text { differences } \\
\text { indicated that the } \\
\text { RR was higher in } \\
\text { older studies with } \\
\text { sotalol. }\end{array}$ \\
\hline
\end{tabular}

months

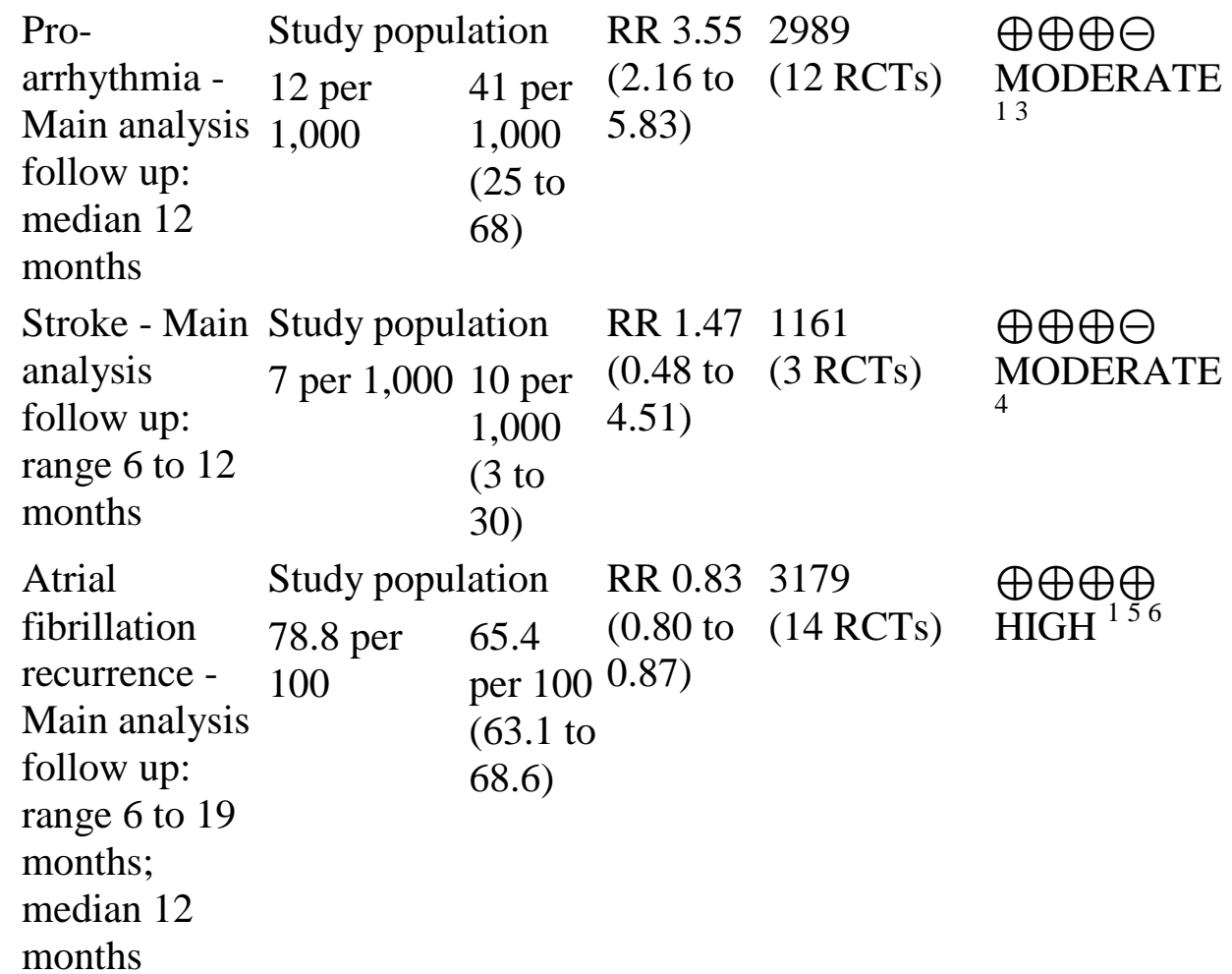

*The risk in the intervention group (and its $95 \%$ confidence interval) is based on the assumed risk in the comparison group and the relative effect of the intervention (and its $95 \%$ 
CI).

CI: Confidence interval; RR: Risk ratio; OR: Odds ratio;

GRADE Working Group grades of evidence

High certainty: We are very confident that the true effect lies close to that of the estimate of the effect

Moderate certainty: We are moderately confident in the effect estimate: The true effect is likely to be close to the estimate of the effect, but there is a possibility that it is substantially different

Low certainty: Our confidence in the effect estimate is limited: The true effect may be substantially different from the estimate of the effect

Very low certainty: We have very little confidence in the effect estimate: The true effect is likely to be substantially different from the estimate of effect

Footnotes

${ }^{1}$ Not downgraded for study limitations. Although the majority of studies had unclear or high risk of bias in at least one of the key domains, the majority of the weight was from studies at low risk of bias in key domains.

${ }^{2}$ Not downgraded for inconsistency. $\mathrm{I}^{2}$ was $56 \%$ for the main analysis but this was partially explained by subgroup analysis.

${ }^{3}$ Downgraded by one level for publication bias: forest plot appears to be asymmetrical.

${ }^{4}$ Downgraded by one level for imprecision: confidence interval includes both possible benefit and harm

${ }^{5}$ Not downgraded for publication bias: funnel plot appears to be broadly symmetrical.

${ }^{6}$ Not downgraded for inconsistency. $\mathrm{I}^{2}$ was $54 \%$ but the forest plot had good overlap in confidence intervals, so a fixed effect model was used to maintain the weight of the few larger studies.

\section{Additional tables}

\section{Number of studies assessing each primary outcome}

Primary outcomes

All-cause mortality

Cardiovascular mortality

Stroke

Adverse effects (Proarrhythmia and

Withdrawals due to adverse effects)
$\mathrm{N}^{\circ}$ Trials reporting $\left(\mathrm{N}^{\circ} \mathrm{N}^{\circ}\right.$ Trials NOT reporting participants) $\left(\mathrm{N}^{\circ}\right.$ participants)

39 (17 586) $3 *(393)$ same as total mortality same as total mortality 11 (9 139) $30(8840)$

$39(16558)$ $3 * *(1421)$ 
Out of 41 studies comparing an active drug with a control group receiving no antiarrhythmic (total 17979 patients)

* Chun 2014, DAPHNE 2008, Santas 2012

** AFIB 1997, Chun 2014, Santas 2012. Others studies did not reported pro-arhythmia but reported withdrawals: DAPHNE, Niu, Villani

\section{Head to head trials: all cause mortality}

Drug 1 vs. drug 2

Disopyramide vs. other Class I drugs

PRODIS 1996

Lloyd 1984

Quinidine vs. other Class I drugs

Richiardi 1992

Lloyd 1984

Quinidine vs. Sotalol

SOPAT 2004

SOCESP 1999

PAFAC 2004

Kalusche 1994

Juul-Moller 1990

Flecainide vs. Propafenone

Aliot 1996

Amiodarone vs. Class I drugs

PITAGORA 2008

AFFIRM Substudy 2003

Amiodarone vs. Dronedarone

DYONISOS 2010

Amiodarone vs. Sotalol

SAFE-T 2005

PITAGORA 2008

AFFIRM Substudy 2003

Sotalol vs. Class I drugs other than quinidine

Reimold 1993

AFFIRM Substudy 2003

Sotalol vs. Dofetilide

EMERALD 2000 drug $1 \quad$ drug $2 \quad$ RR $(95 \%$ CI $)$

events total events total

$$
\begin{array}{lllll}
1 & 31 & 0 & 252.44(0.10,57.37) \\
0 & 29 & 2 & 280.19(0.01,3.86) \\
& & & & \\
0 & 98 & & 2 & 1020.21(0.01,4.28) \\
2 & 28 & & 0 & 295.17(0.26,103.18)
\end{array}
$$

$2518 \quad 22640.51(0.07,3.60)$

$\begin{array}{lllll}0 & 63 & 1 & 58 & 0.31(0.01,7.40)\end{array}$

$9377 \quad 133830.70(0.30,1.63)$

$141 \quad 0 \quad 413.00(0.13,71.56)$

$185 \quad 1 \quad 981.15(0.07,18.15)$

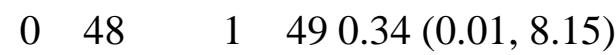

$6 \quad 70 \quad 2 \quad 753.21(0.67,15.40)$

$10106261160.42(0.21,0.83)$

$5255 \quad 22492.44(0.48,12.47)$

$13267 \quad 152610.85(0.41,1.75)$

$670 \quad 0 \quad 315.86(0.34,100.89)$

$15131241250.60(0.33,1.08)$

$250 \quad 0 \quad 505.00(0.25,101.58)$

$13 \quad 88 \quad 17 \quad 950.83(0.43,1.60)$

$\begin{array}{llll}0 & 108 & 1 & 3210.98 \\ (0.04,23.99)\end{array}$ 


\section{Head to head trials: withdrawals due to adverse events}

Drug 1 vs. drug 2

Disopyramide vs. other Class I drugs

Lloyd 1984

PRODIS 1996

Quinidine vs. Flecainide

Naccarelli 1996

Steinbeck 1988

Quinidine vs. other Class I drugs

Lloyd 1984

Naccarelli 1996

Richiardi 1992

Steinbeck 1988

Quinidine vs. Sotalol

Hohnloser 1995

Juul-Moller 1990

Kalusche 1994

PAFAC 2004

SOCESP 1999

SOPAT 2004

Flecainide vs. Propafenone

Aliot 1996

FAPIS 1996

Amiodarone vs. Class I drugs

AFFIRM Substudy 2003

Kochiadakis 2004a

PITAGORA 2008

Villani 1992

Vitolo 1981

Amiodarone vs. Dronedarone

DYONISOS 2010

Amiodarone vs. Sotalol

AFFIRM Substudy 2003

Kochiadakis 2000

Niu 2006

PITAGORA 2008 drug $1 \quad \operatorname{drug} 2 \quad$ RR $(95 \%$ CI $)$
events total events total

$$
\begin{array}{lllll}
2 & 29 & 4 & 280.48(0.10,2.43) \\
4 & 31 & & 8 & 250.40(0.14,1.19)
\end{array}
$$

$$
\begin{array}{rrrrr}
35 & 117 & 22 & 1221.66(1.04,2.65) \\
2 & 15 & 0 & 155.00(0.26,96.13) \\
& & & & \\
4 & 28 & 2 & 29 & 2.07(0.41,10.43) \\
35 & 117 & 22 & 1221.66(1.04,2.65) \\
23 & 98 & 10 & 1022.39(1.20,4.77) \\
2 & 15 & 0 & 155.00(0.26,96.13)
\end{array}
$$

$\begin{array}{llll}10 & 25 & 1 & 2510.00(1.38,72.39)\end{array}$

$\begin{array}{llll}22 & 85 & 11 & 982.31(1.19,4.47)\end{array}$

$\begin{array}{llll}7 & 41 & 3 & 412.33(0.65,8.40)\end{array}$

$94377963830.99(0.78,1.27)$

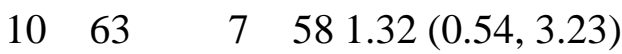

$87518 \quad 532640.84(0.62,1.14)$

$$
\begin{array}{rrrrr}
2 & 48 & 9 & 49 & 0.23(0.05,1.00) \\
10 & 97 & 9 & 103 & 1.18(0.50,2.78)
\end{array}
$$

$$
\begin{array}{rrrrl}
20 & 154 & 47 & 1210.33(0.21,0.53) \\
17 & 72 & 2 & 748.74(2.09,36.46) \\
5 & 70 & 2 & 311.11(0.23,5.40) \\
3 & 35 & 10 & 410.35(0.10,1.18) \\
1 & 28 & 1 & 260.93(0.06,14.09)
\end{array}
$$

$45 \quad 255 \quad 32 \quad 2491.37(0.90,2.09)$

$$
\begin{array}{rrrl}
20 & 154 & 21 & 1350.83(0.47,1.47) \\
11 & 65 & 3 & 613.44(1.01,11.75) \\
5 & 51 & 7 & 510.71(0.24,2.10) \\
6 & 70 & 0 & 315.86(0.34,100.89)
\end{array}
$$


Vijayalaskshmi 2006

$122 \quad 4 \quad 330.38(0.04,3.14)$

Sotalol vs. Class I drugs other than quinidine

AFFIRM Substudy 2003

$\begin{array}{lllll}21 & 135 & 47 & 1210.40(0.25,0.63)\end{array}$

Kochiadakis 2004b

$\begin{array}{llll}5 & 85 & 5 & 861.01(0.30,3.37)\end{array}$

Reimold 1993

$\begin{array}{lllll}6 & 50 \quad 4 & 50 & 1.50 & (0.45,4.99)\end{array}$

Sotalol vs. Dofetilide

EMERALD 2000

$16108 \quad 22 \quad 3212.16(1.18,3.96)$

Sotalol vs. Other Beta-blockers

DAPHNE 2008

$\begin{array}{llll}11 & 69 & 2 & 665.26(1.21,22.84)\end{array}$

Plewan 2001

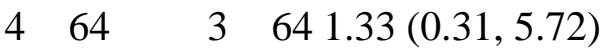

Footnotes

\section{Head to head trials: pro-arrhythmia}

Drug 1 vs. drug 2

Disopyramide vs. other Class I drugs

Lloyd 1984

PRODIS 1996

Quinidine vs. Flecainide

Naccarelli 1996

Steinbeck 1988

Quinidine vs. other Class I drugs

Lloyd 1984

Naccarelli 1996

Richiardi 1992

Steinbeck 1988

Quinidine vs. Sotalol

Hohnloser 1995

Juul-Moller 1990

Kalusche 1994

PAFAC 2004

SOCESP 1999

SOPAT 2004 drug $1 \quad$ drug $2 \quad$ RR $(95 \%$ CI)

events total events total

$$
\begin{aligned}
& \begin{array}{lllll}
0 & 29 & 1 & 28 & 0.32(0.01,7.59)
\end{array} \\
& 131 \quad 1 \quad 250.81(0.05,12.26)
\end{aligned}
$$

$$
\begin{array}{rrrrr}
10 & 117 & 7 & 1221.49(0.59,3.78) \\
2 & 15 & & 1 & 152.00(0.20,19.78)
\end{array}
$$

$\begin{array}{llll}1 & 28 & 0 & 293.10(0.13,73.12)\end{array}$

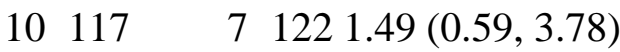

$298 \quad 21021.04(0.15,7.24)$

$2 \quad 15 \quad 1 \quad 152.00(0.20,19.78)$

$\begin{array}{llll}3 & 25 & 1 & 253.00(0.33,26.92)\end{array}$

$185 \quad 1 \quad 981.15(0.07,18.15)$

$14122410.50(0.05,5.30)$

$17377 \quad 203830.86(0.46,1.62)$

$263 \quad 3 \quad 580.61(0.11,3.54)$

$8518 \quad 22642.04(0.44,9.53)$

Flecainide vs. Propafenone

Aliot 1996

$\begin{array}{lllll}0 & 48 & 4 & 49 & 0.11(0.01,2.05)\end{array}$

$297 \quad 11032.12(0.20,23.05)$

Amiodarone vs.. Class I drugs

AFFIRM Substudy 2003 
Kochiadakis 2004a

Vitolo 1981

Amiodarone vs. Dronedarone

DYONISOS 2010

Amiodarone vs.. Sotalol

AFFIRM Substudy 2003

Kochiadakis 2000

SAFE-T 2005

Sotalol vs. Class I drugs other than quinidine

AFFIRM Substudy 2003

Carunchio 1995

Kochiadakis 2004b

Reimold 1993

Sotalol vs. Dofetilide

EMERALD 2000

Sotalol vs. Other Beta-blockers

Plewan 2001
4255

$22491.95(0.36,10.57)$

$272 \quad 2 \quad 741.03(0.15,7.10)$

$128 \quad 1 \quad 260.93(0.06,14.09)$

$5154991350.49(0.17,1.42)$

$\begin{array}{llll}2 & 65 & 2 & 610.94(0.14,6.46)\end{array}$

$626792610.65(0.24,1.81)$

$9135 \quad 201210.40(0.19,0.85)$

$\begin{array}{lllll}5 & 20 & 3 & 201.67(0.46,6.06)\end{array}$

$3 \quad 85 \quad 2 \quad 861.52(0.26,8.86)$

$950 \quad 6 \quad 501.50(0.58,3.90)$

$2108 \quad 73210.85(0.18,4.03)$

$4 \quad 64 \quad 3 \quad 641.33(0.31,5.72)$

Footnotes

\section{Head to head trials: atrial fibrillation recurrence}

drug 1 vs. drug 2

Disopyramide vs. other Class I drugs

Lloyd 1984

PRODIS 1996

Quinidine vs. Flecainide

Naccarelli 1996

Steinbeck 1988

Quinidine vs. other Class I drugs

Lloyd 1984

Naccarelli 1996

Richiardi 1992

Steinbeck 1988

Quinidine vs. Sotalol

Hohnloser 1995

Juul-Moller 1990

Kalusche 1994

PAFAC 2004 drug $1 \quad$ drug $2 \quad$ RR $(95 \% \mathrm{CI})$

events total events total

$$
\begin{array}{lllll}
16 & 29 & 16 & 280.97(0.61,1.53) \\
10 & 31 & 11 & 250.73(0.37,1.44)
\end{array}
$$

$93117931221.04(0.91,1.19)$

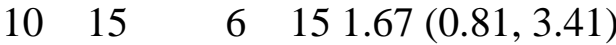

$\begin{array}{llll}16 & 28 & 16 & 29 \\ 1.04 & (0.65,1.64)\end{array}$

$93 \quad 117 \quad 931221.04(0.91,1.19)$

$\begin{array}{lllll}57 & 98 & 53 & 1021.12(0.87,1.44)\end{array}$

$\begin{array}{llll}10 & 15 & 6 & 15 \\ 15.67(0.81,3.41)\end{array}$

$$
\begin{array}{rrrrr}
7 & 25 & 12 & 250.58(0.28,1.23) \\
49 & 85 & 50 & 98 & 1.13(0.87,1.47) \\
15 & 41 & 21 & 410.71(0.43,1.18) \\
244 & 377 & 255 & 3830.97(0.88,1.08)
\end{array}
$$


SOCESP 1999

SOPAT 2004

Flecainide vs. Propafenone

Aliot 1996

FAPIS 1996

Amiodarone vs. Class I drugs

AFFIRM Substudy 2003

Kochiadakis 2004a

PITAGORA 2008

Villani 1992

Vitolo 1981

Amiodarone vs. Dronedarone

DYONISOS 2010

Amiodarone vs. Sotalol

AFFIRM Substudy 2003

Kochiadakis 2000

Niu 2006

PITAGORA 2008

SAFE-T 2005

Vijayalaskshmi 2006

Dronedarone vs. Propafenone

Chun 2014

Sotalol vs. Class I drugs other than quinidine

AFFIRM Substudy 2003

Carunchio 1995

Kochiadakis 2004b

Reimold 1993

Sotalol vs. Dofetilide

EMERALD 2000

Sotalol vs. Beta-blockers

DAPHNE 2008

Plewan 2001
$25 \quad 63 \quad 20 \quad 581.15(0.72,1.84)$

$3755181982640.97(0.88,1.05)$

$19 \quad 48 \quad 26 \quad 490.75(0.48,1.16)$

$30 \quad 97 \quad 30 \quad 1031.06(0.70,1.62)$

$60106991160.66(0.55,0.80)$

$20 \quad 72 \quad 32 \quad 740.64(0.41,1.01)$

$42 \quad 70 \quad 54 \quad 750.83(0.66,1.06)$

$\begin{array}{lllll}14 & 35 & 30 & 41 & 0.55(0.35,0.85)\end{array}$

$\begin{array}{llll}6 & 28 & 14 & 260.40(0.18,0.88)\end{array}$

$1162551632490.69(0.59,0.82)$

$\begin{array}{llll}58 & 131 & 81 & 1250.68(0.54,0.86)\end{array}$

$\begin{array}{lllll}27 & 65 & 39 & 61 & 0.65\end{array}(0.46,0.92)$

$24 \quad 51 \quad 36 \quad 510.67(0.47,0.94)$

$42 \quad 70 \quad 24 \quad 310.78(0.59,1.01)$

$\begin{array}{lllll}133 & 267 & 183 & 2610.71(0.62,0.82)\end{array}$

$311 \quad 10 \quad 170.46(0.16,1.32)$

$36 \quad 50 \quad 37 \quad 500.97(0.77,1.24)$

$\begin{array}{llll}67 & 88 & 81 & 950.89(0.77,1.03)\end{array}$

$\begin{array}{lllll}8 & 20 & 6 & 20 & 1.33(0.57,3.14)\end{array}$

$43 \quad 85 \quad 35 \quad 861.24(0.89,1.73)$

$32 \quad 50 \quad 35 \quad 500.91(0.69,1.20)$

$741081963211.12(0.96,1.31)$

$\begin{array}{llll}57 & 69 & 54 & 66 \\ & 1.01(0.86,1.18)\end{array}$

$31 \quad 64 \quad 29 \quad 641.07(0.74,1.55)$

Footnotes

\section{References to studies}

\section{Included studies}


[CRSSTD: 6980542]

A-COMET-I Investigators, Pritchett EL, Kowey P, Connolly S, Page RL, Kerr C, et al. Antiarrhythmic efficacy of azimilide in patients with atrial fibrillation. Maintenance of sinus rhythm after conversion to sinus rhythm. American Heart Journal 2006 May;151(5):1043-9. [CRSREF: 6980543; PubMed: PMID: 16644334]

\section{A-COMET-II 2006}

[CRSSTD: 6980544]

A-COMET-II Investigators; Lombardi F, Borggrefe M, Ruzyllo W, Lüderitz B. Azimilide vs. placebo and sotalol for persistent atrial fibrillation: the A-COMET-II (AzimilideCardiOversion MaintEnance Trial-II) trial. European Heart Journal 2006 Sep;27(18):222431. [CRSREF: 6980545; PubMed: PMID: 16935870]

\section{AFFIRM Substudy 2003}

[CRSSTD: 6980546]

AFFIRM First Antiarrhythmic Drug Substudy Investigators. Maintenance of sinus rhythm in patients with atrial fibrillation: an AFFIRM substudy of the first antiarrhythmic drug. Journal of the American College of Cardiology 2003;42(1):20-9. [CRSREF: 6980547; MEDLINE: PMID: 12849654; Other: ISSN: 0735-1097]

\section{AFIB 1997}

[CRSSTD: 6980548]

The Atrial Fibrillation Investigation with Bidisomide (AFIB) Investigators. Treatment of atrial fibrillation and paroxysmal supraventricular tachycardia with bidisomide. Circulation 1997;96(8):2625-32. [CRSREF: 6980549; MEDLINE: PMID: 9355903; Other: ISSN 00097322]

\section{Aliot 1996}

[CRSSTD: 6980550]

Aliot E, Denjoy I. The Flecainide AF French Study Group. Comparison of the safety and efficacy of flecainide versus propafenone in hospital out-patients with symptomatic paroxysmal atrial fibrillation/flutter. American Journal of Cardiology 1996;77(3):66A-71A. [CRSREF: 6980551; MEDLINE: PMID: 8607394; Other: ISSN: 0002-9149]

\section{ASAP 2003}

[CRSSTD: 6980552]

Connolly SJ, Schnell DJ, Page RL, Wilkinson WE, Marcello SR, Pritchett EL, Azimilide Supraventricular Arrhythmia Program Investigators. Symptoms at the time of arrhythmia recurrence in patients receiving azimilide for control of atrial fibrillation or flutter: results 
from randomized trials. American Heart Journal 2003;146(3):489-93. [CRSREF: 6980553; MEDLINE: PMID: 12947368; Other: ISSN: 0002-8703]

Connolly SJ, Schnell DJ, Page RL, Wilkinson WE, Marcello SR, Pritchett EL. Dose-response relations of azimilide in the management of symptomatic, recurrent, atrial fibrillation.

American Journal of Cardiology 2001;88(9):974-9. [CRSREF: 6980554; MEDLINE: PMID: 11703992; Other: ISSN 0002-9149]

Page RL, Connolly SJ, Wilkinson WE, Marcello SR, Schnell DJ, Pritchett EL; Azimilide Supraventricular Arrhythmia Program (ASAP) Investigators. Antiarrhythmic effects of azimilide in paroxysmal supraventricular tachycardia: efficacy and dose-response. American Heart Journal 2002;143(4):643-9. [CRSREF: 6980555; MEDLINE: PMID: 11923801; Other: ISSN 0002-8703]

* Page RL, Tilsch TW, Connolly SJ, Schnell DJ, Marcello SR, Wilkinson WE et al. Azimilide Supraventricular Arrhythmia Program (ASAP) Investigators. Asymptomatic or "silent" atrial fibrillation: frequency in untreated patients and patients receiving azimilide. Circulation 2003;107(8):1141-5. [CRSREF: 6980556; MEDLINE: PMID: 12615792; Other: ISSN 0009-7322]

Pritchett EL, Page RL, Connolly SJ, Marcello SR, Schnell DJ, Wilkinson WE. Antiarrhythmic effects of azimilide in atrial fibrillation: efficacy and dose-response. Azimilide Supraventricular Arrhythmia Program 3 (SVA-3) Investigators. Journal of the American College of Cardiology 2000;36(3):794-802. [CRSREF: 6980557; MEDLINE: PMID: 10987602; Other: ISSN 0735-1097]

SVA-4 Investigators, Page RL, Pritchett EL, Connolly S, Wilkinson WE. Azimilide for the treatment of atrial fibrillation, atrial flutter, and paroxysmal supraventricular tachycardia: results of a randomized trial and insights on the concordance of symptoms and recurrent arrhythmias. Journal of Cardiovascular Electrophysiology 2008;19(2):172-7. [CRSREF: 6980882; PubMed: PMID: 17916138]

\section{A-STAR 2006}

[CRSSTD: 6980558]

* A-STAR Investigators, Kerr CR, Connolly SJ, Kowey P, Page RL, Pritchett EL, et al. Efficacy of azimilide for the maintenance of sinus rhythm in patients with paroxysmal atrial fibrillation in the presence and absence of structural heart disease. American Journal of Cardiology 2006;98(2):215-8. [CRSREF: 6980559; PubMed: PMID: 16828595]

\section{ATHENA 2009}

Published and unpublished data [CRSSTD: 6980560]

ATHENA Investigators, Connolly SJ, Crijns HJ, Torp-Pedersen C, van Eickels M, Gaudin C, et al. Analysis of stroke in ATHENA: a placebo-controlled, double-blind, parallel-arm trial to assess the efficacy of dronedarone $400 \mathrm{mg}$ BID for the prevention of cardiovascular hospitalization or death in patients with atrial fibrillation/atrial flutter. Circulation 2009;120(13):1174-80. [CRSREF: 6980561; PubMed: PMID: 19752319] 
* ATHENA Investigators, Hohnloser SH, Crijns HJ, van Eickels M, Gaudin C, Page RL, et al. Effect of dronedarone on cardiovascular events in atrial fibrillation. New England Journal of Medicine 2009;360(2):668-78. [CRSREF: 6980562; PubMed: PMID: 19213680]

\section{Bellandi 2001}

[CRSSTD: 6980563]

Bellandi F, Dabizzi RP, Niccoli L, Cantini F, Palchetti R. Propafenone and sotalol: long-term efficacy and tolerability in the prevention of paroxysmal atrial fibrillation. A placebocontrolled double-blind study [Propafenone e sotalolo: efficacia e tollerabilita a lungo termine nella prevenzione della fibrillazione atriale parossistica. Studio in doppio cieco controllato con placebo]. Giornale Italiano di Cardiologia 1996;26(4):379-90. [CRSREF: 6980564; MEDLINE: PMID: 8707022; Other: ISSN 0046-5968]

Bellandi F, Dabizzi RP, Niccoli L, Cantini F. Propafenone and sotalol in the prevention of paroxysmal atrial fibrillation - Long-term safety and efficacy study [Propafenon und sotalol bei der pravention von paroxysmalem vorhofflimmern. Langzeitstudie zur beurteilung von sicherheit und wirksamkeit]. Munchener Medizinische Wochenschrift 1996;138(12):39-46. [CRSREF: 6980565; MEDLINE: not indexed; Other: EMBASE 1996098252; ISSN: 00272973]

Bellandi F, Dabizzi RP, Niccoli L, Cantini F. Propafenone and sotalol in the prevention of paroxysmal atrial fibrillation: Long-term safety and efficacy study. Current Therapeutic Research, Clinical \& Experimental 1995;56(11):1154-68. [CRSREF: 6980566; MEDLINE: not indexed; Other: EMBASE 1996000327; ISSN: 0011-393X]

Bellandi F, Leoncini M, Maioli M, Gallopin M, Dabizzi RP. Comparing agents for prevention of atrial fibrillation recurrence. Cardiology Review 2002;19(9):18-21. [CRSREF: 6980567; Other: EMBASE 2002284566; ISSN 1061-5377]

* Bellandi F, Simonetti I, Leoncini M, Frascarelli F, Giovannini T, Maioli M, et al. Longterm efficacy and safety of propafenone and sotalol for the maintenance of sinus rhythm after conversion of recurrent symptomatic atrial fibrillation. American Journal of Cardiology 2001;88(6):640-5. [CRSREF: 6980568; MEDLINE: PMID: 11564387; Other: ISSN 00029149]

\section{Benditt 1999}

Published data only (unpublished sought but not used) [CRSSTD: 6980569]

Benditt DG, Williams JH, Jin J, Deering TF, Zucker R, Browne K, et al. Maintenance of sinus rhythm with oral d,l-sotalol therapy in patients with symptomatic atrial fibrillation and/or atrial flutter. d,1-Sotalol Atrial Fibrillation/Flutter Study Group. American Journal of Cardiology 1999;84(3):270-7. [CRSREF: 6980570; MEDLINE: PMID: 10496434; Other: ISSN 0002-9149]

\section{Byrne-Quinn 1970}

[CRSSTD: 6980571] 
Byrne-Quinn E, Wing AJ. Maintenance of sinus rhythm after DC reversion of atrial fibrilllation. A double-blind controlled trial of long-acting quinidine bisulphate. British Heart Journal 1970;32(3):370-6. [CRSREF: 6980572; MEDLINE: PMID: 4911757; Other: ISSN 0007-0769]

\section{Carunchio 1995}

[CRSSTD: 6980573]

Carunchio A, Fera MS, Mazza A, Burattini M, Greco G, Galati A, et al. A comparison between flecainide and sotalol in the prevention of recurrences of paroxysmal atrial fibrillation [Confronto tra flecainide e sotalolo nella profilassi delle recidive di fibrillazione atriale parossistica]. Giornale Italiano di Cardiologia 1995;25(1):51-68. [CRSREF: 6980574; MEDLINE: PMID: 7642012; Other: ISSN 0046-5968]

\section{Channer 2004}

Published and unpublished data [CRSSTD: 6980575]

Channer KS, Birchall A, Steeds RP, Walters SJ, Yeo WW, West JN, et al. A randomized placebo-controlled trial of pre-treatment and short- or long-term maintenance therapy with amiodarone supporting DC cardioversion for persistent atrial fibrillation. European Heart Journal 2004;25(2):144-50. [CRSREF: 6980576; MEDLINE: PMID: 14720531; Other: ISSN 0195-668X]

\section{Chun 2014}

[CRSSTD: 6980577]

Chun KJ, Byeon K, Im SI, Park KM, Park SJ, Kim JS, On YK. Efficacy of dronedarone versus propafenone in the maintenance of sinus rhythm in patients with atrial fibrillation after electrical cardioversion. Clinical Therapeutics 2014 Sep 1;36(9):1169-75. [CRSREF: 6980578; DOI: 10.1016/j.clinthera.2014.07.013; PubMed: 25134972]

\section{DAFNE 2003}

[CRSSTD: 6980579]

Touboul P, Brugada J, Capucci A, Crijns HJ, Edvardsson N, Hohnloser SH. Dronedarone for prevention of atrial fibrillation: a dose-ranging study. European Heart Journal 2003;24(16):1481-7. [CRSREF: 6980580; MEDLINE: PMID: 12919771; Other: ISSN 0195$668 \mathrm{X}]$

\section{DAPHNE 2008}

[CRSSTD: 6980581]

* DAPHNE Study Investigators, Capucci A, Botto G, Molon G, Spampinato A, Favale S, et al. The Drug And Pace Health cliNical Evaluation (DAPHNE) study: a randomized trial comparing sotalol versus beta-blockers to treat symptomatic atrial fibrillation in patients with 
brady-tachycardia syndrome implanted with an antitachycardia pacemaker. American Heart Journal 2008;156(2):373.e1-8. [CRSREF: 6980582; PubMed: PMID: 18657671]

\section{DIAMOND 2001}

[CRSSTD: 6980583]

Moller M, Torp-Pedersen CT, Kober L. Dofetilide in patients with congestive heart failure and left ventricular dysfunction: safety aspects and effect on atrial fibrillation. The Danish Investigators of Arrhythmia and Mortality on Dofetilide (DIAMOND) Study Group. Congestive Heart Failure 2001;7(3):146-50. [CRSREF: 6980584; MEDLINE: PMID: 11828153; Other: ISSN 1527-5299]

* Pedersen OD, Bagger H, Keller N, Marchant B, Kober L, Torp-Pedersen C. Efficacy of dofetilide in the treatment of atrial fibrillation-flutter in patients with reduced left ventricular function: a Danish investigations of arrhythmia and mortality on dofetilide (DIAMOND) substudy. Circulation 2001;104(3):292-6. [CRSREF: 6980585; MEDLINE: PMID: 11457747; Other: ISSN 0009-7322]

Torp-Pedersen C, Moller M, Bloch-Thomsen PE, Kober L, Sandoe E, Egstrup K, et al. Dofetilide in patients with congestive heart failure and left ventricular dysfunction. Danish Investigations of Arrhythmia and Mortality on Dofetilide Study Group. New England Journal of Medicine 1999;341(12):857-65. [CRSREF: 6980586; MEDLINE: PMID: 10486417; Other: ISSN 0028-4793]

Torp-Pedersen CT, Moller M, Bloch-Thomsen PE, Kober L, Sandoe E, Egstrup K, et al. Dofetilide to patients with heart failure and left ventricular dysfunction [Dofetilid til patienter med hjerteinsufficiens og darligt fungerende venstre ventrikel]. Ugeskrift for Laeger 2000;10(44):5948-53. [CRSREF: 6980587; MEDLINE: PMID: 11094565; Other: ISSN: 0041-5782]

\section{Dogan 2004}

[CRSSTD: 6980588]

Dogan A, Ergene O, Nazli C, Kinay O, Altinbas A, Ucarci Y, et al. Efficacy of propafenone for maintaining sinus rhythm in patients with recent onset or persistent atrial fibrillation after conversion: a randomized, placebo-controlled study. Acta Cardiologica 2004;59(3):255-61. [CRSREF: 6980589; MEDLINE: PMID: 15255456; Other: ISSN: 0001-5385]

\section{DYONISOS 2010}

Published data only (unpublished sought but not used) [CRSSTD: 6980590]

Le Heuzey JY, De Ferrari GM, Radzik D, Santini M, Zhu J, Davy JM. A short-term, randomized, double-blind, parallel-group study to evaluate the efficacy and safety of dronedarone versus amiodarone in patients with persistent atrial fibrillation: the DIONYSOS study. Journal of Cardiovascular Electrophysiology 2010;21(6):597-605. [CRSREF: 6980591; PubMed: PMID: 20384650 ]

\section{EMERALD 2000}


Cambell TJ, Greenbaum RA, Channer KS, Dalrymple HW, Kingma JH, Santini M, et al. Mortality in patients with atrial fibrillation - 1 year follow up of EMERALD (European and Australian multicenter evaluative research on atrial fibrillation dofetilide). Journal of the American College of Cardiology 2000;35(2 Suppl A):154A-5A. [CRSREF: 6980593]

Dalrymple HW, Cambell TJ, Channer KS, Greenbaum R, Kingma JH, Santini M, et al. Maintenance of sinus rhythm by dofetilide improves quality of life. The EMERALD (European and Australian multicenter evaluative research on atrial fibrillation dofetilide) study. Circulation 1998;98(Suppl 13-14):66. [CRSREF: 6980594]

Greenbaum R, Campbell TJ, Channer KS, Dalrymple HW, Kingma JH, Santini M, et al. Conversion of atrial fibrillation and maintenace of sinus rhythm by dofetilide. The EMERALD (European and Australian multicenter evaluative research on atrial fibrillation dofetilide) study. Circulation 1998;98(Suppl I-633):3326. [CRSREF: 6980595]

* US Food and Drug Administration. Drug Approval Package: Tikosyn (Dofetilide). Medical Review: Parts 1 and 2 (Study number 345). http://www.accessdata.fda.gov/drugsatfda_docs/nda/99/20-931_Tikosyn.cfm. Accessed 10 August 2010. [CRSREF: 6980596]

\section{EURIDIS ADONIS 2007}

Published and unpublished data [CRSSTD: 6980597]

Brookes, L. Dronedarone on Trial: EURIDIS and ADONIS.

http://www.medscape.com/viewarticle/489226 (accessed January 2007) 2004. [CRSREF: 6980598]

* EURIDIS and ADONIS Investigators; Singh BN, Connolly SJ, Crijns HJ, Roy D, Kowey PR, et al. Dronedarone for maintenance of sinus rhythm in atrial fibrillation or flutter. New England Journal of Medicine 2007;357(10):987-99. [CRSREF: 6980599; MEDLINE: PMID: 17804843]

Hohnloser SH. EURIDIS and ADONIS: maintenance of sinus rhythm with dronedarone in patients with atrial fibrillation or flutter. In: Program and abstracts from the European Society of Cardiology Congress 2004 Aug 28 - Sept 1. Munich, Germany, 2004. [CRSREF: 6980600; MEDLINE: none; Other: none]

\section{FAPIS 1996}

[CRSSTD: 6980601]

Chimienti M, Cullen MT Jr, Casadei G. Safety of flecainide versus propafenone for the longterm management of symptomatic paroxysmal supraventricular tachyarrhythmias. Report from the Flecainide and Propafenone Italian Study (FAPIS) Group. European Heart Journal 1995;16(12):1943-51. [CRSREF: 6980602; MEDLINE: PMID: 8682031; Other: ISSN: 0195$668 \mathrm{X}]$ 
* Chimienti M, Cullen MT Jr, Casadei G. Safety of long-term flecainide and propafenone in the management of patients with symptomatic paroxysmal atrial fibrillation: report from the Flecainide and Propafenone Italian Study Investigators. American Journal of Cardiology 1996;77(3):60A-75A. [CRSREF: 6980603; MEDLINE: PMID: 8607393; Other: ISSN: 00029149]

\section{Flec-SL 2012}

[CRSSTD: 6980604]

Kirchhof P, Andresen D, Bosch R, Borggrefe M, Meinertz T, Parade U, et al. Short-term versus long-term antiarrhythmic drug treatment after cardioversion of atrial fibrillation (FlecSL): a prospective, randomised, open-label, blinded endpoint assessment trial. Lancet 2012;380(9838):238-46. [CRSREF: 6980605; PubMed: 22713626]

\section{GEFACA 2001}

[CRSSTD: 6980606]

Galperin J, Elizari MV, Chiale PA, Molina RT, Ledesma R, Scapin AO, et al. Efficacy of amiodarone for the termination of chronic atrial fibrillation and maintenance of normal sinus rhythm: a prospective, multicenter, randomized, controlled, double blind trial. Journal of Cardiovascular Pharmacology and Therapeutics 2001;6(4):341-50. [CRSREF: 6980607; MEDLINE: PMID: 11907636; Other: ISSN 1074-2484]

\section{Hillestad 1971}

[CRSSTD: 6980608]

Hillestad L, Bjerkelund C, Dale J, Maltau J, Storstein O. Quinidine in maintenance of sinus rhythm after electroconversion of chronic atrial fibrillation. A controlled clinical study. British Heart Journal 1971;33(4):518-21. [CRSREF: 6980609; MEDLINE: PMID: 4934041; Other: ISSN 0007-0769]

\section{Hohnloser 1995}

[CRSSTD: 6980610]

Hohnloser SH, van de Loo A, Baedeker F. Efficacy and proarrhythmic hazards of pharmacologic cardioversion of atrial fibrillation: prospective comparison of sotalol versus quinidine. Journal of the American College of Cardiology 1995;26(4):852-8. [CRSREF: 6980611; MEDLINE: PMID: 7560608; Other: ISSN: 0735-1097]

\section{Juul-Moller 1990}

[CRSSTD: 6980612]

Juul-Moller S, Edvardsson N, Rehnqvist-Ahlberg N. Sotalol versus quinidine for the maintenance of sinus rhythm after direct current conversion of atrial fibrillation. Circulation 1990;82(6):1932-9. [CRSREF: 6980613; MEDLINE: PMID: 2242519; Other: ISSN: 00097322] 


\section{Kalusche 1994}

[CRSSTD: 6980614]

Kalusche D, Stockinger J, Betz P, Roskamm H. Sotalol and quinidine/verapamil (Cordichin) in chronic atrial fibrillation - conversion and 12-month follow-up - a randomized comparison [Sotalol und Chinidin/Verapamil (Cordichin) bei chronischem Vorhoflimmern - Konversion und 12-Monats-Follow-up - ein randomisierter Vergleich]. Zeitschrift fur Kardiologie 1994;83 Suppl 5:109-16. [CRSREF: 6980615; MEDLINE: PMID: 7846939; Other: ISSN: 0300-5860]

\section{Karlson 1998}

[CRSSTD: 6980616]

* Karlson BW, Torstensson I, Abjorn C, Jansson SO, Peterson LE. Disopyramide in the maintenance of sinus rhythm after electroconversion of atrial fibrillation. A placebocontrolled one-year follow-up study. European Heart Journal 1988;9(3):284-90. [CRSREF: 6980617; MEDLINE: PMID: 3289932; Other: ISSN 0195-668X]

Karlson BW, Torstensson I, Abjorn C, Kallryd A, Jonsson J, Jansson SO, Peterson LE. Preventive disopyramide after electroconversion of atrial fibrillation--a good alternative [Disopyramid som profylax efter elregularisering av formaksflimmer--ett bra alternativ]. Lakartidningen 1991;88(24):2242-5. [CRSREF: 6980618; MEDLINE: PMID: 2056838; Other: ISSN: 0023-7205]

\section{Kochiadakis 2000}

[CRSSTD: 6980619]

* Kochiadakis GE, Igoumenidis NE, Marketou ME, Kaleboubas MD, Simantirakis EN, Vardas PE. Low dose amiodarone and sotalol in the treatment of recurrent, symptomatic atrial fibrillation: a comparative, placebo controlled study. Heart 2000;84(3):251-7.

[CRSREF: 6980620; MEDLINE: PMID: 10956284; Other: ISSN 1355-6037]

Kochiadakis GE, Igoumenidis NE, Marketou ME, Solomou MC, Kanoupakis EM, Vardas PE. Low-dose amiodarone versus sotalol for suppression of recurrent symptomatic atrial fibrillation. American Journal of Cardiology 1998;81(8):995-8. [CRSREF: 6980621; MEDLINE: PMID: 9576159; Other: ISSN: 0002-9149]

Kochiadakis GE, Marketou ME, Igoumenidis NE, Chrysostomakis SI, Mavrakis HE, Kaleboubas MD, et al. Amiodarone, sotalol, or propafenone in atrial fibrillation: which is preferred to maintain normal sinus rhythm? Pacing and Clinical Electrophysiology 2000;23(11 Pt 2):1883-7. [CRSREF: 6980622; MEDLINE: PMID: 11139949; Other: ISSN 0147-8389]

\section{Kochiadakis 2004a}

[CRSSTD: 6980623] 
Kochiadakis GE, Igoumenidis NE, Hamilos MI, Tzerakis PG, Klapsinos NC, Zacharis EA, et al. Long-term maintenance of normal sinus rhythm in patients with current symptomatic atrial fibrillation: amiodarone vs propafenone, both in low doses. Chest 2004;125(2):377-83. [CRSREF: 6980624; MEDLINE: PMID: 14769712; Other: ISSN: 0012-3692]

\section{Kochiadakis 2004b}

[CRSSTD: 6980625]

Kochiadakis GE, Igoumenidis NE, Hamilos ME, Tzerakis PG, Klapsinos NC, Chlouverakis GI, et al. Sotalol versus propafenone for long-term maintenance of normal sinus rhythm in patients with recurrent symptomatic atrial fibrillation. American Journal of Cardiology 2004;94(12):1563-6. [CRSREF: 6980626; MEDLINE: PMID: 15589019; Other: ISSN: 00029149]

\section{Kuhlkamp 2000}

[CRSSTD: 6980627]

Kuhlkamp V, Schirdewan A, Stangl K, Homberg M, Ploch M, Beck OA. Use of metoprolol $\mathrm{CR} / \mathrm{XL}$ to maintain sinus rhythm after conversion from persistent atrial fibrillation: a randomized, double-blind, placebo-controlled study. Journal of the American College of Cardiology 2000;36(1):139-46. [CRSREF: 6980628; MEDLINE: PMID: 10898425; Other: ISSN 0735-1097]

\section{Lloyd 1984}

[CRSSTD: 6980629]

Lloyd EA, Gersh BJ, Forman R. The efficacy of quinidine and disopyramide in the maintenance of sinus rhythm after electroconversion from atrial fibrillation. A double-blind study comparing quinidine, disopyramide and placebo. South African Medical Journal 1984;65(10):367-9. [CRSREF: 6980630; MEDLINE: PMID: 6367096; Other: ISSN: 00382469]

\section{Naccarelli 1996}

[CRSSTD: 6980631]

Naccarelli GV, Dorian P, Hohnloser SH, Coumel P. Prospective comparison of flecainide versus quinidine for the treatment of paroxysmal atrial fibrillation/flutter. American Journal of Cardiology 1996;77(3):53A-9A. [CRSREF: 6980632; MEDLINE: PMID: 8607392; Other: ISSN: 0002-9149]

\section{Nergardh 2007}

[CRSSTD: 6980633]

* Nergårdh AK, Rosenqvist M, Nordlander R, Frick M. Maintenance of sinus rhythm with metoprolol CR initiated before cardioversion and repeated cardioversion of atrial fibrillation: 
a randomized double-blind placebo-controlled study. European Heart Journal 2007

Jun;28(11):1351-7. [CRSREF: 6980634; PubMed: PMID: 17329409]

\section{Niu 2006}

[CRSSTD: 6980635]

* Niu F, Huang CX, Jiang H, Yang B, Guo WL, Chen YX, et al. Effects of amiodarone versus sotalol in treatment of atrial fibrillation: a random controlled clinical study [Original in Chinese]. Zhonghua Yi Xue Za Zhi 2006;86(2):121-3. [CRSREF: 6980636; PubMed: PMID: 16620720]

\section{Okishige 2000}

[CRSSTD: 6980637]

Okishige K, Nishizaki M, Azegami K, Igawa M, Yamawaki N, Aonuma K. Pilsicainide for conversion and maintenance of sinus rhythm in chronic atrial fibrillation: A placebocontrolled, multicenter study. American Heart Journal 2000;140(3):e13. [CRSREF: 6980638; MEDLINE: PMID: 10966544; Other: ISSN 0002-8703]

\section{PAFAC 2004}

[CRSSTD: 6980639]

* Fetsch T, Bauer P, Engberding R, Koch HP, Lukl J, Meinertz T, et al. Prevention of atrial fibrillation after cardioversion: results of the PAFAC trial. European Heart Journal 2004;25(16):1385-94. [CRSREF: 6980640; MEDLINE: PMID: 15302102; Other: ISSN: 0195-668X]

Fetsch T, Burschel G, Breithardt G, Engberding R, Koch HP, Lukl J, et al. Medicamentous prevention after electric cardioversion of chronic atrial fibrillation. Goals and design of the PAFAC Study [Die medikamentöse Prophylaxe nach elektronischer Kardioversion von chronischem Vorhofflimmern. Ziele und Design der PAFAC-Studie]. Zeitschrift fur Kardiologie 1999;88(3):195-207. [CRSREF: 6980641; MEDLINE: PMID: 10355070; Other: ISSN 0300-5860]

\section{PITAGORA 2008}

[CRSSTD: 6980642]

* PITAGORA Study Investigators, Gulizia M, Mangiameli S, Orazi S, Chiarandà G, Piccione $\mathrm{G}$, et al. A randomized comparison of amiodarone and class IC antiarrhythmic drugs to treat atrial fibrillation in patients paced for sinus node disease: the PITAGORA trial. American Heart Journal 2008;155(1):107.e1. [CRSREF: 6980643; PubMed: PMID: 18082498]

\section{Plewan 2001}

[CRSSTD: 6980644] 
Plewan A, Lehmann G, Ndrepepa G, Schreieck J, Alt EU, Schomig A, et al. Maintenance of sinus rhythm after electrical cardioversion of persistent atrial fibrillation; sotalol vs bisoprolol. European Heart Journal 2001;22(16):1504-10. [CRSREF: 6980645; MEDLINE: PMID: 11482924; Other: ISSN: 0195-668X]

\section{PRODIS 1996}

[CRSSTD: 6980646]

Crijns HJ, Gosselink AT, Lie KI. Propafenone versus disopyramide for maintenance of sinus rhythm after electrical cardioversion of chronic atrial fibrillation: a randomized, double-blind study. Cardiovascular Drugs and Therapy 1996;10(2):145-52. [CRSREF: 6980647; MEDLINE: PMID: 8842506; Other: ISSN: 0920-3206]

\section{RAFT 2003}

[CRSSTD: 6980648]

Pritchett EL, Page RL, Carlson M, Undesser K, Fava G. Efficacy and safety of sustainedrelease propafenone (propafenone SR) for patients with atrial fibrillation. American Journal of Cardiology 2003;92(8):941-6. [CRSREF: 6980649; MEDLINE: PMID: 14556870; Other: ISSN 0002-9149]

\section{Reimold 1993}

[CRSSTD: 6980650]

Reimold SC, Cantillon CO, Friedman PL, Antman EM. Propafenone versus sotalol for suppression of recurrent symptomatic atrial fibrillation. American Journal of Cardiology 1993;71(7):558-63. [CRSREF: 6980651; MEDLINE: PMID: 8438741; Other: ISSN: 00029149]

\section{Richiardi 1992}

[CRSSTD: 6980652]

Richiardi E, Gaita F, Greco C, Gaschino G, Comba Costa G, Rosettani E, et al. Propafenone versus hydroquinidine in long-term pharmacological prophylaxis of atrial fibrillation [Propafenone versus idrochinidina nella profilassi farmacologica a lungo termine della fibrillazione atriale]. Cardiologia 1992;37(2):123-7. [CRSREF: 6980653; MEDLINE: PMID: 1600529; Other: ISSN: 0393-1978]

\section{SAFE-T 2005}

[CRSSTD: 6980654]

* Singh BN, Singh SN, Reda DJ, Tang XC, Lopez B, Harris CL, et al. Amiodarone versus sotalol for atrial fibrillation. New England Journal of Medicine 2005;352(18):1861-72. [CRSREF: 6980655; MEDLINE: PMID: 15872201; Other: ISSN: 0028-4793] 
Singh SN, Singh BN, Reda DJ, Fye CL, Ezekowitz MD, Fletcher RD, et al. Comparison of sotalol versus amiodarone in maintaining stability of sinus rhythm in patients with atrial fibrillation (Sotalol-Amiodarone Fibrillation Efficacy Trial [Safe-T]). American Journal of Cardiology 2003;92(4):468-72. [CRSREF: 6980656; MEDLINE: PMID: 12914883; Other: ISSN 0002-9149]

\section{SAFIRE-D 2000}

[CRSSTD: 6980657]

Singh S, Zoble RG, Yellen L, Brodsky MA, Feld GK, Berk M, et al. Efficacy and safety of oral dofetilide in converting to and maintaining sinus rhythm in patients with chronic atrial fibrillation or atrial flutter: the symptomatic atrial fibrillation investigative research on dofetilide (SAFIRE-D) study. Circulation 2000;102(19):2385-90. [CRSREF: 6980658; MEDLINE: PMID: 11067793; Other: ISSN 0009-7322]

\section{Santas 2012}

Published data only (unpublished sought but not used) [CRSSTD: 6980659]

Santas E, Dominguez E, Martinez-Brotons A, Ruiz-Granell R, Ruiz V, Ferrero A, et al. Early withdrawal of amiodarone after cardioversion in atrial fibrillation patients treated with irbesartan. A prospective randomized study. Abstract from the ESC Congress 25-29 August 2012; Munchen, Germany. European Heart Journal 2012;33 Suppl 1:380. [CRSREF: 6980660; DOI: 10.1093/eurheartj/ehs282; PubMed: 23805432]

\section{Singh 1991}

[CRSSTD: 6980661]

Singh S, Saini RK, DiMarco J, Kluger J, Gold R, Chen YW. Efficacy and safety of sotalol in digitalized patients with chronic atrial fibrillation. The Sotalol Study Group. American Journal of Cardiology 1991;68(11):1227-30. [CRSREF: 6980662; MEDLINE: PMID: 1951086; Other: ISSN: 0002-9149]

\section{SMART 2002}

[CRSSTD: 6980663]

* Atarashi H, Inoue H, Fukunami M, Sugi K, Hamada C, Origasa H. Double-blind placebocontrolled trial of aprindine and digoxin for the prevention of symptomatic atrial fibrillation. Circulation Journal 2002;66(6):553-6. [CRSREF: 6980664; MEDLINE: PMID: 12074271; Other: ISSN 1346-9843]

\section{SOCESP 1999}

[CRSSTD: 6980665]

Veloso $\mathrm{HH}$, de Paola AA. Analysis of atrial fibrillation recurrence during therapy with sotalol or quinidine. Researchers of +SOCESP [Analise da recorrencia de fibrilacao atrial durante terapia com sotalol ou quinidina. Investigadores da SOCESP]. Arquivos Brasileiros de 
Cardiologia 1998;70(1):43-9. [CRSREF: 6980666; MEDLINE: PMID: 9629687; Other: ISSN: 0066-782X]

* de Paola AA, Veloso HH. Efficacy and safety of sotalol versus quinidine for the maintenance of sinus rhythm after conversion of atrial fibrillation. SOCESP Investigators. American Journal of Cardiology 1999;84(9):1033-7. [CRSREF: 6980667; MEDLINE: PMID: 10569659; Other: ISSN: 0002-9149]

\section{Sodermark 1975}

[CRSSTD: 6980668]

Sodermark T, Jonsson B, Olsson A, Oro L, Wallin H, Edhag O, et al. Effect of quinidine on maintaining sinus rhythm after conversion of atrial fibrillation or flutter. A multicentre study from Stockholm. British Heart Journal 1975;37(5):486-92. [CRSREF: 6980669; MEDLINE: PMID: 1093559; Other: ISSN 0007-0769]

\section{SOPAT 2004}

[CRSSTD: 6980670]

Patten M, Koch HP, Sonntag F, Luderitz B, Meinertz T. Medicamentous prevention of symptomatic paroxysmal atrial fibrillation/flutter onset. Goals and design of the SOPAT study. Executive committee of the investigators representing trial physicians [Die medikamentose Anfallsprophylaxe bei symptomatischem paroxysmalem Vorhofflimmern/flattern. Ziele und Design der SOPAT-Studie. Investigators in Vertretung der Prufarzte]. Zeitschrift fur Kardiologie 1999;88(3):185-94. [CRSREF: 6980671; MEDLINE: PMID: 10355069; Other: ISSN: 0300-5860]

* Patten M, Maas R, Bauer P, Luderitz B, Sonntag F, Dluzniewski M, et al. Suppression of paroxysmal atrial tachyarrhythmias--results of the SOPAT trial. European Heart Journal 2004;25(16):1395-404. [CRSREF: 6980672; MEDLINE: PMID: 15321697; Other: ISSN: 0195-668X]

\section{Steinbeck 1988}

[CRSSTD: 6980673]

Steinbeck G, Doliwa R, Bach P. Therapy of paroxysmal atrial fibrillation. Cardiac glycosides alone or combined with anti-arrhythmia agents? [Therapie des paroxysmalen Vorhofflimmerns. Herzglykoside allein oder in Kombination mit Antiarrhythmika?]. Deutsche Medizinische Wochenschrift 1988;113(48):1867-71. [CRSREF: 6980674; MEDLINE: PMID: 3143539; Other: ISSN: 0012-0472]

\section{Stroobandt 1997}

[CRSSTD: 6980675]

Stroobandt R, Stiels B, Hoebrechts R. Propafenone for conversion and prophylaxis of atrial fibrillation. Propafenone Atrial Fibrillation Trial Investigators. American Journal of 
Cardiology 1997;79(4):418-23. [CRSREF: 6980676; MEDLINE: PMID: 9052343; Other: ISSN 0002-9149]

\section{Van Gelder 1989}

[CRSSTD: 6980677]

* Van Gelder IC, Crijns HJ, Van Gilst WH, Van Wijk LM, Hamer HP, Lie KI. Efficacy and safety of flecainide acetate in the maintenance of sinus rhythm after electrical cardioversion of chronic atrial fibrillation or atrial flutter. American Journal of Cardiology

1989;64(19):1317-21. [CRSREF: 6980678; MEDLINE: PMID: 2511744; Other: ISSN: 00029149]

Van Gelder IC, et al. Efficacy of flecainide to maintain sinus rhythm after cardioversion of chronic atrial fibrillation and flutter. Abstracts from the 61st scientific sessions. American Heart Association. Washington, DC, November 1988. Circulation 1988;78(4 Pt 2):III626. [CRSREF: 6980679; MEDLINE: PMID: 3168202; Other: ISSN: 0009-7322]

\section{Vijayalaskshmi 2006}

\section{[CRSSTD: 6980680]}

* Vijayalakshmi K, Whittaker VJ, Sutton A, Campbell P, Wright RA, Hall JA, et al. A randomized trial of prophylactic antiarrhythmic agents (amiodarone and sotalol) in patients with atrial fibrillation for whom direct current cardioversion is planned. American Heart Journal 2006;151(4):863.e1-6. [CRSREF: 6980681; PubMed: 16569550]

\section{Villani 1992}

[CRSSTD: 6980682]

Villani R, Zoletti F, Veniani M, Locati F, Nava S. A comparison between amiodarone and disopyramide in a delayed-release formulation in the prevention of recurrences of symptomatic atrial fibrillation [Confronto fra amiodarone e disopiramide in formulazione retard nella prevenzione delle recidive di fibrillazione atriale sintomatica]. La Clinica Terapeutica 1992;140(1 Pt 2):35-9. [CRSREF: 6980683; MEDLINE: PMID: 1559321; Other: ISSN: 0009-9074]

\section{Vitolo 1981}

[CRSSTD: 6980684]

Vitolo E, Tronci M, Larovere MT, Rumolo R, Morabito A. Amiodarone versus quinidine in the prophylaxis of atrial fibrillation. Acta Cardiologica 1981;36(6):431-44. [CRSREF:

6980685; MEDLINE: PMID: 7039195; Other: ISSN: 0001-5385]

\section{Excluded studies}

\section{Aberg 1968}

[CRSSTD: 6980686] 
Aberg H, Cullhed I. Procaine amide quinidine as prophylactic drugs against relapse of atrial fibrillation [Prokainamid och kinidin som profylaktikum mot recidiv av formaksflimmer]. Nordisk Medicin 1968;79(24):781-2. [CRSREF: 6980687; MEDLINE: PMID: 4880307; Other: ISSN 0029-1420]

* Aberg H. Procaine amide as a prophylactic drug against atrial fibrillation. A controlled study [Prokainamid som profylax mot formaksflimmer. En kontrollerad studie]. Nordisk Medicin 1969;82(33):1011-3. [CRSREF: 6980688; MEDLINE: PMID:\&\#160;5808590; Other: ISSN: 0029-1420]

\section{Adamyan 2015}

[CRSSTD: 6980689]

Adamyan KG, Tunyan LG, Chilingaryan AL. Comparative efficacy of amiodarone with ivabradin combination or amiodarone with bisoprolol combination in the prevention of atrial fibrillation recurrence in patients with left ventricular diastolic dysfunction. Rational Pharmacotherapy in Cardiology 2015;11(5):483-488. [CRSREF: 6980690; DOI: 10.20996/1819-6446-2015-11-5-483-488]

\section{AF-CHF 2002}

[CRSSTD: 6980691]

Atrial Fibrillation and Congestive Heart Failure (AF-CHF) investigators. Rationale and design of a study assessing treatment strategies of atrial fibrillation in patients with heart failure: the Atrial Fibrillation and Congestive Heart Failure (AF-CHF) trial. American Heart Journal 2002 Oct;144(4):597-607. [CRSREF: 6980692; PubMed: PMID: 12360154]

* Atrial Fibrillation and Congestive Heart Failure (AF-CHF) investigators. Rationale and design of a study assessing treatment strategies of atrial fibrillation in patients with heart failure: the Atrial Fibrillation and Congestive Heart Failure (AF-CHF) trial. American Heart Journal 2002;144(4):597-607. [CRSREF: 6980693; MEDLINE: PMID 12360154; Other: ISSN 0002-8703, EMBASE 2002364426]

\section{AFFIRM 2002}

[CRSSTD: 6980694]

AFFIRM Investigators; Chung MK, Shemanski L, Sherman DG, Greene HL, Hogan DB, Kellen JC, et al. Functional status in rate- versus rhythm-control strategies for atrial fibrillation: results of the Atrial Fibrillation Follow-Up Investigation of Rhythm Management (AFFIRM) Functional Status Substudy. Journal of the American College of Cardiology 2005 Nov 15;46(10):1891-9. [CRSREF: 6980695; PubMed: PMID: 16286177]

AFFIRM Investigators; Corley SD, Epstein AE, DiMarco JP, Domanski MJ, Geller N, Greene HL, et al. Relationships between sinus rhythm, treatment, and survival in the Atrial Fibrillation Follow-Up Investigation of Rhythm Management (AFFIRM) Study. Circulation 2004 Mar 30;109(12):1509-13. [CRSREF: 6980696; PubMed: PMID: 15007003] 
* Wyse DG, Waldo AL, DiMarco JP, Domanski MJ, Rosenberg Y, Schron EB, et al. A comparison of rate control and rhythm control in patients with atrial fibrillation. New England Journal of Medicine 2002;347(23):1825-33. [CRSREF: 6980697; MEDLINE: PMID: 12466506; Other: ISSN 0028-4793]

\section{Anderson 1994}

[CRSSTD: 6980698]

Anderson JL, Gilbert EM, Alpert BL, Henthorn RW, Waldo AL, Bhandari AK, et al. Prevention of symptomatic recurrences of paroxysmal atrial fibrillation in patients initially tolerating antiarrhythmic therapy. A multicenter, double-blind, crossover study of flecainide and placebo with transtelephonic monitoring. Flecainide Supraventricular Tachycardia Study Group. Circulation 1989;80(6):1557-70. [CRSREF: 6980699; MEDLINE: PMID: 2513143; Other: ISSN 0009-7322]

* Anderson JL, Platt ML, Guarnieri T, Fox TL, Maser MJ, Pritchett EL. Flecainide acetate for paroxysmal supraventricular tachyarrhythmias. The Flecainide Supraventricular Tachycardia Study Group. American Journal of Cardiology 1994;74(6):578-84. [CRSREF: 6980700; MEDLINE: PMID: 8074041; Other: ISSN: 0002-9149]

Anderson JL. Long-term safety and efficacy of flecainide in the treatment of supraventricular tachyarrhythmias: the United States experience. The Flecainide Supraventricular Tachyarrhythmia Investigators. American Journal of Cardiology 1992;70(5):11 A-7A. [CRSREF: 6980701; MEDLINE: PMID: 1509993; Other: ISSN: 0002-9149]

\section{Andromeda 2008}

[CRSSTD: 6980702]

* Dronedarone Study Group; Køber L, Torp-Pedersen C, McMurray JJ, Gøtzsche O, Lévy S, Crijns $\mathrm{H}$, et al. Increased mortality after dronedarone therapy for severe heart failure. New England Journal of Medicine 2008 Jun 19;358(25):2678-87. [CRSREF: 6980703; PubMed: 18565860]

\section{Antman 1990}

[CRSSTD: 6980704]

* Antman EM, Beamer AD, Cantillon C, McGowan N, Friedman PL. Therapy of refractory symptomatic atrial fibrillation and atrial flutter: a staged care approach with new antiarrhythmic drugs. Journal of the American College of Cardiology 1990;15(3):698-707. [CRSREF: 6980705; MEDLINE: PMID: 2303641; Other: ISSN: 0735-1097]

Antman EM, Beamer AD, Cantillon C, McGowan N, Goldman L, Friedman PL. Long-term oral propafenone therapy for suppression of refractory symptomatic atrial fibrillation and atrial flutter. Journal of the American College of Cardiology 1988;12(4):1005-11. [CRSREF: 6980706; MEDLINE: PMID: 3417972; Other: ISSN: 0735-1097]

\section{Aros 1978}


Aros F, Valles V, Alegria E, Loma-Osorio A, Malpartida F. Maintaining sinus rhythm with quinidine and amiodarone after electric cardioversion [Mantenimiento del ritmo sinusal con quinidina y amiodarona tras cardioversion electrica]. Revista Espanola de Cardiologia 1978;31(1 Pt 2):185-91. [CRSREF: 6980708; MEDLINE: PMID: 663366; Other: ISSN: 0300-8932]

\section{Babuty 1999}

[CRSSTD: 6980709]

Babuty D, D'Hautefeuille B, Scheck F, Mycinsky C, Pruvost P, Peraudeau P. Cibenzoline versus flecainide in the prevention of paroxysmal atrial arrhythmias: a double-blind randomized study. Journal of Clinical Pharmacology 1995;35(5):471-7. [CRSREF: 6980710; MEDLINE: PMID: 7657846; Other: ISSN: 0091-2700]

* Babuty D, Maison-Blanche P, Fauchier L, Brembilla-Perrot B, Medvedowsky JL, BineScheck F. Double-blind comparison of cibenzoline versus flecainide in the prevention of recurrence of atrial tachyarrhythmias in 139 patients. Annals of Noninvasive Electrocardiology 1999;4(1):53-9. [CRSREF: 6980711; MEDLINE: not indexed; Other: EMBASE 1999048462; ISSN: 1082-720X]

Maison-Blanche P, Brembilla-Perrot B, Fauchier JP, Babuty D, Garnier LF, Rouesnel P, et al. Comparative study of cibenzoline and flecainide by oral route for preventing recurrence of paroxysmal atrial tachyarrhythmias [Étude comparative de la cibenzoline et du flecaïnide administrés par voie orale dans la prévention de récidive des tachycardies auriculaires]. Annales de Cardiologie et d Angeiologie 1997;46(2):109-16. [CRSREF: 6980712; MEDLINE: PMID: 9137677; Other: ISSN: 0003-3928]

\section{Beck 1978}

[CRSSTD: 6980713]

Beck OA, Lehmann HU, Hochrein H. Propafenone and lidoflazine in chronic atrial fibrillation and flutter (author's transl) [Original title: Propafenon und Lidoflazin bei chronischem Vorhofflimmern und -flattern. Vergleichende Untersuchungen]. Deutsche Medizinische Wochenschrift 1978;103(26):1068-72. [CRSREF: 6980714; MEDLINE: PMID:\&\#160;668524; Other: ISSN: 0012-0472]

\section{Berns 1987}

[CRSSTD: 6980715]

Berns E, Rinkenberger RL, Jeang MK, Dougherty AH, Jenkins M, Naccarelli GV. Efficacy and safety of flecainide acetate for atrial tachycardia or fibrillation. American Journal of Cardiology 1987;59(15):1337-41. [CRSREF: 6980716; MEDLINE: PMID: 3109229; Other: ISSN: 0002-9149]

\section{Blevins 1987}


Blevins RD, Kerin NZ, Benaderet D, Frumin H, Faitel K, Jarandilla R, et al. Amiodarone in the management of refractory atrial fibrillation. Archives of Internal Medicine

1987;147(8):1401-4. [CRSREF: 6980718; MEDLINE: PMID: 3307669; Other: ISSN: 00039926]

\section{Blomstrom 1984}

[CRSSTD: 6980719]

Blomstrom P, Edvardsson N, Olsson SB. Amiodarone in atrial fibrillation. Acta Medica Scandinavica 1984;216(5):517-24. [CRSREF: 6980720; MEDLINE: PMID: 6524456; Other: ISSN: 0001-6101]

\section{Boissel 1981}

[CRSSTD: 6980721]

Boissel JP, Wolf E, Gillet J, Soubrane A, Cavallaro A, Mazoyer G, Delahaye JP. Controlled trial of a long-acting quinidine for maintenance of sinus rhythm after conversion of sustained atrial fibrillation. European Heart Journal 1981;2(1):49-55. [CRSREF: 6980722; MEDLINE: PMID: 7274266; Other: ISSN 0195-668X]

\section{Brodsky 1987}

[CRSSTD: 6980723]

Brodsky MA, Allen BJ, Walker CJ 3rd, Casey TP, Luckett CR, Henry WL. Amiodarone for maintenance of sinus rhythm after conversion of atrial fibrillation in the setting of a dilated left atrium. American Journal of Cardiology 1987;60(7):572-5. [CRSREF: 6980724; MEDLINE: PMID: 3630939; Other: ISSN: 0002-9149]

\section{CHF-STAF 1998}

[CRSSTD: 6980725]

Deedwania PC, Singh BN, Ellenbogen K, Fisher S, Fletcher R, Singh SN. Spontaneous conversion and maintenance of sinus rhythm by amiodarone in patients with heart failure and atrial fibrillation: observations from the veterans affairs congestive heart failure survival trial of antiarrhythmic therapy (CHF-STAT). Circulation 1998;98(23):2574-9. [CRSREF: 6980726; MEDLINE: PMID: 9843465; Other: ISSN 0009-7322]

\section{Chun 1995}

[CRSSTD: 6980727]

Chun SH, Sager PT, Stevenson WG, Nademanee K, Middlekauff HR, Singh BN. Long-term efficacy of amiodarone for the maintenance of normal sinus rhythm in patients with refractory atrial fibrillation or flutter. American Journal of Cardiology 1995;76(1):47-50. [CRSREF: 6980728; MEDLINE: PMID: 7793402; Other: ISSN: 0002-9149] 


\section{Clementy 1992}

[CRSSTD: 6980729]

Clementy J, Dulhoste MN, Laiter C, Denjoy I, Dos Santos P. Flecainide acetate in the prevention of paroxysmal atrial fibrillation: a nine-month follow-up of more than 500 patients. American Journal of Cardiology 1992;70(5):44A-9A. [CRSREF: 6980730; MEDLINE: PMID: 1509998; Other: ISSN: 0002-9149]

\section{Connolly 1989}

[CRSSTD: 6980731]

Connolly SJ, Hoffert DL. Usefulness of propafenone for recurrent paroxysmal atrial fibrillation. American Journal of Cardiology 1989;63(12):817-9. [CRSREF: 6980732; MEDLINE: PMID: 2648787; Other: ISSN 0002-9149]

\section{CTAF 2000}

[CRSSTD: 6980733]

Dorian P, Paquette M, Newman D, Green M, Connolly SJ, Talajic M, et al. Quality of life improves with treatment in the Canadian Trial of Atrial Fibrillation. American Heart Journal 2002;143(6):984-90. [CRSREF: 6980734; MEDLINE: PMID: 12075253; Other: ISSN: 00028703]

Lumer GB, Roy D, Talajic M, Couturier A, Lambert J, Frasure-Smith N, Thibault B, et al. Amiodarone reduces procedures and costs related to atrial fibrillation in a controlled clinical trial. European Heart Journal 2002;23(13):1050-6. [CRSREF: 6980735; MEDLINE: PMID: 12093058; Other: ISSN: 0195-668X]

* Roy D, Talajic M, Dorian P, Connolly S, Eisenberg MJ, Green M, Kus T, et al. Amiodarone to prevent recurrence of atrial fibrillation. Canadian Trial of Atrial Fibrillation Investigators. New England Journal of Medicine 2000;342(13):913-20. [CRSREF: 6980736; MEDLINE: PMID: 10738049; Other: ISSN: 0028-4793]

Roy D, Talajic M, Thibault B, Dubuc M, Nattel S, Eisenberg MJ, et al. Pilot study and protocol of the Canadian Trial of Atrial Fibrillation (CTAF). American Journal of Cardiology 1997;80(4):464-8. [CRSREF: 6980737; MEDLINE: PMID: 9285659; Other: ISSN: 00029149]

\section{Cuan-Perez 1971}

[CRSSTD: 6980738]

Cuan Perez M, Ortiz A. Comparative study of quinidine, propranolol and diphenylhydantoin for preventing recurrence in post-cardioversion auricular fibrillation [Estudio comparativo entre quinidina, propranolol y difenil-hidantoinato para prevenir la recaida en fibrilacion auricular post-cardioversion]. Archivos del Instituto de Cardiologia de Mexico 1971;41(3):278-84. [CRSREF: 6980739; MEDLINE: PMID: 5566599; Other: ISSN 0020$3785]$ 


\section{Darkner 2014}

[CRSSTD: 6980740]

Darkner S, Chen X, Hansen J, Pehrson S, Johannessen A, Nielsen JB, Svendsen JH.

Recurrence of arrhythmia following short-term oral AMIOdarone after CATheter ablation for atrial fibrillation: a double-blind, randomized, placebo-controlled study (AMIO-CAT trial). Eur Heart J 2014;35(47):3356-3364. [CRSREF: 6980741; DOI: 10.1093/eurheartj/ehu354]

\section{Di Biase 2016}

[CRSSTD: 6980742]

Di Biase L, Mohanty P, Mohanty S, Santangeli P, Trivedi C, Lakkireddy D, Reddy M, Jais P, Themistoclakis S, Dello Russo A, Casella M, Pelargonio G, Narducci ML, Schweikert R, Neuzil P, Sanchez J, Horton R, Beheiry S, Hongo R, Hao S, Rossillo A, Forleo G, Tondo C, Burkhardt JD, Haissaguerre M, Natale A. Ablation Versus Amiodarone for Treatment of Persistent Atrial Fibrillation in Patients With Congestive Heart Failure and an Implanted Device: Results From the AATAC Multicenter Randomized Trial. Circulation 2016 Apr 26;133(17):1637-44. [CRSREF: 6980743; DOI: 10.1161/CIRCULATIONAHA.115.019406]

\section{Enriquez 2014}

[CRSSTD: 6980744]

Enriquez A, Conde D, Hopman W, Mondragon I, Chiale PA, de Luna AB, Baranchuk A. Advanced Interatrial Block is Associated with Recurrence of Atrial Fibrillation Post Pharmacological Cardioversion. Cardiovasclar Therapeutics 2014 Apr;32(2):52-6. [CRSREF: 6980745; DOI: 10.1111/1755-5922.12063]

\section{ERAFT 2002}

[CRSSTD: 6980746]

Meinertz T, Lip GY, Lombardi F, Sadowski ZP, Kalsch B, Camez A, et al. Efficacy and safety of propafenone sustained release in the prophylaxis of symptomatic paroxysmal atrial fibrillation. The European Rythmol/Rytmonorm Atrial Fibrillation Trial (ERAFT) Study. American Journal of Cardiology 2002;90(12):1300-6. [CRSREF: 6980747; MEDLINE: PMID: 12480038; Other: ISSN 0002-9149]

\section{Faivre 1970}

[CRSSTD: 6980748]

Faivre G, Polu JM. Disopyramide in the preparation for electric shock in atrial fibrillation and in the maintenance of subsequent sinus rhythm [La disopiramide nella preparazione allo shock elettrico della fibrillazione atriale e nel mantenimento dell'ulteriore ritmo sinusale]. Minerva Medica 1970;61(71 Suppl):3745-7. [CRSREF: 6980749; MEDLINE: PMID: 5454439; Other: ISSN 0026-4806]

\section{Farkowski 2012}


[CRSSTD: 6980750]

Farkowski MM, Maciag A, Dabrowski R, Pytkowski M, Kowalik I, Szwed H. Clinical efficacy of antazoline in rapid cardioversion of paroxysmal atrial fibrillation - a protocol of a single center, randomized, double-blind, placebo-controlled study (the AnPAF Study). Trials 2012 Sep 11;13:162. [CRSREF: 6980751; DOI: 10.1186/1745-6215-13-162]

\section{Fernandez 1998}

[CRSSTD: 6980752]

Fernández JM, Martínez-Marcos FJ, Ortega A, García JL, Camacho C, et al. Comparative study of propafenone, amiodarone and flecainide in the treatment of paroxystic atrial fibrillation [Estudio comparativo de propafenona, amiodarona y flecainida en el tratamiento de la fibrilación auricular paroxística]. Revista Espanola de Cardiologia 1998;51 Suppl 5:84. [CRSREF: 6980753; MEDLINE: Not indexed; Other: ISSN: 0300-8932]

\section{Feyrer 2014}

[CRSSTD: 6980754]

Feyrer R, Ballazhi F, Seitz T, Weyand M and Harig F. Impact of Medical Treatment on Long-Term Results after Surgical Ablation of Atrial Fibrillation in Cardiac Surgical Patients. Annals of Thoracic \& Cardiovascular Surgery 2014;20(3):207-12. [CRSREF: 6980755; MEDLINE: 23558224]

\section{Fragakis 2012}

[CRSSTD: 6980756]

* Fragakis N, Koskinas KC, Katritsis DG, Pagourelias ED, Zografos T, Geleris P. Comparison of effectiveness of ranolazine plus amiodarone versus amiodarone alone for conversion of recent-onset atrial fibrillation. American Journal of Cardiology 2012 Sep 1;110(5):673-7. [CRSREF: 6980757; DOI: 10.1016/j.amjcard.2012.04.044; PubMed: 22621799]

Koskinas KC, Fragakis N, Pagourelias ED, Rossios K, Abramidou A, Sotiriou P, et al. Ranolazine added to amiodarone vs. amiodarone alone for the conversion of recent-onset atrial fibrillation. Abstract from the ESC Congress 25-29 August 2012; Munchen, Germany. European Heart Journal 2012;33 Suppl 1:383. [CRSREF: 6980758; DOI: 10.1093/eurheartj/ehs282; PubMed: 23805432]

\section{Frances 1985}

[CRSSTD: 6980759]

Frances Y, Luccioni R, Delaage M, Donnarel G, Medvedowsky JL, Quiret JC. Long-term prevention of the recurrence of auricular fibrillation using cibenzoline. Multicenter study apropos of 89 case reports [Prevention au long cours des recidives de fibrillation auriculaire par la cibenzoline. Etude multicentrique a propos de 89 observations]. Archives des Maladies 
du Coeur et des Vaisseaux 1985;78(Spec No):99-103. [CRSREF: 6980760; MEDLINE:

PMID: 3938266; Other: ISSN: 0003-9683]

\section{Galperin 2014}

[CRSSTD: 6980761]

Galperin J, Elizari MV, Bonato R, Ledesma R, Vazquez Blanco M, Lago M, et al. Short-term amiodarone therapy after reversion of persistent atrial fibrillation reduces recurrences at 18 months. Cardiology Journal 2014;21(4):397-404. [CRSREF: 6980762; DOI:

10.5603/CJ.a2013.0152; PubMed: 24293165]

\section{Gold 1986}

[CRSSTD: 6980763]

Gold RL, Haffajee CI, Charos G, Sloan K, Baker S, Alpert JS. Amiodarone for refractory atrial fibrillation. American Journal of Cardiology 1986;57(1):124-7. [CRSREF: 6980764; MEDLINE: PMID: 3942054; Other: ISSN: 0002-9149]

\section{Gosselink 1992}

[CRSSTD: 6980765]

Gosselink AT, Crijns HJ, Van Gelder IC, Hillige H, Wiesfeld AC, Lie KI. Low-dose amiodarone for maintenance of sinus rhythm after cardioversion of atrial fibrillation or flutter. JAMA 1992;267(24):3289-93. [CRSREF: 6980766; MEDLINE: PMID: 1597910; Other: ISSN 0098-7484]

\section{Graboys 1983}

[CRSSTD: 6980767]

Graboys TB, Podrid PJ, Lown B. Efficacy of amiodarone for refractory supraventricular tachyarrhythmias. American Heart Journal 1983;106(4 Pt 2):870-6. [CRSREF: 6980768; MEDLINE: PMID: 6613832; Other: ISSN: 0002-8703]

\section{Gramley 2011}

[CRSSTD: 6980769]

Gramley F, Koellensperger E, Munzel T, Kettering KC. Dronedarone therapy after catheter ablation of atrial fibrillation: a new hybrid therapy option. Abstract from EHRA Europace 2629 June 2011 Madrid, Spain. Europace 2011;13 Suppl 3:NP. [CRSREF: 6980770; DOI: doi:10.1093/europace/eur214]

\section{Grigoriyan 2011}

[CRSSTD: 6980771] 
Grigoryan S, Hazarapetyan LGC. Procoralan as a preventive treatment for paroxysmal atrial fibrillation. Abstract from the ESC Congress 27-31 August 2011; Paris, France. European Heart Journal 2011;32 Suppl 1:624. [CRSREF: 6980772; DOI: 10.1093/eurheartj/ehr323]

\section{Gu 2012}

[CRSSTD: 6980773]

Gu J, Liu X, Tan H, Zhou L, Gu J, Jiang W, et al. Extensive antiarrhythmic drugs after catheter ablation of persistent atrial fibrillation. Acta Cardiologica 2012 Aug;67(4):407-14. [CRSREF: 6980774; PubMed: 22997994]

\section{GUSTO 2002}

[CRSSTD: 6980775]

* Wong CK, White HD, Wilcox RG, Criger DA, Califf RM, Topol EJ, Ohman EM. Management and outcome of patients with atrial fibrillation during acute myocardial infarction: the GUSTO-III experience. Global use of strategies to open occluded coronary arteries. Heart 2002;88(4):357-62. [CRSREF: 6980776; MEDLINE: PMID: 12231591; Other: ISSN 1355-6037]

\section{Hammill 1988}

[CRSSTD: 6980777]

Hammill SC, Wood DL, Gersh BJ, Osborn MJ, Holmes DR Jr. Propafenone for paroxysmal atrial fibrillation. American Journal of Cardiology 1988;61(6):473-4. [CRSREF: 6980778; MEDLINE: PMID: 3341233; Other: ISSN: 0002-9149]

\section{Hartel 1970}

[CRSSTD: 6980779]

Härtel G, Louhija A, Halonen PI. Investigations on the value of quinidine therapy after electrical rhythmization of atrial fibrillation [Untersuchungen über den Wert der Chinidinbehandlung nach elektrischer Rhythmisierung von Vorhofflimmern]. Die Medizinische Welt 1969;20(25):1464. [CRSREF: 6980780; MEDLINE: not indexed; Other: CENTRAL: CN-00247601]

Härtel G, Louhija A, Halonen PI. The value of quinidine therapy in order to maintain sinus rhythm after electrical rhythmization of atrial fibrillation [Der Wert der Chinidinbehandlung für die Erhaltung des Sinusrhythmus nach elektrischer Rhythmisierung von Vorhofflimmern]. Klinische Wochenschrift 1969;47(17):942. [CRSREF: 6980781; MEDLINE: not indexed; Other: CENTRAL: CN-00247602; ISSN: 0023-2173]

* Hartel G, Louhija A, Konttinen A, Halonen PI. Value of quinidine in maintenance of sinus rhythm after electric conversion of atrial fibrillation. British Heart Journal 1970;32(1):57-60. [CRSREF: 6980782; MEDLINE: PMID: 5417847; Other: ISSN 0007-0769]

\section{Hartel 1974}


[CRSSTD: 6980783]

Hartel G, Louhija A, Konttinen A. Disopyramide in the prevention of recurrence of atrial fibrillation after electroconversion. Clinical Pharmacology and Therapeutics 1974;15(6):5515. [CRSREF: 6980784; MEDLINE: PMID: 4601741; Other: ISSN 0009-9236]

\section{Hopson 1996}

[CRSSTD: 6980785]

Hopson JR, Buxton AE, Rinkenberger RL, Nademanee K, Heilman JM, Kienzle MG. Safety and utility of flecainide acetate in the routine care of patients with supraventricular tachyarrhythmias: results of a multicenter trial. The Flecainide Supraventricular Tachycardia Study Group. American Journal of Cardiology 1996;77(3):72A-82A. [CRSREF: 6980786; MEDLINE: PMID: 8607395; Other: ISSN 0002-9149]

\section{Horowitz 1985}

[CRSSTD: 6980787]

Horowitz LN, Spielman SR, Greenspan AM, Mintz GS, Morganroth J, Brown R, et al. Use of amiodarone in the treatment of persistent and paroxysmal atrial fibrillation resistant to quinidine therapy. Journal of the American College of Cardiology 1985;6(6):1402-7. [CRSREF: 6980788; MEDLINE: PMID: 4067122; Other: ISSN: 0735-1097]

\section{HOT-CAFE 2003}

[CRSSTD: 6980789]

Opolski G, Torbicki A, Kosior D, Stolarz P, Dawidowska R, Zawadzka M, et al. Should sinus rhythm be restored in patients with chronic atrial fibrillation? Preliminary results from the Polish "Hot Cafe" study [Czy przywracac rytm zatokowy u chorych z przewleklym migotaniem przedsionkow? Wstepne wyniki polskiego badania "Hot Cafe"]. Polskie Archiwum Medycyny Wewnetrznej 1999;101(5):413-8. [CRSREF: 6980790; MEDLINE: PMID: 10740421; Other: ISSN: 0032-3772]

Opolski G, Torbicki A, Kosior D, Szulc M, Zawadzka M, Pierscinska M, et al. Rhythm control versus rate control in patients with persistent atrial fibrillation. Results of the HOT CAFE Polish Study. Kardiologia Polska 2003;59(7):1-16. [CRSREF: 6980791; MEDLINE: PMID: 14560344; Other: ISSN 0022-9032]

* Opolski G, Torbicki A, Kosior DA, Szulc M, Wozakowska-Kaplon B, Kolodziej P, et al. Rate control vs rhythm control in patients with nonvalvular persistent atrial fibrillation: the results of the Polish How to Treat Chronic Atrial Fibrillation (HOT CAFE) Study. Chest 2004;126(2):476-86. [CRSREF: 6980792; MEDLINE: PMID: 15302734; Other: ISSN: 00123692]

\section{Ishiguro 2008}

[CRSSTD: 6980793] 
Ishiguro H, Ikeda T, Abe A, Tsukada T, Mera H, Nakamura K, Yusu S, Yoshino H. Antiarrhythmic effect of bisoprolol, a highly selective beta1-blocker, in patients with paroxysmal atrial fibrillation. International Heart Journal 2008 May;49(3):281-93. [CRSREF: 6980794; PubMed: 18612186]

\section{J-BAF 2009}

[CRSSTD: 6980795]

J-BAF Investigators, Yamashita T, Ogawa S, Sato T, Aizawa Y, Atarashi H, Fujiki A, et al. Dose-response effects of bepridil in patients with persistent atrial fibrillation monitored with transtelephonic electrocardiograms: a multicenter, randomized, placebo-controlled,doubleblind study (J-BAF Study). Circulation Journal 2009 Jun;73(6):1020-7. [CRSREF: 6980796; PubMed: PMID: 19359813]

\section{Jong 2006}

[CRSSTD: 6980797]

Jong GP, Chang MH, Chang TC, Chou P, Fu CY, Tien LY, et al. Long-term efficacy and safety of very-low-dose amiodarone treatment for the maintenance of sinus rhythm in patients with chronic atrial fibrillation after successful direct-current cardioversion. Chinese Medical Journal (English) 2006 Dec 20;119(24):2030-5. [CRSREF: 6980798; PubMed: PMID: 17199952]

\section{J-RHYTHM 2009}

[CRSSTD: 6980799]

J-RHYTHM Investigators, Ogawa S, Yamashita T, Yamazaki T, Aizawa Y, Atarashi H, Inoue $\mathrm{H}$, et al. Optimal treatment strategy for patients with paroxysmal atrial fibrillation: JRHYTHM Study. Circulation Journal 2009 Feb;73(2):242-8. [CRSREF: 6980800; PubMed: PMID: 19060419]

\section{Kanoupakis 2004}

[CRSSTD: 6980801]

Kanoupakis EM, Manios EG, Mavrakis HE, Tzerakis PG, Mouloudi HK, Vardas PE. Comparative effects of carvedilol and amiodarone on conversion and recurrence rates of persistent atrial fibrillation. American Journal of Cardiology 2004;94(5):659-62. [CRSREF: 6980802; MEDLINE: PMID: 15342304; Other: ISSN: 0002-9149]

\section{Kennelly 1977}

[CRSSTD: 6980803]

Kennelly BM. Comparison of lidoflazine and quindine in prophylactic treatment of arrhythmias. British Heart Journal 1977;39(5):540-6. [CRSREF: 6980804; MEDLINE: not indexed; Other: CENTRAL: CN-00345795; ISSN: 0007-0769] 


\section{Kerr 1988}

[CRSSTD: 6980805]

Kerr CR, Klein GJ, Axelson JE, Cooper JC. Propafenone for prevention of recurrent atrial fibrillation. American Journal of Cardiology 1988;61(11):914-6. [CRSREF: 6980806; MEDLINE: PMID: 3354467; Other: ISSN: 0002-9149]

\section{Khitri 2012}

[CRSSTD: 6980807]

Khitri AR, Aliot EM, Capucci A, Connolly SJ, Crijns H, Hohnloser SH, et al. Celivarone for maintenance of sinus rhythm and conversion of atrial fibrillation/flutter. Journal of Cardiovascular Electrophysiology 2012 May;23(5):462-72. [CRSREF: 6980808; DOI: 10.1111/j.1540-8167.2011.02234.x; PubMed: 22171925]

\section{Komatsu 2006}

[CRSSTD: 6980809]

Komatsu T, Sato Y, Tachibana H, Nakamura M, Horiuchi D, Okumura K. Randomized crossover study of the long-term effects of pilsicainide and cibenzoline in preventing recurrence of symptomatic paroxysmal atrial fibrillation: influence of the duration of arrhythmia before therapy. Circulation Journal 2006 Jun;70(6):667-72. [CRSREF: 6980810; PubMed: 16723785]

\section{Kosior 2001}

[CRSSTD: 6980811]

Kosior D, Karpinski G, Wretowski D, Stolarz P, Stawicki S, Rabczenko D, et al. Sequential prophylactic antiarrhythmic therapy for maintenance of sinus rhythm after cardioversion of persistent atrial fibrillation - One year follow-up. Kardiologia Polska 2002;56(4):361-7. [CRSREF: 6980812; MEDLINE: not indexed; Other: EMBASE: 2002162110; ISSN: 00229032]

Kosior D, Opolski G, Torbicki A. Efficacy of sequential antiarrhythmic treatment in sinus rhythm maintenance after successful electrocardioversion in patients with chronic nonvalvular atrial fibrillation. Medical Science Monitor 2001;7(1):68-73. [CRSREF: 6980813; MEDLINE: PMID: 11208496; Other: ISSN 1234-1010]

* Kosior D, Szulc M, Zawadzka M, PierScinska M, Stawicki S, Rabczenko D, et al. Role of amiodarone in sinus rhythm maintenance after successful cardioversion in patients with chronic non-valvular atrial fibrillation [Rola amiodaronu w utrzymaniu rytmu zatokowego po skutecznej kardiowersji elektrycznej u chorych z przetrwalym migotaniem]. Polskie Archiwum Medycyny Wewnetrznej 2002;108(6):1151-60. [CRSREF: 6980814; MEDLINE: PMID 12687927, MEDLINE 22574733; Other: ISSN 0032-3772]

\section{Kosior 2009}


Kosior DA, Kochanowski J, Scisło P, Piatkowski R, Postuła M, Rabczenko D, Opolski G. Efficacy and tolerability of oral propafenone versus quinidine in the treatment of recent onset atrial fibrillation: A randomized, prospective study. Cardiology Journal 2009;16(6):521-7. [CRSREF: 6980816; PubMed: 19950088]

\section{Kyles 1991}

[CRSSTD: 6980817]

Kyles AE, Murdock CJ, Yeung-Lai-Wah JA, Vorderbrugge S, Kerr CR. Long term efficacy of propafenone for prevention of atrial fibrillation. Canadian Journal of Cardiology 1991;7(9):407-9. [CRSREF: 6980818; MEDLINE: PMID: 1756420; Other: ISSN: 0828282X]

\section{Lardoux 1996}

[CRSSTD: 6980819]

Lardoux H, Maison Blanche P, Marchand X, Canler A, Rouesnel P, Bleinc D, et al. Cibenzoline versus propafenone by the oral route for preventing recurrence of atrial arrhythmia: multicenter, randomized, double-blind study [Cibenzoline versus propafénone par voie orale dans la prévention de la récidive des arythmies auriculaires: étude multicentrique randomisée realisée en double aveugle]. Annales de Cardiologie et d Angeiologie 1996;45(8):469-79. [CRSREF: 6980820; MEDLINE: PMID: 8952741; Other: ISSN: 0003-3928]

\section{Lau 1992}

[CRSSTD: 6980821]

Lau CP, Leung WH, Wong CK. A randomized double-blind crossover study comparing the efficacy and tolerability of flecainide and quinidine in the control of patients with symptomatic paroxysmal atrial fibrillation. American Heart Journal 1992;124(3):645-50. [CRSREF: 6980822; MEDLINE: PMID: 1514492; Other: ISSN: 0002-8703]

\section{Lee 2014}

[CRSSTD: 6980823]

Park L, Park S, Ko L, Choi L, Park K. Effect of pilsicainide versus other class IC antiarrhythmic drugs after catheter ablation of paroxysmal atrial fibrillation; prospective randomized study. In: 35th Annual Scientific Sessions of the Heart Rhythm Society, Heart Rhythm 2014. San Francisco, CA, United States. 2014 May 7-10. [CRSREF: 6980824; Other: https://clinicaltrials.gov/ct2/show/NCT01775891]

\section{Levi 1973}

[CRSSTD: 6980825] 
* Levi G, Proto C, Rovetta A. Double-blind evaluation of practolol and quinidine in the treatment of chronic atrial fibrillation. Cardiology 1973;58(6):364-8. [CRSREF: 6980826; MEDLINE: PMID: 4608474; Other: ISSN 0008-6312]

Quadri A, Levi GP, Proto C. Treatment of chronic artrial fibrillation with practolol-quinidine [Trattamento della fibrillazione atriale cronica con practololo-chinidina]. Minerva Cardioangiologica 1973;21(10):668-71. [CRSREF: 6980827; MEDLINE: PMID: 4589190; Other: ISSN 0026-4725]

\section{Li 2004}

[CRSSTD: 6980828]

Li H, Riedel R, Oldemeyer JB, Rovang K, Hee T. Comparison of recurrence rates after direct-current cardioversion for new-onset atrial fibrillation in patients receiving versus those not receiving rhythm-control drug therapy. American Heart Journal 2004;93(1):45-8.

[CRSREF: 6980829; MEDLINE: PMID: 14697464; Other: ISSN 0002-9149]

\section{Lobe 2013}

[CRSSTD: 6980830]

Löbe S, Salmáš J, John S, Kornej J, Husser D, Hindricks G, et al. Usefulness of dronedarone in patients with atrial arrhythmias. American Journal of Cardiology 2013;111(9):1311-4. [CRSREF: 6980831; DOI: 10.1016/j.amjcard.2012.12.057; PubMed: 23465099]

\section{Lodzinski 2014}

[CRSSTD: 6980832]

Lodziński P, Kiliszek M, Koźluk E, Piątkowska A, Balsam P, Kochanowski J, Scisło P, Piątkowski R, Opolski G. Does a blanking period after pulmonary vein isolation impact longterm results? Results after 55 months of follow-up. Cardiology Journal 2014;21(4):384-91. [CRSREF: 6980833; DOI: 10.5603/CJ.a2013.0144]

\section{Mă̌kov 2015}

[CRSSTD: 6980834]

Măkov EB, Iuricheva IuA, Mironov NIu, Sokolov SF, Golitsyn SP, Rozenshtraukh LV, Chazov EI. [Refralon (niferidil) is a new class III antiarrhythmic agent for pharmacological cardioversion for persistent atrial fibrillation and atrial flutter] [Article in Russian]. Terapevticheskii arkhiv 2015;87(1):38-48. [CRSREF: 6980835; DOI: 10.17116/terarkh201587138-48]

\section{Manios 2003}

[CRSSTD: 6980836]

Manios EG, Mavrakis HE, Kanoupakis EM, Kallergis EM, Dermitzaki DN, Kambouraki DC, et al. Effects of amiodarone and diltiazem on persistent atrial fibrillation conversion and 
recurrence rates: a randomized controlled study. Cardiovascular Drugs and Therapy 2003;17(1):31-9. [CRSREF: 6980837; MEDLINE: PMID: 12843685; Other: ISSN: 09203206]

\section{Martin 1986}

[CRSSTD: 6980838]

Martin A, Benbow LJ, Leach C, Bailey RJ. Comparison of amiodarone and disopyramide in the control of paroxysmal atrial fibrillation and atrial flutter. British Journal of Clinical Practice. Supplement 1986;44:52-60. [CRSREF: 6980839; MEDLINE: PMID: 3089263; Other: ISSN: 0260-8767]

\section{Mary-Rabine 1990}

[CRSSTD: 6980840]

Mary-Rabine L, Kulbertus HE. Clinical efficacy of flecainide acetate in atrial fibrillation. Cardiology 1990;77(6):443-9. [CRSREF: 6980841; MEDLINE: PMID: 2127378; Other: ISSN: 0008-6312]

\section{Massacci 1991}

[CRSSTD: 6980842]

Massacci E, Morellini C, De PG, Chioffi M, Longobardi M, Cellino F, et al. Flecainide versus amiodarone in preventing paroxysmal idiopathic atrial fibrillation. New Trends in Arrhythmias 1991;7(4):693-8. [CRSREF: 6980843; MEDLINE: not indexed; Other: EMBASE 1992241383]

\section{Meng 2015}

[CRSSTD: 6980844]

Meng Z, Tan J, He Q, Zhu M, Li X, Zhang J, Jia Q, Wang S, Zhang G, Zheng W. Wenxin Keli versus Sotalol for Paroxysmal Atrial Fibrillation Caused by Hyperthyroidism: A Prospective, Open Label, and Randomized Study. Evidence-Based Complementary and Alternative Medicine 2015;2015:101904. [CRSREF: 6980845; DOI: 10.1155/2015/101904]

\section{Mizutani 1995}

[CRSSTD: 6980846]

Mizutani N, Oki Y, Wakida Y, Iwa T, Haga M, Mizutani K, et al. Pilsicainide in the acute conversion and the prevention of paroxysmal atrial fibrillation. Japanese Pharmacology \& Therapeutics 1995;23(7):113-20. [CRSREF: 6980847; MEDLINE: not indexed; Other: EMBASE 1995251738]

\section{Mont 2014}

[CRSSTD: 6980848] 
Mont L, Bisbal F, Hernández-Madrid A, Pérez-Castellano N, Viñolas X, Arenal A, Arribas F, Fernández-Lozano I, Bodegas A, Cobos A, Matía R, Pérez-Villacastín J, Guerra JM, Ávila P, López-Gil M, Castro V, Arana JI, Brugada J; SARA investigators. Catheter ablation vs. antiarrhythmic drug treatment of persistent atrial fibrillation: a multicentre, randomized, controlled trial (SARA study). Eur Heart J 2014 Feb;35(8):501-7. [CRSREF: 6980849; DOI: 10.1093/eurheartj/eht457]

\section{Nedostup 1990}

[CRSSTD: 6980850]

Nedostup AV, Alekseevskaia MA, Novikov ID, Maevskaia IV. A comparison of the efficacy of quinidine and kordaron as agents to stabilize the recovered sinus rhythm in patients with the permanent form of atrial fibrillation [Sravnenie effektivnosti khinidina i kordarona kak sredstv stabilizatsii vosstanovlennogo sinusovogo ritma u bol'nykh s postoianno formo mertsatel'no aritmii]. Terapevticheskii Arkhiv 1990;62(9):47-51. [CRSREF: 6980851; MEDLINE: PMID: 2281406; Other: ISSN: 0040-3660]

\section{Opolski 1997}

[CRSSTD: 6980852]

Opolski G, Stanislawska J, Gorecki A, Swiecicka G, Torbicki A, Kraska T. Amiodarone in restoration and maintenance of sinus rhythm in patients with chronic atrial fibrillation after unsuccessful direct-current cardioversion. Clinical Cardiology 1997;20(4):337-40. [CRSREF: 6980853; MEDLINE: PMID: 9098591; Other: ISSN: 0160-9289]

\section{PEPS 2002}

[CRSSTD: 6980854]

Simon T, Mary-Krause M, Funck-Brentano C, Davy JM, Weingrod M, Jaillon P. Efficacy and tolerance of propafenone after correction of atrial fibrillation: PEPS pharmacoepidemiologic study [Efficacité et tolérance de la propafénone après régularisation de la fibrillation auriculaire: étude pharmaco-épidémiologique PEPS]. Archives des Maladies du Coeur et des Vaisseaux 2002;95(6):567-72. [CRSREF: 6980855; MEDLINE: PMID: 12138815; Other: ISSN 0003-9683]

\section{PIAF 2000}

[CRSSTD: 6980856]

Gronefeld GC, Lilienthal J, Kuck KH, Hohnloser SH. Impact of rate versus rhythm control on quality of life in patients with persistent atrial fibrillation. Results from a prospective randomized study. European Heart Journal 2003;24(15):1430-6. [CRSREF: 6980857; MEDLINE: PMID: 12909072; Other: ISSN: 0195-668X]

* Hohnloser SH, Kuck KH, Lilienthal J. Rhythm or rate control in atrial fibrillation-Pharmacological Intervention in Atrial Fibrillation (PIAF): a randomised trial. Lancet 2000;356(9244):1789-94. [CRSREF: 6980858; MEDLINE: PMID: 11117910; Other: ISSN 0140-6736] 


\section{Pietersen 1991}

[CRSSTD: 6980859]

* Pietersen AH, Hellemann H. Usefulness of flecainide for prevention of paroxysmal atrial fibrillation and flutter. Danish-Norwegian Flecainide Multicenter Study Group. American Journal of Cardiology 1991;67(8):713-7. [CRSREF: 6980860; MEDLINE: PMID: 1900978; Other: EMBASE 1991186337; ISSN: 0002-9149]

\section{Piot 1998}

[CRSSTD: 6980861]

* Piot O, Flammang D, Dambrine P, Cheikel J, Jouannon C, Graux P, et al. A randomized double-blind trial comparing cibenzoline and disopyramide in the prevention of recurrences of atrial tachyarrhythmia [Etude randomisee en double aveugle comparant la cibenzoline et le disopyramide dans la prevention de recidives de tachyarythmies atriales]. Archives des Maladies du Coeur et des Vaisseaux 1998;91(12):1481-6. [CRSREF: 6980862; MEDLINE: PMID: 9891831; Other: ISSN: 0003-9683]

\section{Porterfield 1989}

[CRSSTD: 6980863]

Porterfield JG, Porterfield LM. Therapeutic efficacy and safety of oral propafenone for atrial fibrillation. American Journal of Cardiology 1989;63(1):114-6. [CRSREF: 6980864;

MEDLINE: PMID: 2909141; Other: ISSN: 0002-9149]

\section{PSVT 1995}

[CRSSTD: 6980865]

Cobbe SM, Rae AP, Poloniecki JD, Chong E, Balnave K, Moriarty A, et al. A randomized, placebo-controlled trial of propafenone in the prophylaxis of paroxysmal supraventricular tachycardia and paroxysmal atrial fibrillation. UK Propafenone PSVT Study Group. Circulation 1995;92(9):2550-7. [CRSREF: 6980866; MEDLINE: PMID: 7586356; Other: ISSN 0009-7322]

\section{Qin 2016}

[CRSSTD: 6980867]

Qin D, Leef G, Bilal Alam M, Rattan R, Bilal Munir M, Patel D, Khattak F, Adelstein E, Jain SK, Saba S. Comparative effectiveness of antiarrhythmic drugs for rhythm control of atrial fibrillation. Journal of Cardiology May 2016;67(5):471-476. [CRSREF: 6980868; PubMed: 26233885]

\section{RACE 2002}

[CRSSTD: 6980869] 
Van Gelder IC, Hagens VE, Bosker HA, Kingma JH, Kamp O, Kingma T, et al. A comparison of rate control and rhythm control in patients with recurrent persistent atrial fibrillation. New England Journal of Medicine 2002;347(23):1834-40. [CRSREF: 6980870; MEDLINE: PMID: 12466507; Other: ISSN 0028-4793]

\section{Rakhmanova 2014}

Published data only (unpublished sought but not used) [CRSSTD: 6980871]

Rakhmanova MM. [Efficacy and safety of allapinine and quinidine bisulphate in the treatment of patients with persistent atrial fibrillation after cardioversion]. [Original in Russian]. Kardiologiia 2014;54(9):33-8. [CRSREF: 6980872; PubMed: 25702400]

\section{Rasmussen 1981}

[CRSSTD: 6980873]

Rasmussen K, Wang H, Fausa D. Comparative efficiency of quinidine and verapamil in the maintenance of sinus rhythm after DC conversion of atrial fibrillation. A controlled clinical trial. Acta Medica Scandinavica - Supplementum 1981;645:23-8. [CRSREF: 6980874; MEDLINE: PMID: 7015799; Other: ISSN 0365-463X]

\section{Resnekov 1971}

[CRSSTD: 6980875]

Resnekov L, Gibson D, Waich S, Muir J, McDonald L. Sustained-release quinidine (Kinidin Durules) in maintaining sinus rhythm after electroversion of atrial dysrhythmias. British Heart Journal 1971;33(2):220-5. [CRSREF: 6980876; MEDLINE: PMID: 5572656; Other: ISSN 0007-0769]

\section{STAF 2003}

[CRSSTD: 6980877]

Carlsson J, Miketic S, Windeler J, Cuneo A, Haun S, Micus S, et al. Randomized trial of ratecontrol versus rhythm-control in persistent atrial fibrillation: the Strategies of Treatment of Atrial Fibrillation (STAF) study. Journal of the American College of Cardiology 2003;41(10):1690-6. [CRSREF: 6980878; MEDLINE: PMID: 12767648; Other: ISSN 07351097]

\section{Steeds 1999}

[CRSSTD: 6980879]

Steeds RP, Birchall AS, Smith M, Channer KS. An open label, randomised, crossover study comparing sotalol and atenolol in the treatment of symptomatic paroxysmal atrial fibrillation. Heart 1999;82(2):170-5. [CRSREF: 6980880; MEDLINE: PMID 10409530, MEDLINE 99340341; Other: ISSN 1355-6037]

\section{Tonet 1986}


Tonet JL, Bernardeau C, Lechat P, Frank R, Touzet I, Fontaine G, et al. Comparison between the efficacy of amiodarone and quinidine in the treatment of atrial cardiac arrhythmias. British Journal of Clinical Practice. Supplement 1986;44:42-8. [CRSREF: 6980884; MEDLINE: PMID: 3089261; Other: ISSN: 0262-8767]

\section{Torp-Pedersen 2011}

[CRSSTD: 6980885]

Torp-Pedersen C, Raev DH, Dickinson G, Butterfield NN, Mangal B, Beatch GN. A randomized, placebo-controlled study of vernakalant (oral) for the prevention of atrial fibrillation recurrence after cardioversion. Circulation. Arrhythmia and Electrophysiology 2011;4(5):637-43. [CRSREF: 6980886; DOI: 10.1161/CIRCEP.111.962340; PubMed: 21841207]

\section{Touboul 1995}

[CRSSTD: 6980887]

Touboul P, Brembilla-Perrot B, Scheck F, Gabriel A, Lardoux H, Marchand X. Comparative effects of cibenzoline and hydroquinidine in the prevention of auricular fibrillation. A randomized double-blind study [Effets comparés de la cibenzoline et de l'hydroquinidine dans la prévention de la fibrillation auriculaire. Une étude randomisée en double aveugle]. Annales de Cardiologie et d Angeiologie 1995;44(9):525-31. [CRSREF: 6980888; MEDLINE: PMID: 8745663; Other: ISSN: 0003-3928]

\section{Van Wijk 1989}

[CRSSTD: 6980889]

van Wijk LM, den Heijer P, Crijns HJ, van Gilst WH, Lie KI. Flecainide versus quinidine in the prevention of paroxysms of atrial fibrillation. Journal of Cardiovascular Pharmacology 1989;13(1):32-6. [CRSREF: 6980890; MEDLINE: PMID:\&\#160;2468933; Other: ISSN: 0160-2446]

\section{VEPARAF 2003}

[CRSSTD: 6980891]

De Simone A, De Pasquale M, De Matteis C, Canciello M, Manzo M, Sabino L et al. VErapamil plus antiarrhythmic drugs reduce atrial fibrillation recurrences after an electrical cardioversion (VEPARAF Study). European Heart Journal 2003;25(15):1425-9. [CRSREF: 6980892; MEDLINE: PMID: 12909071; Other: 0195-668X]

\section{Wanless 1997}

[CRSSTD: 6980893] 
Wanless RS, Anderson K, Joy M, Joseph SP. Multicenter comparative study of the efficacy and safety of sotalol in the prophylactic treatment of patients with paroxysmal supraventricular tachyarrhythmias. American Heart Journal 1997;133(4):441-6. [CRSREF: 6980894; MEDLINE: PMID: 9124166; Other: ISSN: 0002-8703]

\section{Zehender 1992}

[CRSSTD: 6980895]

* Zehender M, Hohnloser S, Muller B, Meinertz T, Just H. Effects of amiodarone versus quinidine and verapamil in patients with chronic atrial fibrillation: results of a comparative study and a 2-year follow-up. Journal of the American College of Cardiology 1992;19(5):1054-9. [CRSREF: 6980896; MEDLINE: PMID: 1552095; Other: ISSN: 07351097]

Zehender M, Meinertz T, Just H. Amiodarone and verapamil/chinidin in the treatment of patients with chronic atrial fibrillation [Amiodaron und Verapamil/Chinidin in der Behandlung von Patienten mit chronischem Vorhofflimmern]. Zeitschrift fur Kardiologie 1994;83 Suppl 5:101-8. [CRSREF: 6980897; MEDLINE: not indexed; Other: EMBASE 1994379000; ISSN: 0300-5860]

\section{Zeriouh 2014}

[CRSSTD: 6980898]

Zeriouh M, Heider A, Rahmanian PB, Choi YH, Sabashnikov A, Scherner M, Popov AF, Weymann A, Ghodsizad A, Deppe AC, Kröner A, Kuhn-Régnier F, Wippermann J, Wahlers T. A novel treatment strategy of new onset atrial fibrillation after cardiac surgery: an observational prospective stud. Journal of Cardiothoracic Surgery 2014 May 12;9:83. [CRSREF: 6980899; DOI: 10.1186/1749-8090-9-83]

\section{Ongoing studies}

\section{Park 2017}

Park YM, Cha MS, Kang WC, Han SH, Koh KK, Ahn T, Choi IS, Shin EK. Efficacy of short- and long-term antiarrhythmic use (flecainide) in maintaining sinus rhythm in patients with first developed paroxysmal atrial fibrillation; Prospective-randomized study, interim analysis (Conference Abstract). Heart Rhythm 2017;14(5 Supplement 1):S304.

Park YM, Cha MS, Kang WC, Han SH, Koh KK, Ahn T, Choi IS, Shin EK. Efficacy of short-and long-term anti-arrhythmic use in maintaining sinus rhythm in patients with first developed paroxysmal atrial fibrillation; prospective-randomized stud, interim analysis (Conference Abstract). Europace 2017;19(Supplement 3):iii46.

\section{Other references}

\section{Additional references}




\section{ACC/AHA/ESC 2014}

January CT, Wann LS, Alpert JS, Calkins H, Cigarroa JE, Cleveland JC Jr, et al. 2014 AHA/ACC/HRS guideline for the management of patients with atrial fibrillation: a report of the American College of Cardiology/American Heart Association Task Force on Practice Guidelines and the Heart Rhythm Society. J Am Coll Cardiol 2014;64(21):e1-76. [DOI: 10.1016/j.jacc.2014.03.022; MEDLINE: PMID: 24685669]

\section{Alboni 2004}

Alboni P, Botto GL, Baldi N, Luzi M, Russo V, Gianfranchi L, et al. Outpatient treatment of recent-onset atrial fibrillation with the "pill-in-the-pocket" approach. New England Journal of Medicine 2004;351(23):2384-91. [MEDLINE: PMID: 15575054; Other: ISSN: 0028-4793]

\section{Anter 2009}

Anter E, Callans DJ, Wyse DG. Pharmacological and electrical conversion of atrial fibrillation to sinus rhythm is worth the effort. Circulation 2009 Oct 6;120(14):1436-43. [PubMed: 19805660]

\section{APAF 2006}

Pappone C, Augello G, Sala S, Gugliotta F, Vicedomini G, Gulletta S, Paglino G, Mazzone P, Sora N, Greiss I, Santagostino A, LiVolsi L, Pappone N, Radinovic A, Manguso F, Santinelli V. A randomized trial of circumferential pulmonary vein ablation versus antiarrhythmic drug therapy in paroxysmal atrial fibrillation: the APAF Study. J Am Coll Cardiol 2006 Dec 5;48(11):2340-7. [DOI: 10.1016/j.jacc.2006.08.037; PubMed: 17161267]

\section{Benjamin 1998}

Benjamin EJ, Wolf PA, D'Agostino RB, Silbershatz H, Kannel WB, Levy D. Impact of atrial fibrillation on the risk of death: the Framingham Heart Study. Circulation 1998;98(10):94652. [MEDLINE: PMID: 9737513; Other: ISSN 0009-7322]

\section{Caldeira 2012}

Caldeira D, David C, Sampaio C. Rate versus rhythm control in atrial fibrillation and clinical outcomes: updated systematic review and meta-analysis of randomized controlled trials. Archives of Cardiovascular Diseases 2012;105(4):226-38. [DOI: 10.1016/j.acvd.2011.11.005; PubMed: 22633297]

\section{Caldwell 2015}

Caldwell DM, Dias S, Welton NJ. Extending treatment networks in health technology assessment: how far should we go? Value Health 2015;18(5):673-681. [DOI: 10.1016/j.jval.2015.03.1792]

\section{CAST 1991}


Echt DS, Liebson PR, Mitchell LB, Peters RW, Obias-Manno D, Barker AH, et al. Mortality and morbidity in patients receiving encainide, flecainide, or placebo. The Cardiac Arrhythmia Suppression Trial. New England Journal of Medicine 1991;324:781-8. [Other: PMID: 1900101]

\section{CASTLE-AF 2018}

Marrouche NF, Brachmann J, Andresen D, Siebels J, Boersma L, Jordaens L, Merkely B, Pokushalov E, Sanders P, Proff J, Schunkert H, Christ H, Vogt J, Bänsch D; CASTLE-AF Investigators. Catheter Ablation for Atrial Fibrillation with Heart Failure. N Engl J Med 2018 Feb 1;378(5):417-427. [DOI: 10.1056/NEJMoa1707855; PubMed: 29385358]

\section{Chatterjee 2013}

Chatterjee S, Sardar P, Lichstein E, Mukherjee D, Aikat S. Pharmacologic rate versus rhythm-control strategies in atrial fibrillation: an updated comprehensive review and metaanalysis. Pacing and Clinical Electrophysiology: PACE 2013;36(1):122-33. [DOI: 10.1111/j.1540-8159.2012.03513.x; PubMed: 22978656]

\section{Chen 2012}

Chen HS, Wen JM, Wu SN, Liu JP. Catheter ablation for paroxysmal and persistent atrial fibrillation. Cochrane Database of Systematic Reviews 2012, Issue 4. Art. No.: CD007101. DOI: 10.1002/14651858.CD007101.pub2.

\section{Chugh 2014}

Chugh SS, Havmoeller R, Narayanan K, Singh D, Rienstra M, Benjamin EJ, et al. Worldwide epidemiology of atrial fibrillation: a Global Burden of Disease 2010 Study. Circulation 2014;129(8):837-47. [DOI: 10.1161/CIRCULATIONAHA.113.005119; PubMed: 24345399]

\section{Cipriani 2013}

Cipriani A, Higgins JP, Geddes JR, Salanti G. Conceptual and technical challenges in network meta-analysis. Ann Intern Med 2013;159(2):130-137. [DOI: 10.7326/0003-4819159-2-201307160-00008]

\section{Connolly 2000}

Connolly SJ. Appropriate outcome measures in trials evaluating treatment of atrial fibrillation. American Heart Journal 2000;139:752-60. [Other: PMID: 10783204]

\section{Coplen 1990}

Coplen SE, Antman EM, Berlin JA, Hewitt P, Chalmers TC. Efficacy and safety of quinidine therapy for maintenance of sinus rhythm after cardioversion. A meta-analysis of randomized control trials. Circulation 1990;82:1106-16. [Other: PMID: 2144796]

\section{Cordina 2005}


Cordina J, Mead G. Pharmacological cardioversion for atrial fibrillation and flutter. Cochrane Database of Systematic Reviews 2005, Issue 2. Art. No.: CD003713. DOI:

10.1002/14651858.CD003713.pub2. [MEDLINE: PMID 15846675]

\section{Denus 2005}

de Denus S, Sanoski CA, Carlsson J, Opolski G, Spinler SA. Rate vs rhythm control in patients with atrial fibrillation: a meta-analysis. Archives of Internal Medicine

2005;165(3):258-62. [MEDLINE: PMID: 15710787; Other: ISSN: 0003-9926]

\section{ESC 2016}

Kirchhof P, Benussi S, Kotecha D, Ahlsson A, Atar D, Casadei B, et al; ESC Scientific Document Group. 2016 ESC Guidelines for the management of atrial fibrillation developed in collaboration with EACTS. Eur Heart J 2016;37(38):2893-2962. [DOI:

10.1093/eurheartj/ehw210; PubMed: 27567408 ]

\section{Flaker 1995}

Flaker GC, Fletcher KA, Rothbart RM, Halperin JL, Hart RG: Stroke Prevention in Atrial Fibrillation (SPAF) Investigators. Clinical and echocardiographic features of intermittent atrial fibrillation that predict recurrent atrial fibrillation. American Journal of Cardiology 1995;76:355-8. [Other: PMID: 7639159]

\section{Freemantle 2011}

Freemantle N, Lafuente-Lafuente C, Mitchell S, Eckert L, Reynolds M. Mixed treatment comparison of dronedarone, amiodarone, sotalol, flecainide and propafenone, for the management of atrial fibrillation. Europace 2011;13(3):329-45. [PubMed: 21227948]

\section{Frick 2001}

Frick M, Frykman V, Jensen-Urstad M, Ostergren J, Rosenqvist M. Factors predicting success rate and recurrence of atrial fibrillation after first electrical cardioversion in patients with persistent atrial fibrillation. Clinical Cardiology 2001;24:238-44. [Other: PMID: 11288971]

\section{Friedman 1998}

Friedman PL, Stevenson WG. Proarrhythmia. American Journal of Cardiology 1998;82(8A):50N-8N. [MEDLINE: PMID: 9809901; Other: ISSN: 0002-9149]

\section{Gelder 1996}

Van Gelder IC, Crijns HJ, Tieleman RG, Brugemann J, De Kam PJ, Gosselink AT, et al. Chronic atrial fibrillation. Success of serial cardioversion therapy and safety of oral anticoagulation. Archives of Internal Medicine 1996;156:2585-92. [Other: PMID: 8951302]

\section{Geleris 2001}


Geleris P, Stavrati A, Afthonidis D, Kirpizidis H, Boudoulas H. Spontaneous conversion to sinus rhythm of recent (within 24 hours) atrial fibrillation. Journal of Cardiology 2001;37:103-7. [Other: PMID: 11255692]

\section{Go 2001}

Go AS, Hylek EM, Phillips KA, Chang Y, Henault LE, Selby JV, et al. Prevalence of diagnosed atrial fibrillation in adults: national implications for rhythm management and stroke prevention: the Anticoagulation and Risk Factors in Atrial Fibrillation (ATRIA) Study. JAMA 2001;285:2370-5. [Other: PMID: 11343485]

\section{Golzari 1996}

Golzari H, Cebul RD, Bahler RC. Atrial fibrillation: restoration and maintenance of sinus rhythm and indications for anticoagulation therapy. Annals of Internal Medicine 1996;125:311-23. [Other: PMID: 8678396]

\section{Harris 1983}

Harris L, McKenna WJ, Roxland E, Holt DW, Storey GC, Krikler DM. Side effects of longterm amiodarone therapy. Circulation 1983;67(1):45-51. [MEDLINE: PMID: 6291807;

Other: ISSN: 0009-7322]

\section{Haïssaguerre 1998}

Garrigue S, Bordier P, Jaïs P, Shah DC, Hocini M, Raherison C, et al. Spontaneous initiation of atrial fibrillation by ectopic beats originating in the pulmonary veins. New England Journal of Medicine 1998 Sep 3;339(10):659-66. [PubMed: 9725923]

\section{Heeringa 2006}

Heeringa J, van der Kuip DA, Hofman A, Kors JA, van Herpen G, Stricker BH, et al. Prevalence, incidence and lifetime risk of atrial fibrillation: the Rotterdam study. European Heart Journal 2006 Apr 27;27(8):949-53. [PubMed: 16527828]

\section{Higgins 2011}

Higgins JPT, Green S (editors). Cochrane Handbook for Systematic Reviews of Interventions Version 5.1.0 [updated March 2011]. The Cochrane Collaboration, 2011. Available from www.cochrane-handbook.org.

\section{Higgins 2017}

Higgins JPT, Altman DG, Sterne JAC (editors). Chapter 8: Assessing risk of bias in included studies.. In: Higgins JPT, Churchill R, Chandler J, Cumpston MS, editor(s). Cochrane Handbook for Systematic Reviews of Interventions version 5.2.0 (updated June2017). Cochrane, 2017.

\section{Khan 2014}


Khan AR, Khan S, Sheikh MA, Khuder S, Grubb B, Moukarbel GV. Catheter ablation and antiarrhythmic drug therapy as first- or second-line therapy in the management of atrial fibrillation: systematic review and meta-analysis. Circ Arrhythm Electrophysiol 2014 Oct;7(5):853-60. [DOI: 10.1161/CIRCEP.114.001853; PMID: 25110162]

\section{Knuiman 2014}

Knuiman M, Briffa T, Divitini M, Chew D, Eikelboom J, McQuillan B, et al. A cohort study examination of established and emerging risk factors for atrial fibrillation: the Busselton Health Study. European Journal of Epidemiology 2014 Mar;29(3):181-90. [DOI: 10.1007/s10654-013-9875-y; PubMed: 24389686]

\section{Krahn 1995}

Krahn AD, Manfreda J, Tate RB, Mathewson FA, Cuddy TE. The natural history of atrial fibrillation: incidence, risk factors, and prognosis in the Manitoba Follow-Up Study. American Journal of Medicine 1995;98:476-84. [Other: PMID: 7733127]

\section{Lafuente-Lafuente 2009}

Lafuente-Lafuente C, Alvarez JC, Leenhardt A, Mouly S, Extramiana F, Caulin C, et al. Amiodarone concentrations in plasma and fat tissue during chronic treatment and related toxicity. British Journal of Clinical Pharmacology 2009 May;67(5):511-9. [PubMed: 19552745]

\section{Lefebvre 2011}

Lefebvre C, Manheimer E, Glanville J. Chapter 6: Searching for studies. In: Higgins JT, Green S, editor(s). Cochrane Handbook for Systematic Reviews of Interventions Version 5.1.0 (updated March 2011). The Cochrane Collaboration, 2011. Available from www.cochrane-handbook.org..

\section{Miller 2000}

Miller MR, McNamara RL, Segal JB, Kim N, Robinson KA, Goodman SN, et al. Efficacy of agents for pharmacologic conversion of atrial fibrillation and subsequent maintenance of sinus rhythm: a meta-analysis of clinical trials. Journal of Family Practice 2000;49:1033-46. [Other: PMID: 11093570]

\section{MMWR 2003}

Ayala C, Wattigney WA, Croft JB, Hyduk A, Mensah GA, Davis H. Atrial fibrillation as a contributing cause of death and Medicare hospitalization -- United States, 1999. MMWR Morbidity and Mortality Weekly Report MMWR: Morbidity and Mortality Weekly Report 2003;52(7):128-31. [Other: PMID: 12617537]

\section{NICE 2014}


UK National Institute for Health and Clinical Excellence. Atrial fibrillation: the management of atrial fibrillation. (Clinical guideline 180). http://guidance.nice.org.uk/CG180 (Accessed 17 June 2014) 2014.

\section{Nichol 2002}

Nichol G, McAlister F, Pham B, Laupacis A, Shea B, Green M, et al. Meta-analysis of randomised controlled trials of the effectiveness of antiarrhythmic agents at promoting sinus rhythm in patients with atrial fibrillation. Heart 2002;87:535-43. [Other: PMID: 12010934]

\section{Oral 2006}

Oral H, Pappone C, Chugh A, Good E, Bogun F, et al. Circumferential pulmonary-vein ablation for chronic atrial fibrillation. New England Journal of Medicine 2006;354(9):934-41. [MEDLINE: PMID: 16510747; Other: ISSN: 0028-4793]

\section{Piccini 2009}

Piccini JP, Hasselblad V, Peterson ED, Washam JB, Califf RM, Kong DF. Comparative efficacy of dronedarone and amiodarone for the maintenance of sinus rhythm in patients with atrial fibrillation. J Am Coll Cardiol 2009;54(12):1089-95. [DOI:

10.1016/j.jacc.2009.04.085]

\section{PRISMA 2009}

PRISMA Group; Moher D, Liberati A, Tetzlaff J, Altman DG. Preferred reporting items for systematic reviews and meta-analyses: the PRISMA statement. PLoS Medicine 2009 Jul 21;6(7):e1000097. [PubMed: 19621072]

\section{Ruigomez 2002}

Ruigomez A, Johansson S, Wallander MA, Rodriguez LA. Incidence of chronic atrial fibrillation in general practice and its treatment pattern. Journal of Clinical Epidemiology 2002;55:358-63. [Other: PMID: 11927203]

\section{Saborido 2010}

Saborido CM, Hockenhull J, Bagust A, Boland A, Dickson R, Todd D. Systematic review and cost-effectiveness evaluation of 'pill-in-the-pocket' strategy for paroxysmal atrial fibrillation compared to episodic in-hospital treatment or continuous antiarrhythmic drug therapy. Health Technol Assess 2010 Jun;14(31):iii-iv, 1-75. [DOI: 10.3310/hta14310; PubMed: 20569652]

\section{SPAF 1992}

Flaker GC, Blackshear JL, McBride R, Kronmal RA, Halperin JL, Hart RG. Antiarrhythmic drug therapy and cardiac mortality in atrial fibrillation. The Stroke Prevention in Atrial Fibrillation Investigators. Journal of the American College of Cardiology 1992;20:527-32. [Other: PMID: 1512329] 


\section{Stewart 2002}

Stewart S, Hart CL, Hole DJ, McMurray JJ. A population-based study of the long-term risks associated with atrial fibrillation: 20-year follow-up of the Renfrew/Paisley study. American Journal of Medicine 2002;113:359-64. [Other: PMID: 12401529]

\section{Terasawa 2009}

Terasawa T, Balk EM, Chung M, Garlitski AC, Alsheikh-Ali AA, Lau J, Ip S. Systematic review: Comparative effectiveness of radiofrequency catheter ablation for atrial fibrillation. Annals of Internal Medicine 2009 Aug 4;15(3):191-202. [PubMed: 19581635]

\section{Testa 2005}

Testa L, Biondi-Zoccai GG, Russo AD, Bellocci F, Andreotti F, Crea F. Rate-control vs rhythm-control in patients with atrial fibrillation: a meta-analysis. European Heart Journal 2005;26(19):2000-6. [MEDLINE: PMID 15872032; Other: ISSN 0195-668X]

\section{Tonin 2017}

Tonin FS, Rotta I, Mendes AM, Pontarolo R. Network meta-analysis: a technique to gather evidence from direct and indirect comparisons. Pharmacy Practice 2017;15(1):943.

\section{Vaughan Williams 1984}

Vaughan Williams EM. A classification of antiarrhythmic actions reassessed after a decade of new drugs. Journal of Clinical Pharmacology 1984;24(4):129-47. [MEDLINE: PMID: 6144698; Other: ISSN: 0091-2700]

\section{Wattigney 2003}

Wattigney WA, Mensah GA, Croft JB. Increasing trends in hospitalization for atrial fibrillation in the United States, 1985 through 1999: implications for primary prevention. Circulation 2003;108:711-6. [Other: PMID: 12885749]

\section{Other published versions of this review}

\section{Lafuente-Lafuente}

Lafuente-Lafuente C, Mouly S, Longás-Tejero MA, Mahé I, Bergmann JF. Antiarrhythmic drugs for maintaining sinus rhythm after cardioversion of atrial fibrillation: a systematic review of randomised controlled trials. Archives of Internal Medicine 2006;166(7):719-28. [MEDLINE: PMID: 16606807; Other: ISSN: 0003-9926]

\section{Lafuente-Lafuente 2012}

Lafuente-Lafuente C, Longas-Tejero MA, Bergmann JF, Belmin J. Antiarrhythmics for maintaining sinus rhythm after cardioversion of atrial fibrillation. Cochrane Database of 
Systematic Reviews 2012, Issue 5. Art. No.: CD005049. DOI:

10.1002/14651858.CD005049.pub3.

\section{Lafuente-Lafuente 2015}

Lafuente-Lafuente C, Valembois L, Bergmann JF, Belmin J. Antiarrhythmics for maintaining sinus rhythm after cardioversion of atrial fibrillation. Cochrane Database of Systematic Reviews 2015, Issue 3. Art. No.: CD005049. DOI: 10.1002/14651858.CD005049.pub4.

\section{Classification pending references}

\section{Data and analyses}

\section{Quinidine vs. placebo / no treatment}

Outcome or Subgroup Studies Participants Statistical Method Effect Estimate

1.1 All-cause mortality - 6

main analysis

1.2 All-cause mortality - 6 sensitivity analysis ITT

Worst case: missing patients counted as events

1.3 All-cause mortality - 6 subgroup analysis: older and recent studies

1.3.1 Older studies, $\quad 4$ higher dose

1.3.2 More recent studies, 2 lower dose

1.4 All-cause mortality - 5 sensitivity analysis:

Persistent atrial fibrillation

1.5 All-cause mortality 2

Sensitivity analysis: Low risk of bias studies

1.6 All-cause mortality - 2

Sensitivity analysis:

Studies > 200 patients

1.7 Withdrawals due to adverse effects - main analysis

1.8 Withdrawals due to 7 adverse effects - subgroup analysis: older and recent studies
$1646 \quad$ Risk Ratio (M-H, Fixed, 2.01 [0.84, 4.77] 95\% CI)

1646 Risk Ratio (M-H, Fixed, 2.12 [0.96, 4.67] 95\% CI)

1646 Risk Ratio (M-H, Fixed, $2.01[0.84,4.77]$ 95\% CI)

$412 \quad$ Risk Ratio (M-H, Fixed, $2.74[0.85,8.83]$ 95\% CI)

1234 Risk Ratio (M-H, Fixed, 1.29 [0.34, 4.92] 95\% CI)

$865 \quad$ Risk Ratio (M-H, Fixed, $1.82[0.73,4.53]$ 95\% CI)

1234 Risk Ratio (M-H, Fixed, 1.29 [0.34, 4.92] 95\% CI)

1234 Risk Ratio (M-H, Fixed, 1.29 [0.34, 4.92] 95\% CI)

1669 Risk Ratio (M-H, Random, 1.56 [0.87, 2.78] 95\% CI)

1669 Risk Ratio (M-H, Random, 1.56 [0.87, 2.78] 95\% CI) 
1.8.1 Older studies,

higher dose

1.8.2 More recent studies, 2 lower dose

1.9 Withdrawals due to 5 adverse effects - sensitivity analysis: Persistent atrial fibrillation

1.10 Withdrawals due to 2 adverse effects -

Sensitivity analysis: Low risk of bias studies

1.11 Withdrawals due to 2 adverse effects -

Sensitivity analysis:

Studies $>200$ patients

1.12 Pro-arrhythmia - main 7 analysis

1.13 Pro-arrhythmia 7 subgroup analysis: older and recent studies

1.13.1 Older studies, $\quad 5$ higher dose

1.13.2 More recent

2

studies, lower dose

1.14 Pro-arrhythmia - 5

sensitivity analysis:

Persistent atrial fibrillation

1.15 Pro-arrhythmia - 2

Sensitivity analysis: Low

risk of bias studies

1.16 Pro-arrhythmia -

Sensitivity analysis:

Studies > 200 patients

1.17 Stroke - main analysis 4

1.18 Stroke - sensitivity 3 analysis: Persistent atrial fibrillation

1.19 Stroke - Sensitivity 1 analysis: Low risk of bias studies

1.20 Stroke - Sensitivity 1 analysis: Studies > 200 patients

1.21 Atrial fibrillation
435 Risk Ratio (M-H, Random, 3.05 [1.29, 7.22] 95\% CI)

1234 Risk Ratio (M-H, Random, 0.88 [0.61, 1.27] 95\% CI)

877 Risk Ratio (M-H, Random, 2.19 [0.99, 4.87] 95\% CI)

$1234 \quad$ Risk Ratio (M-H, Fixed, 0.85 [0.66, 1.08] 95\% CI)

$1234 \quad$ Risk Ratio (M-H, Fixed, $\quad 0.86$ [0.67, 1.09] 95\% CI)

1676 Risk Ratio (M-H, Fixed, 2.05 [0.95, 4.41] 95\% CI)

1677 Risk Ratio (M-H, Fixed, 2.05 [0.96, 4.42] 95\% CI)

$442 \quad$ Risk Ratio (M-H, Fixed, 3.14 [0.87, 11.32] 95\% CI)

1235 Risk Ratio (M-H, Fixed, 1.60 [0.61, 4.24] 95\% CI)

$877 \quad$ Risk Ratio (M-H, Fixed, $2.64[0.93,7.53]$ 95\% CI)

1235 Risk Ratio (M-H, Fixed, $\quad 1.60$ [0.61, 4.24] 95\% CI)

1235 Risk Ratio (M-H, Fixed, $\quad 1.60$ [0.61, 4.24] 95\% CI)

$1107 \quad$ Risk Ratio (M-H, Fixed, 0.97 [0.25, 3.83] 95\% CI)

$338 \quad$ Risk Ratio (M-H, Fixed, $0.88[0.19,4.01]$ 95\% CI)

Risk Ratio (M-H, Fixed, Subtotals only 95\% CI)

Risk Ratio (M-H, Fixed, Subtotals only 95\% CI)

1624 Risk Ratio (M-H, Fixed, 0.83 [0.78, 0.88] 
recurrence - main analysis

1.22 Atrial fibrillation

recurrence - sensitivity

analysis: Persistent atrial

fibrillation

1.23 Atrial fibrillation recurrence - Sensitivity analysis: Low risk of bias studies

1.24 Atrial fibrillation recurrence - Sensitivity analysis: Studies > 200 patients
$95 \% \mathrm{CI})$

$825 \quad$ Risk Ratio (M-H, Fixed, $\quad 0.77$ [0.70, 0.85] 95\% CI)

$1234 \quad$ Risk Ratio (M-H, Fixed, $\quad 0.85$ [0.80, 0.91] 95\% CI)

$1234 \quad$ Risk Ratio (M-H, Fixed, $0.86[0.80,0.92]$ $95 \% \mathrm{CI})$

\section{Disopyramide vs placebo/ no treatment}

\section{Outcome or Subgroup Studies Participants Statistical Method Effect Estimate}

2.1 All-cause mortality - 1

main analysis

2.2 All-cause mortality -

ITT Worst case: missing

patients counted as events

2.4 Withdrawals due to 2 adverse effects - main analysis

2.5 Withdrawals due to adverse effects -

Sensitivity analysis:

Persistent atrial fibrillation

2.7 Stroke - main analysis 2

2.8 Stroke - Subgroup 2

analysis: Persistent atrial

fibrillation

2.9 Atrial fibrillation 2

recurrence - main analysis

2.10 Atrial fibrillation

recurrence - sensitivity

analysis: Persistent atrial

fibrillation
92

Risk Ratio (M-H, Fixed, 95\% CI)

$5.00[0.25$,

101.37]

146 Risk Ratio (M-H, Fixed， 5.55 [0.68, 45.09] 95\% CI)

$146 \quad$ Risk Ratio (M-H, Fixed, 3.68 [0.95, 14.24] 95\% CI)

$146 \quad$ Risk Ratio (M-H, Fixed, 3.68 [0.95, 14.24] 95\% CI)

$146 \quad$ Risk Ratio (M-H, Fixed, $0.31[0.03,2.91]$ 95\% CI)

$146 \quad$ Risk Ratio (M-H, Fixed, 0.31 [0.03, 2.91] 95\% CI)

146 Risk Ratio (M-H, Fixed, $0.77[0.59,1.01]$ 95\% CI)

146 Risk Ratio (M-H, Fixed, $0.77[0.59,1.01]$ 95\% CI)

\section{Propafenone vs. placebo / no treatment}


3.1 All-cause mortality - 2

main analysis

3.2 All-cause mortality ITT Worst case: missing patients counted as events

3.3 All-cause mortality Sensitivity analysis: Low risk of bias studies

3.4 Withdrawals due to adverse effects - main analysis

3.5 Withdrawals due to adverse effects -

Sensitivity analysis:

Studies > 200 patients

3.6 Pro-arrhythmia - main 3 analysis

3.7 Pro-arrhythmia -

Sensitivity analysis: Low risk of bias studies

3.8 Atrial fibrillation recurrence - main analysis

3.9 Atrial fibrillation recurrence - Sensitivity analysis: Low risk of bias studies

3.10 Atrial fibrillation recurrence - Sensitivity analysis: Studies $>200$ patients
212 Risk Ratio (M-H, Fixed, 95\% CI)

$406 \quad$ Risk Ratio (M-H, Fixed, $1.28[0.45,3.62]$ 95\% CI)

102 Risk Ratio (M-H, Fixed, $0.11[0.00,2.64]$ 95\% CI)

1098 Risk Ratio (M-H, Fixed, 1.62 [1.07, 2.46] 95\% CI)

$523 \quad$ Risk Ratio (M-H, Fixed, 1.29 [0.79, 2.11] 95\% CI)

$381 \quad$ Risk Ratio (M-H, Fixed, 1.32 [0.39, 4.47] 95\% CI)

102 Risk Ratio (M-H, Fixed, $\quad 0.49$ [0.09, 2.75] 95\% CI)

1098 Risk Ratio (M-H, Fixed, 0.67 [0.61, 0.74] 95\% CI)

$102 \quad$ Risk Ratio (M-H, Fixed, $0.71[0.50,1.01]$ $95 \% \mathrm{CI})$

$523 \quad$ Risk Ratio (M-H, Fixed, $0.71[0.63,0.79]$ $95 \% \mathrm{CI})$

\section{Flecainide $v s$. placebo / no treatment}

\section{Outcome or Subgroup Studies Participants Statistical Method Effect Estimate}

4.1 All-cause mortality - 0

main analysis

4.2 All-cause mortality -

ITT Worst case: missing patients counted as events

4.3 Withdrawals due to 1 adverse effects - main analysis
0

362

73
Risk Ratio (M-H, Fixed, Not estimable 95\% CI)

Risk Ratio (M-H, Fixed, 95\% CI)

$1.30[0.45,3.72]$

Risk Ratio (M-H, Fixed, 95\% CI)

$15.41[0.91$, 260.19]

4.6 Pro-arrhythmia - main 4
Risk Ratio (M-H, Fixed, 
analysis

4.7 Pro-arrhythmia -

2

Sensitivity analysis:

Persistent atrial fibrillation

4.8 Pro-arrhythmia -

2

Sensitivity analysis: Low

risk of bias studies

4.9 Pro-arrhythmia -

Sensitivity analysis:

Studies > 200 patients

4.10 Stroke - main analysis 1

4.11 Stroke - Subgroup 1 analysis: Persistent atrial fibrillation

4.12 Stroke - Sensitivity 1 analysis: Low risk of bias studies

4.13 Stroke - Sensitivity 1 analysis: Studies $>200$

patients

4.14 Atrial fibrillation 4 recurrence - main analysis

4.15 Atrial fibrillation 2 recurrence - Sensitivity analysis: Persistent atrial fibrillation

4.16 Atrial fibrillation 2 recurrence - Sensitivity analysis: Low risk of bias studies

4.17 Atrial fibrillation $\quad 1$ recurrence - Sensitivity analysis: Studies $>200$ patients
$95 \% \mathrm{CI})$

$435 \quad$ Risk Ratio (M-H, Fixed, 6.35 [0.91, 44.22] 95\% CI)

$435 \quad$ Risk Ratio (M-H, Fixed, 6.35 [0.91, 44.22] 95\% CI)

Risk Ratio (M-H, Fixed, Subtotals only 95\% CI)

362 Risk Ratio (M-H, Fixed, 2.04 [0.11, 39.00] 95\% CI)

Risk Ratio (M-H, Fixed, Subtotals only 95\% CI)

Risk Ratio (M-H, Fixed, Subtotals only 95\% CI)

Risk Ratio (M-H, Fixed, Subtotals only 95\% CI)

$511 \quad$ Risk Ratio (M-H, Fixed, 0.65 [0.55, 0.77] 95\% CI)

$435 \quad$ Risk Ratio (M-H, Fixed, 0.71 [0.60, 0.85] 95\% CI)

$435 \quad$ Risk Ratio (M-H, Fixed, $0.71[0.60,0.85]$ 95\% CI)

Risk Ratio (M-H, Fixed, Subtotals only 95\% CI)

\section{Metoprolol vs. placebo / no treatment}

\section{Outcome or Subgroup Studies Participants Statistical Method Effect Estimate}

5.1 All-cause mortality - 2

main analysis

5.2 All-cause mortality ITT Worst case: missing patients counted as events
$562 \quad$ Risk Ratio (M-H, Fixed, 2.02 [0.37, 11.05] 95\% CI)

$562 \quad$ Risk Ratio (M-H, Fixed, $0.77[0.41,1.43]$ $95 \% \mathrm{CI})$ 
5.3 All-cause mortality - $\quad 2$

Sensitivity analysis:

Persistent atrial fibrillation

5.4 All-cause mortality - 2

Sensitivity analysis: Low

risk of bias studies

5.5 All-cause mortality - 1

Sensitivity analysis:

Studies > 200 patients

5.6 Withdrawals due to 2 adverse effects - main

analysis

5.7 Withdrawals due to adverse effects -

Sensitivity analysis:

Persistent atrial fibrillation

5.8 Withdrawals due to 2 adverse effects -

Sensitivity analysis: Low

risk of bias studies

5.9 Withdrawals due to 1 adverse effects -

Sensitivity analysis:

Studies > 200 patients

5.10 Pro-arrhythmia - main 2 analysis

5.11 Pro-arrhythmia -

2

Sensitivity analysis:

Persistent atrial fibrillation

5.12 Pro-arrhythmia - 2

Sensitivity analysis: Low

risk of bias studies

5.13 Pro-arrhythmia - 1

Sensitivity analysis:

Studies > 200 patients

5.14 Atrial fibrillation 2

recurrence - main analysis

5.15 Atrial fibrillation 2

recurrence - Sensitivity

analysis: Persistent atrial

fibrillation

5.16 Atrial fibrillation recurrence - Sensitivity analysis: Low risk of bias studies

5.17 Atrial fibrillation
$562 \quad$ Risk Ratio (M-H, Fixed, 2.02 [0.37, 11.05] 95\% CI)

$562 \quad$ Risk Ratio (M-H, Fixed, 2.02 [0.37, 11.05] 95\% CI)

$394 \quad$ Risk Ratio (M-H, Fixed, 7.00 [0.36,

95\% CI) 134.63]

$562 \quad$ Risk Ratio (M-H, Fixed, 3.47 [1.48, 8.15] 95\% CI)

$562 \quad$ Risk Ratio (M-H, Fixed, $\quad 3.47[1.48,8.15]$ 95\% CI)

$562 \quad$ Risk Ratio (M-H, Fixed, $3.47[1.48,8.15]$ 95\% CI)

$394 \quad$ Risk Ratio (M-H, Fixed, $3.33[1.37,8.12]$ 95\% CI)

562 Risk Ratio (M-H, Fixed, 18.14 [2.42, 95\% CI)

135.66]

562 Risk Ratio (M-H, Fixed, 18.14 [2.42, $95 \% \mathrm{CI}) \quad 135.66]$

562 Risk Ratio (M-H, Fixed, 18.14 [2.42, 95\% CI) 135.66]

Risk Ratio (M-H, Fixed, Subtotals only 95\% CI)

562 Risk Ratio (M-H, Random, 0.83 [0.68, 1.02] 95\% CI)

562 Risk Ratio (M-H, Random, 0.83 [0.68, 1.02] 95\% CI)

562 Risk Ratio (M-H, Random, 0.83 [0.68, 1.02] 95\% CI)

Risk Ratio (M-H, Fixed, Subtotals only 


\section{Amiodarone vs. placebo / no treatment}

\section{Outcome or Subgroup Studies Participants Statistical Method Effect Estimate}

\begin{tabular}{|c|c|c|c|c|}
\hline $\begin{array}{l}\text { 6.1 All-cause mortality - } \\
\text { Main analysis }\end{array}$ & 2 & 444 & $\begin{array}{l}\text { Risk Ratio (M-H, Fixed, } \\
95 \% \text { CI) }\end{array}$ & $1.66[0.55,4.99]$ \\
\hline $\begin{array}{l}6.2 \text { All-cause mortality - } \\
\text { ITT Worst case: missing }\end{array}$ & 2 & 444 & $\begin{array}{l}\text { Risk Ratio (M-H, Fixed, } \\
95 \% \text { CI) }\end{array}$ & $1.35[0.64,2.82]$ \\
\hline
\end{tabular}
patients counted as events

6.3 All-cause mortality - 2

Sensitivity analysis:

Persistent atrial fibrillation

6.4 Withdrawals due to 4 adverse effects - Main analysis

6.6 Withdrawals due to 1 adverse effects -

Sensitivity analysis: Low risk of bias studies

6.7 Pro-arrhythmia - Main 4 analysis

6.8 Pro-arrhythmia -

Sensitivity analysis:

Persistent atrial fibrillation

6.9 Pro-arrhythmia - 1

Sensitivity analysis: Low

risk of bias studies

6.10 Pro-arrhythmia - $\quad 1$

Sensitivity analysis:

Studies > 200 patients

6.11 Stroke - Main analysis 1

6.12 Stroke - Sensitivity 1 analysis: Persistent atrial fibrillation

6.13 Stroke - Sensitivity 1 analysis: Studies > 200 patients

6.14 Atrial fibrillation 6 recurrence - Main analysis

6.15 Atrial fibrillation 5
$444 \quad$ Risk Ratio (M-H, Fixed, $\quad 1.66[0.55,4.99]$ 95\% CI)

$319 \quad$ Risk Ratio (M-H, Fixed, 6.70 [1.91, 23.45] 95\% CI)

$99 \quad$ Risk Ratio (M-H, Fixed, 4.98 [0.65, 38.29] 95\% CI)

673 Risk Ratio (M-H, Fixed, $2.22[0.71,6.96]$ 95\% CI)

$498 \quad$ Risk Ratio (M-H, Fixed, $2.03[0.52,7.96]$ 95\% CI)

Risk Ratio (M-H, Fixed, Subtotals only 95\% CI)

Risk Ratio (M-H, Fixed, Subtotals only 95\% CI)

$399 \quad$ Risk Ratio (M-H, Fixed, $\quad 1.15$ [0.30, 4.39] 95\% CI)

Risk Ratio (M-H, Fixed, Subtotals only 95\% CI)

Risk Ratio (M-H, Fixed, Subtotals only 95\% CI)

812 Risk Ratio (M-H, Fixed, $0.52[0.46,0.58]$ 95\% CI)

687 Risk Ratio (M-H, Fixed, $0.52[0.46,0.58]$ 
recurrence - Sensitivity

analysis: Persistent atrial

fibrillation

6.16 Atrial fibrillation

recurrence - Sensitivity

analysis: Low risk of bias

studies

6.17 Atrial fibrillation $\quad 1$

recurrence - Sensitivity

analysis: Studies > 200

patients

2
$95 \% \mathrm{CI})$

498

Risk Ratio (M-H, Fixed, 95\% CI)

Risk Ratio (M-H, Fixed, Subtotals only 95\% CI)

\section{Dofetilide vs. placebo / no treatment}

Outcome or Subgroup Studies Participants Statistical Method Effect Estimate

7.1 All-cause mortality - 3

Main analysis

7.2 All-cause mortality - 3

ITT Worst case: missing

patients counted as events

7.3 All-cause mortality - 3

Sensitivity analysis:

Persistent atrial fibrillation

7.4 All-cause mortality -

Sensitivity analysis: Low

risk of bias studies

7.5 All-cause mortality - 3

Sensitivity analysis:

Studies > 200 patients

7.6 Withdrawals due to

adverse effects - Main

analysis

7.7 Withdrawals due to

adverse effects -

Sensitivity analysis:

Persistent atrial fibrillation

7.8 Withdrawals due to 2

adverse effects -

Sensitivity analysis:

Studies > 200 patients

7.9 Pro-arrhythmia - Main 3 analysis

7.10 Pro-arrhythmia -

Sensitivity analysis:

Persistent atrial fibrillation
1183 Risk Ratio (M-H, Fixed, $0.98[0.76,1.27]$ 95\% CI)

1183 Risk Ratio (M-H, Fixed, $1.02[0.79,1.31]$ 95\% CI)

1183 Risk Ratio (M-H, Fixed, $0.98[0.76,1.27]$ 95\% CI)

$506 \quad$ Risk Ratio (M-H, Fixed, 0.99 [0.77, 1.29] 95\% CI)

1183 Risk Ratio (M-H, Fixed, 0.98 [0.76, 1.27] 95\% CI)

677 Risk Ratio (M-H, Fixed, 1.77 [0.75, 4.18] 95\% CI)

677 Risk Ratio (M-H, Fixed, $1.77[0.75,4.18]$ 95\% CI)

$677 \quad$ Risk Ratio (M-H, Fixed, $\quad 1.77$ [0.75, 4.18] 95\% CI)

1183 Risk Ratio (M-H, Fixed, $\quad 5.50$ [1.33, 22.76] 95\% CI)

1183 Risk Ratio (M-H, Fixed, $\quad 5.50$ [1.33, 22.76] 95\% CI) 
7.11 Pro-arrhythmia -

Sensitivity analysis: Low

risk of bias studies

7.12 Pro-arrhythmia -

Sensitivity analysis:

Studies > 200 patients

7.13 Atrial fibrillation recurrence - Main analysis

7.14 Atrial fibrillation recurrence - sensitivity analysis: Persistent atrial fibrillation

7.15 Atrial fibrillation recurrence - Sensitivity analysis: Low risk of bias studies

7.16 Atrial fibrillation recurrence - Sensitivity analysis: Studies > 200 patients
$506 \quad$ Risk Ratio (M-H, Fixed, $9.29[0.50$ 95\% CI)

171.62]

1183 Risk Ratio (M-H, Fixed, $\quad 5.50$ [1.33, 22.76] 95\% CI)

1183 Risk Ratio (M-H, Random, 0.72 [0.61, 0.85] 95\% CI)

1183 Risk Ratio (M-H, Random, $0.72[0.61,0.85]$ 95\% CI)

$506 \quad$ Risk Ratio (M-H, Fixed, $0.62[0.54,0.70]$ $95 \% \mathrm{CI})$

1183 Risk Ratio (M-H, Random, $0.72[0.61,0.85]$ 95\% CI)

\section{Dronedarone $v s$. placebo / no treatment}

Outcome or Subgroup Studies Participants Statistical Method Effect Estimate

8.1 All-cause mortality - 3

Main analysis

8.2 All-cause mortality ITT Worst case: missing patients counted as events

8.3 All-cause mortality - 1

Sensitivity analysis:

Persistent atrial fibrillation

8.4 All-cause mortality - 1

Sensitivity analysis: Low

risk of bias studies

8.5 All-cause mortality - 2

Sensitivity analysis:

Studies $>200$ patients

8.6 Withdrawals due to 3

adverse effects - Main

analysis

8.7 Withdrawals due to 1 adverse effects -

Sensitivity analysis:

Persistent atrial fibrillation
6071 Risk Ratio (M-H, Fixed, $\quad 0.86$ [0.68, 1.09] 95\% CI)

$6071 \quad$ Risk Ratio (M-H, Fixed, 0.85 [0.67, 1.07] 95\% CI)

$199 \quad$ Risk Ratio (M-H, Fixed, 0.97 [0.04, 23.36] 95\% CI)

$4628 \quad$ Risk Ratio (M-H, Fixed, $\quad 0.84[0.66,1.07]$ 95\% CI)

$5872 \quad$ Risk Ratio (M-H, Fixed, $\quad 0.86[0.68,1.09]$ 95\% CI)

$6071 \quad$ Risk Ratio (M-H, Fixed, $1.58[1.34,1.85]$ 95\% CI)

199 Risk Ratio (M-H, Fixed, 14.51 [0.90, 95\% CI)
$234.74]$ 
8.8 Withdrawals due to 1 adverse effects -

Sensitivity analysis: Low risk of bias studies

8.9 Withdrawals due to 2 adverse effects -

Sensitivity analysis:

Studies > 200 patients

8.10 Pro-arrhythmia - main 2 analysis

8.11 Pro-arrhythmia - 1

Sensitivity analysis: Low risk of bias studies

8.12 Pro-arrhythmia - 1

Sensitivity analysis:

Studies > 200 patients

8.13 Stroke - Main analysis 2

8.14 Stroke - Sensitivity 2

analysis: Studies > 200

patients

8.15 Atrial fibrillation 2

recurrence - Main analysis

8.16 Atrial fibrillation 1

recurrence - Sensitivity

analysis: Persistent atrial

fibrillation

8.17 Atrial fibrillation $\quad 1$

recurrence - Sensitivity

analysis: Studies > 200

patients
4628

Risk Ratio (M-H, Fixed,

95\% CI)

$5872 \quad$ Risk Ratio (M-H, Fixed, $1.53[1.31,1.80]$ 95\% CI)

5872 Risk Ratio (M-H, Random, 1.95 [0.77, 4.98] 95\% CI)

Risk Ratio (M-H, Fixed, Subtotals only 95\% CI)

Risk Ratio (M-H, Fixed, Subtotals only 95\% CI)

$5872 \quad$ Risk Ratio (M-H, Fixed, $\quad 0.66$ [0.47, 0.95] 95\% CI)

5872 Risk Ratio (M-H, Fixed, $\quad 0.66$ [0.47, 0.95] 95\% CI)

1443 Risk Ratio (M-H, Fixed, 0.85 [0.80, 0.91] 95\% CI)

Risk Ratio (M-H, Fixed, Subtotals only 95\% CI)

Risk Ratio (M-H, Fixed, Subtotals only 95\% CI)

\section{Sotalol vs. placebo / no treatment}

Outcome or Subgroup Studies Participants Statistical Method Effect Estimate

9.1 All-cause mortality - $\quad 5 \quad 1882 \quad$ Risk Ratio (M-H, Fixed, $2.23[1.03,4.81]$

Main analysis 95\% CI)

9.2 All-cause mortality - $\quad 10$

2757 Risk Ratio (M-H, Fixed, 2.02 [1.28, 3.20]

ITT Worst case: missing 95\% CI)

patients counted as events

9.3 All-cause mortality - 3

1311 Risk Ratio (M-H, Fixed, 2.51 [1.06, 5.98]

Sensitivity analysis:

95\% CI)

Persistent atrial fibrillation

9.4 All-cause mortality - $\quad 3$

1311 Risk Ratio (M-H, Fixed, $2.51[1.06,5.98]$ 
Sensitivity analysis: Low

risk of bias studies

9.5 All-cause mortality - 4

Sensitivity analysis:

Studies > 200 patients

9.6 Withdrawals due to

adverse effects - Main

analysis

9.7 Withdrawals due to adverse effects - Sotalol:

heterogeneity study

9.7.1 PAFAC and

SOPAT trials

9.7.2 Rest of studies

10

1701

9.8 Withdrawals due to

6

adverse effects -

Sensitivity analysis:

Persistent atrial fibrillation

9.9 Withdrawals due to 4

adverse effects -

4

Sensitivity analysis: Low

risk of bias studies

9.10 Withdrawals due to

adverse effects -

5

Sensitivity analysis:

Studies > 200 patients

9.11 Pro-arrhythmia -

Main analysis

9.12 Pro-arrhythmia -

Sotalol: heterogeneity study

9.12.1 PAFAC and

SOPAT trials

9.12.2 Rest of studies

9

9.13 Pro-arrhythmia -

6

Sensitivity analysis:

Persistent atrial fibrillation

9.14 Pro-arrhythmia - 4

Sensitivity analysis: Low

risk of bias studies

9.15 Pro-arrhythmia - 6

Sensitivity analysis:

Studies > 200 patients

9.16 Stroke - Main analysis 3
$95 \% \mathrm{CI})$

1826 Risk Ratio (M-H, Fixed, 2.65 [1.16, 6.09] 95\% CI)

2688 Risk Ratio (M-H, Random, 1.95 [1.23, 3.11]

95\% CI)

2688 Risk Ratio (M-H, Random, 1.95 [1.23, 3.11]

95\% CI)

987 Risk Ratio (M-H, Random, $0.96[0.74,1.25]$ 95\% CI)

Risk Ratio (M-H, Random, 2.77 [1.81, 4.22] 95\% CI)

1350 Risk Ratio (M-H, Fixed, 1.75 [1.28, 2.41] 95\% CI)

1686 Risk Ratio (M-H, Random, 1.52 [0.82, 2.81] 95\% CI)

$1900 \quad$ Risk Ratio (M-H, Random, 1.81 [0.97, 3.35] 95\% CI)

$12 \quad 2989 \quad$ Risk Ratio (M-H, Fixed, $3.55[2.16,5.83]$ 95\% CI)

2826 Risk Ratio (M-H, Fixed, 3.43 [2.07, 5.67] 95\% CI)

$986 \quad$ Risk Ratio (M-H, Fixed, 1.49 [0.51, 4.37] 95\% CI)

$1840 \quad$ Risk Ratio (M-H, Fixed, 4.32 [2.40, 7.76] 95\% CI)

1687 Risk Ratio (M-H, Fixed, 4.37 [2.25, 8.52] 95\% CI)

1686 Risk Ratio (M-H, Fixed, $3.05[1.73,5.40]$ 95\% CI)

$2293 \quad$ Risk Ratio (M-H, Fixed, $\quad 3.00$ [1.77, 5.06] 95\% CI)

$1161 \quad$ Risk Ratio (M-H, Fixed, $1.47[0.48,4.51]$ 
9.17 Stroke - Sensitivity analysis: Persistent atrial fibrillation

9.18 Stroke - Sensitivity analysis: Low risk of bias studies

9.19 Stroke - Sensitivity

3 analysis: Studies > 200

patients

9.20 Atrial fibrillation $\quad 14$

recurrence - Main analysis

9.21 Atrial fibrillation

recurrence - Sensitivity analysis: Persistent atrial fibrillation

9.22 Atrial fibrillation recurrence - Sensitivity analysis: Low risk of bias studies

9.23 Atrial fibrillation 6 recurrence - Sensitivity analysis: Studies > 200 patients
$95 \% \mathrm{CI})$

$393 \quad$ Risk Ratio (M-H, Fixed, 1.35 [0.36, 5.00] 95\% CI)

$768 \quad$ Risk Ratio (M-H, Fixed, $\quad 1.85[0.20,16.71]$ 95\% CI)

$1161 \quad$ Risk Ratio (M-H, Fixed, 1.47 [0.48, 4.51] 95\% CI)

$3179 \quad$ Risk Ratio (M-H, Fixed, 0.83 [0.80, 0.87] 95\% CI)

1743 Risk Ratio (M-H, Fixed, $0.81[0.77,0.86]$ 95\% CI)

1686 Risk Ratio (M-H, Fixed, $0.86[0.82,0.91]$ 95\% CI)

Risk Ratio (M-H, Fixed, $\quad 0.85$ [0.81, 0.89] 95\% CI)

\section{Figures}

\section{Figure 1}


58 studies included from previous vesion of this review (1 previously included study was a duplicate with another included study and they have now been merged)

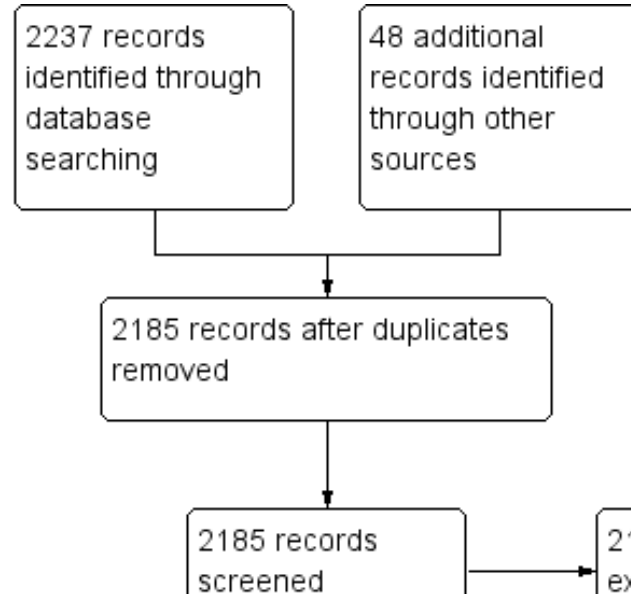

2163 records excluded

Full text excluded: 20

- Non-controlled or non-randomised trials: 8

- Acute treatment of AF only: 3

- Follow-up $<6$ months: 3

- Inadequate drug comparison (drug combination, not tested versus placebo): 6

Ongoing study: 1

Selection of studies for inclusion. 


\section{Figure 2 (Analysis 9.6)}

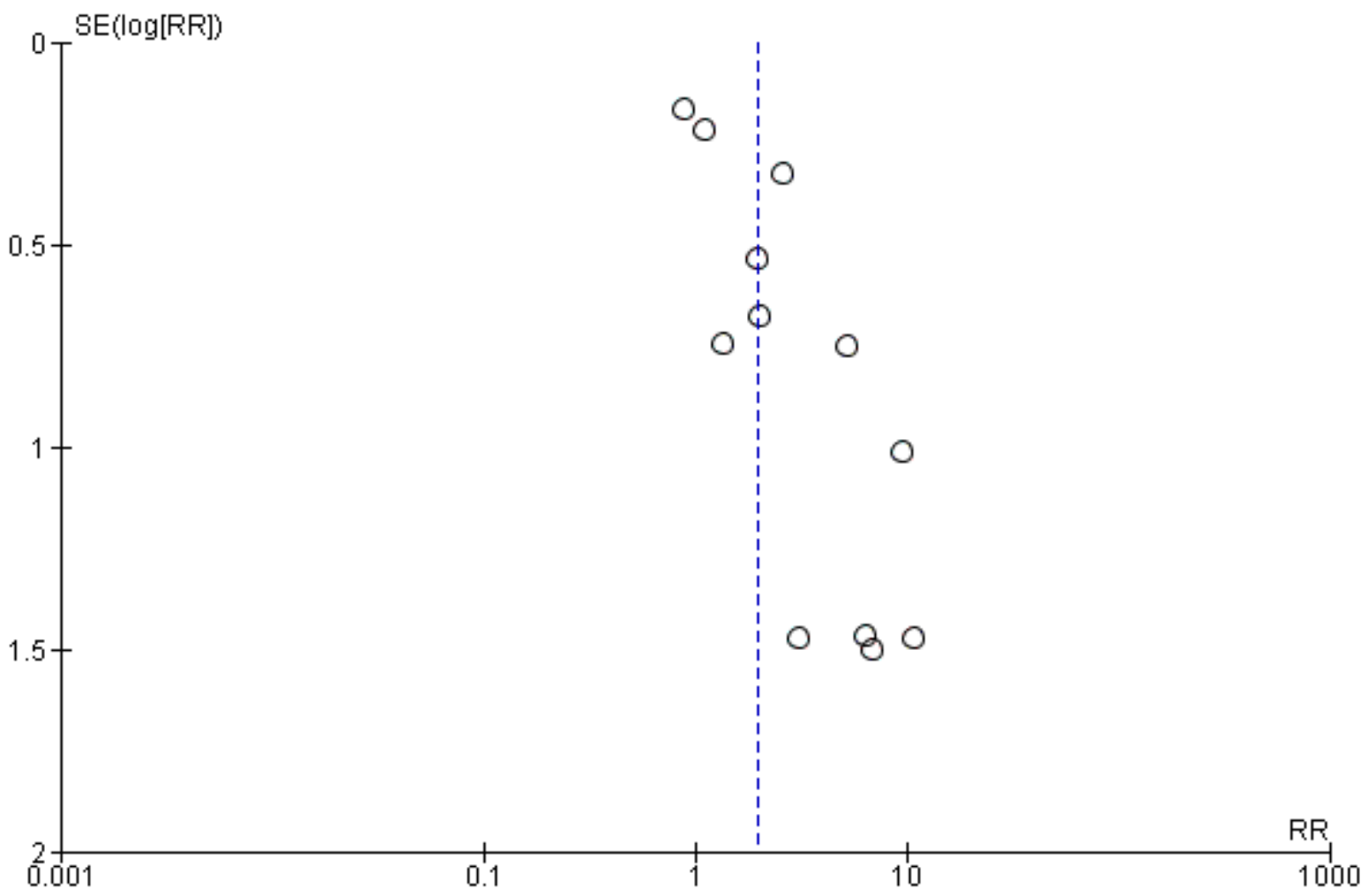

Funnel plot of comparison: 9 Sotalol $v s$. placebo / no treatment, outcome: 9.6 Withdrawals due to adverse effects - Main analysis.

\section{Figure 3}

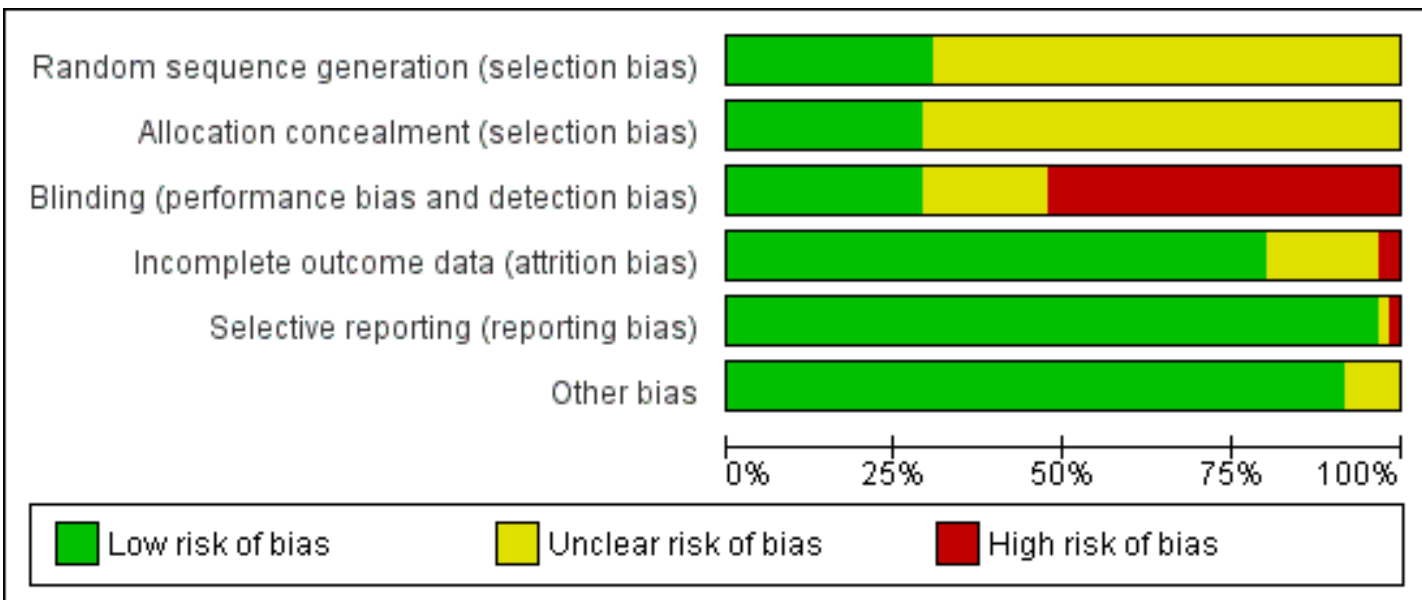

Risk of bias graph: review authors' judgements about each risk of bias item presented as percentages across all included studies.

\section{Figure 4}




\begin{tabular}{|c|c|c|c|c|c|c|}
\hline & 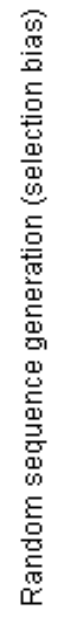 & 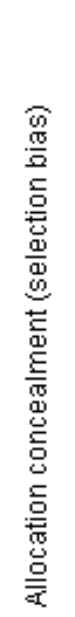 & 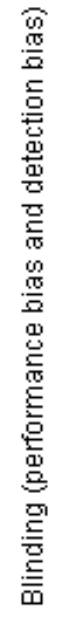 & 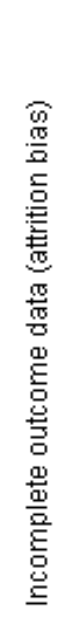 & 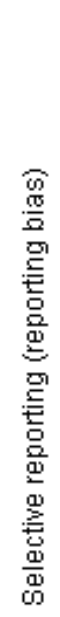 & 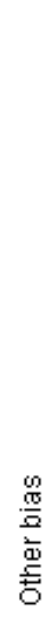 \\
\hline A-COMET-I 2006 & $?$ & $?$ & $\odot$ & $\odot$ & 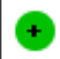 & + \\
\hline A-COMET-\| 2006 & + & $\odot$ & $\odot$ & $\odot$ & + & $\odot$ \\
\hline AFFIRM Substudy 2003 & + & + & $\odot$ & + & + & + \\
\hline AFIB 1997 & $?$ & $?$ & - & 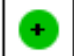 & + & + \\
\hline Aliot 1996 & ? & $?$ & $\odot$ & + & + & + \\
\hline ASAP 2003 & $?$ & $?$ & $?$ & 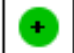 & + & $?$ \\
\hline A-STAR 2006 & $?$ & $?$ & $\odot$ & $?$ & + & + \\
\hline ATHENA 2009 & $?$ & $\odot$ & $?$ & 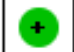 & $\odot$ & + \\
\hline Bellandi 2001 & $?$ & $?$ & $?$ & + & $\odot$ & + \\
\hline Benditt 1999 & + & + & + & + & + & + \\
\hline Byme-Quinn 1970 & $?$ & $?$ & + & - & + & + \\
\hline Carunchio 1995 & ? & $?$ & $\Theta$ & + & $\odot$ & $\odot$ \\
\hline Channer 2004 & + & + & + & + & + & + \\
\hline Chun 2014 & $?$ & $?$ & $O$ & + & $\theta$ & + \\
\hline DAFNE 2003 & $?$ & $?$ & $?$ & $?$ & + & + \\
\hline DAPHNE 2008 & $?$ & $?$ & $O$ & + & + & $?$ \\
\hline DIAMOND 2001 & + & + & + & + & + & $?$ \\
\hline Dogan 2004 & ? & $?$ & $\Theta$ & + & $\odot$ & + \\
\hline DYONISOS 2010 & $?$ & + & ? & + & $\odot$ & $\odot$ \\
\hline EMERALD 2000 & ? & $?$ & $?$ & + & + & + \\
\hline EURIDIS ADONIS 2007 & + & $?$ & + & + & + & $?$ \\
\hline FAPIS 1996 & + & $?$ & $O$ & + & + & + \\
\hline Flec-SL 2012 & + & + & $O$ & + & + & + \\
\hline GEFACA 2001 & ? & $?$ & $?$ & $?$ & $\odot$ & $\odot$ \\
\hline Hillestad 1971 & ? & $?$ & - & - & + & + \\
\hline Hohnloser 1995 & ? & $?$ & O & + & + & + \\
\hline Juul-Moller 1990 & ? & $?$ & $\Theta$ & + & $\odot$ & + \\
\hline Kalusche 1994 & $?$ & $?$ & $\Theta$ & + & + & + \\
\hline Karlson 1998 & $?$ & $\odot$ & $?$ & 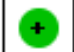 & + & 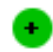 \\
\hline
\end{tabular}


Risk of bias summary: review authors' judgements about each risk of bias item for each included study.

\section{Figure 5 (Analysis 9.11)}

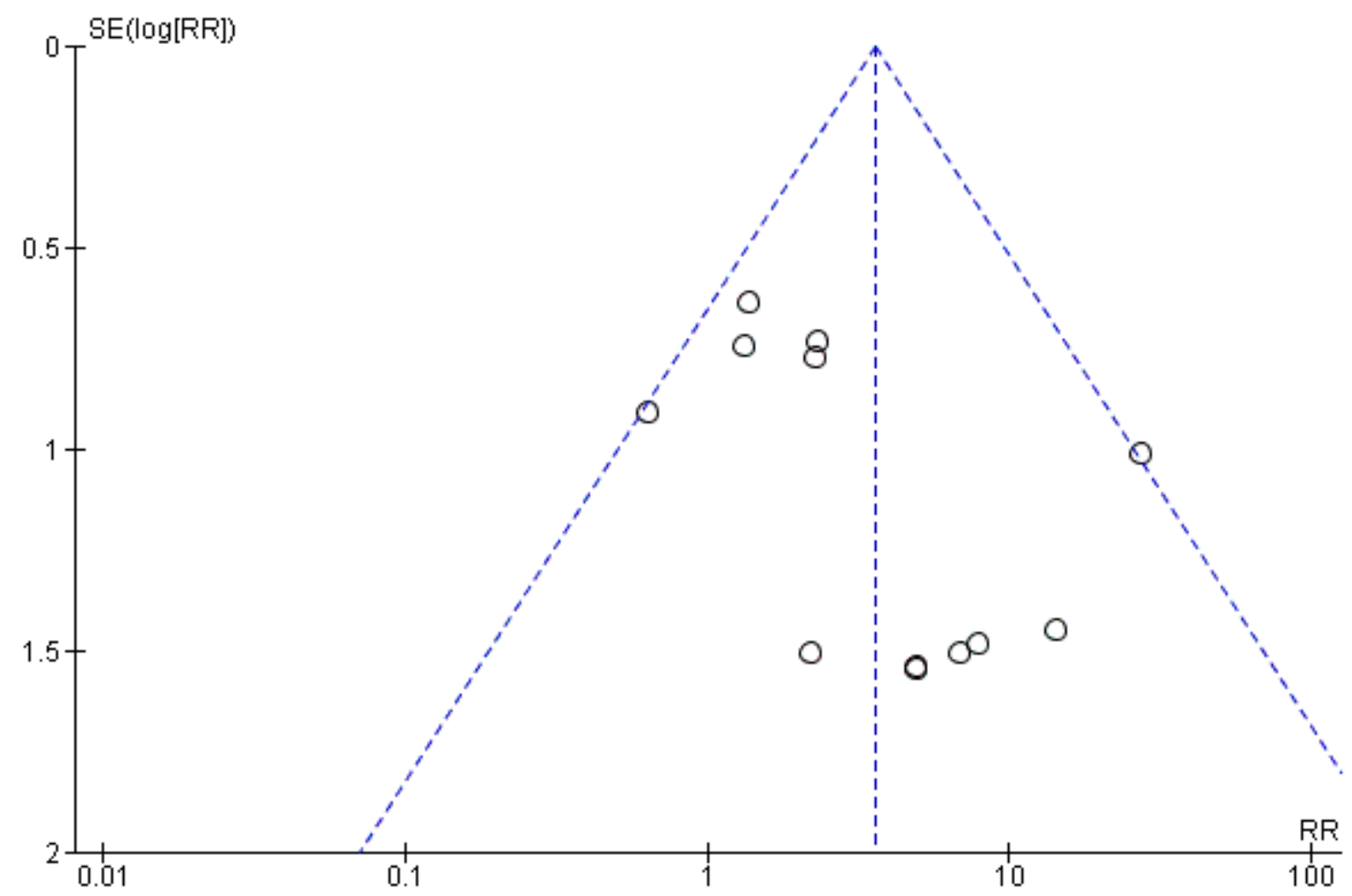

Funnel plot of comparison: 9 Sotalol vs. placebo / no treatment, outcome: 9.11 Proarrhythmia - Main analysis.

\section{Figure 6 (Analysis 9.20)}




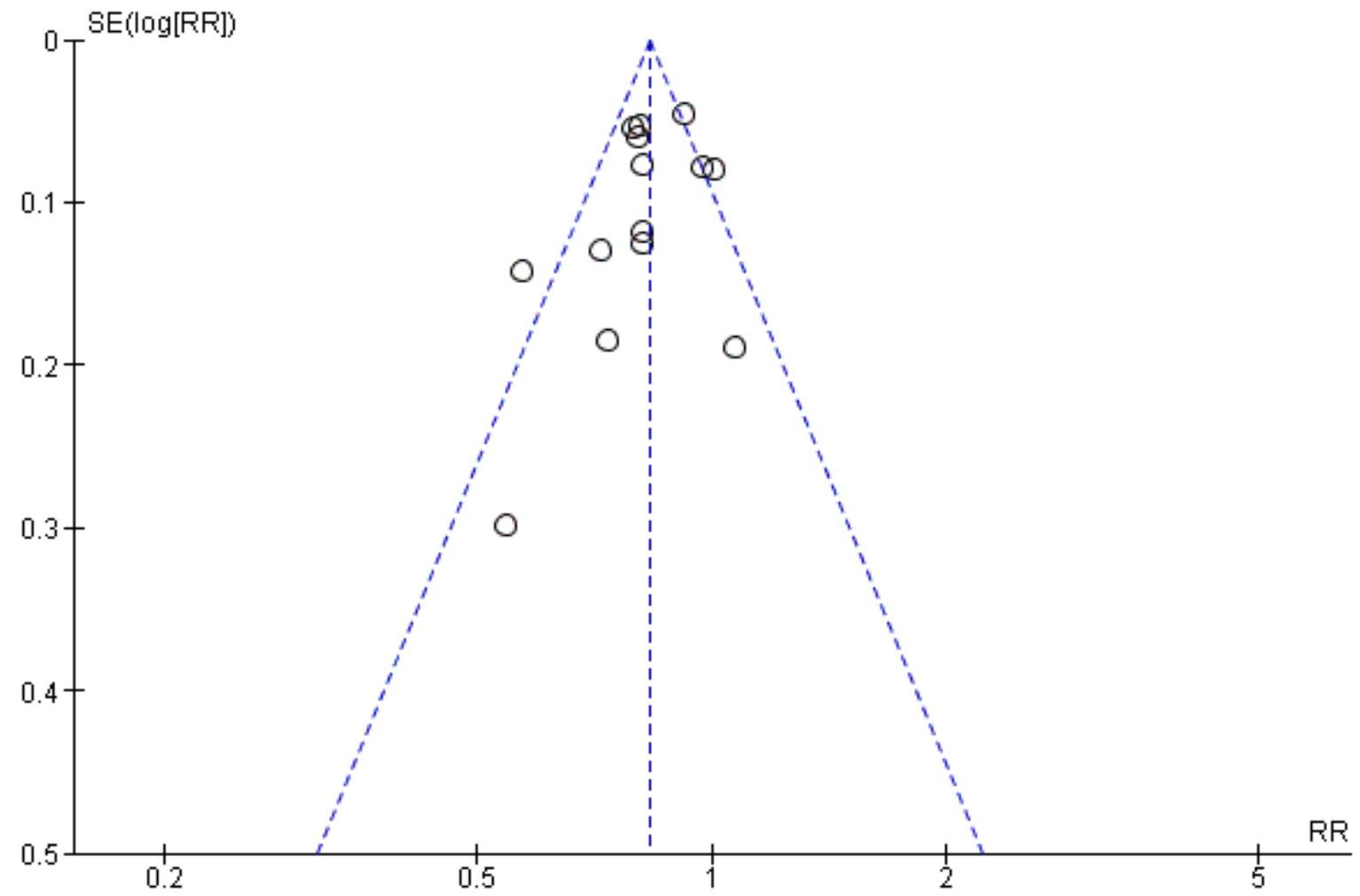

Funnel plot of comparison: 9 Sotalol vs. placebo / no treatment, outcome: 9.20 Atrial fibrillation recurrence - Main analysis.

\section{Figure 7 (Analysis 9.1)}

\begin{tabular}{|c|c|c|c|c|c|c|c|c|c|}
\hline \multirow[b]{2}{*}{ Study or Subgroup } & \multicolumn{2}{|c|}{ sotalol } & \multicolumn{2}{|c|}{ placebo / no treatment } & \multicolumn{3}{|c|}{ Risk Ratio } & \multirow{2}{*}{\multicolumn{2}{|c|}{$\begin{array}{c}\text { Risk Ratio } \\
\text { M-H, Fixed, 95\% C }\end{array}$}} \\
\hline & Events & Total & Events & Total & Weight & M-H, Fixed, $95 \% \mathrm{Cl}$ & & & \\
\hline A-COMET-\| 2006 & 4 & 223 & 0 & 224 & $5.0 \%$ & $9.04[0.49,166.93]$ & & & \\
\hline PAFAC 2004 & 13 & 383 & 2 & 88 & $32.5 \%$ & $1.49[0.34,6.50]$ & & & \\
\hline SAFE-T 2005 & 15 & 261 & 3 & 132 & $39.8 \%$ & $2.53[0.75,8.58]$ & & & \\
\hline SOPAT 2004 & 2 & 264 & 0 & 251 & $5.1 \%$ & $4.75[0.23,98.55]$ & & & \\
\hline Vijayalaskshmi 2006 & 0 & 33 & 1 & 23 & $17.6 \%$ & $0.24[0.01,5.53]$ & & & \\
\hline Total $(95 \% \mathrm{Cl})$ & & 1164 & & 718 & $100.0 \%$ & $2.23[1.03,4.81]$ & & & \\
\hline Total events & 34 & & 6 & & & & & & \\
\hline $\begin{array}{l}\text { Heterogeneity: } \mathrm{Chi}^{2}= \\
\text { Test for overall effect: }\end{array}$ & $\begin{array}{l}40, \mathrm{df}= \\
=2.04 \mathrm{~B}\end{array}$ & $\begin{array}{l}(P=0 \\
=0.04\end{array}$ & $49) ; I^{2}=0 \%$ & & & & 0.005 & 0.1 & L \\
\hline
\end{tabular}

\footnotetext{
Risk of bias legend

(A) Random sequence generation (selection bias)

(B) Allocation concealment (selection bias)

(C) Blinding (performance bias and detection bias)

(D) Incomplete outcome data (attrition bias)

(E) Selective reporting (reporting bias)

(F) Other bias
}

All-cause mortality with Sotalol compared with placebo / no treatment: Main analysis. 


\section{Sources of support}

\section{Internal sources}

- Unité de Recherches Thérapeutiques, Hôpital Lariboisière, Paris, France

- Assistance Publique - Hôpitaux de Paris, France

- Sorbonne Université, Paris, France

\section{External sources}

- No sources of support provided

\section{Appendices}

\section{Search strategies 2005}

\section{CENTRAL}

1 ATRIAL FIBRILLATION

2 (atrial near fibrillat*)

3 (auricular* near fibrillat*)

4 (atrium near fibrillat*)

5 (atrial next arrhythmi*)

6 (\#1 or \#2 or \#3 or \#4 or \#5)

7 ANTI-ARRHYTHMIA AGENTS

8 antiarrhythmi*

9 anti-arrhythmi*

10 (anti next arrhythmi*)

11 procainamide

12 disopyramide

13 quinidine

14 mexiletine

15 flecainide

16 propafenone

17 bisoprolol

18 esmolol

19 amiodarone

20 dofetilide

21 sotalol

22 azimilide

23 ibutilide

24 cibenzoline

25 moricizine

26 (\#7 or \#8 or \#9 or \#10 or \#11 or \#12 or \#13 or \#14 or \#15 or \#16 or \#17) 
27 (\#18 or \#19 or \#20 or \#21 or \#22 or \#23 or \#24 or \#25 or \#26)

28 (\#26 or \#27)

29 (\#6 and \#28)

\section{Search strategy for MEDLINE in PubMed}

("Atrial Fibrillation" (mh) OR ((atrial OR atrium OR auricular) AND fibrillat*)) AND

("Anti-Arrhythmia Agents" (mh) OR antiarrhythmi* (tw) OR anti-arrhythmi* (tw) OR procainamide (tw) OR disopyramide (tw) OR quinidine (tw) OR mexiletine (tw) OR flecainide (tw) propafenone (tw) OR bisoprolol (tw) OR esmolol (tw) OR amiodarone (tw) OR dofetilide (tw) OR sotalol (tw) OR ibutilide (tw) OR azimilide (tw) OR moricizine (tw) OR cibenzoline (tw))

AND

("randomized controlled trial" (pt) OR "controlled clinical trial" (pt) OR "randomized controlled trials" (mh) OR "random allocation" (mh) OR "double-blind method" (mh) OR "single-blind method" (mh) OR "clinical trial" (pt) OR "clinical trials" (mh) OR ("clinical trial" (tw)) OR ((singl* (tw) OR doubl* (tw) OR trebl* (tw) OR tripl* (tw)) AND (mask* (tw) OR blind* (tw))) OR ( placebos (mh) OR placebo* (tw) OR random* (tw) OR "research design" (mh:noexp) OR "comparative study" (mh) OR "evaluation studies" (mh) OR "followup studies" (mh) OR "prospective studies" (mh) OR control* (tw) OR prospectiv* (tw) OR volunteer* (tw)) NOT (animal (mh) NOT human (mh)))

Notes: The strategy to locate randomized controlled trials is the Cochrane highly sensitive search strategy (all phases), as contained in the Cochrane Reviewer's Handbook (ref: CR Handbook 2003).

The "related articles" feature of PubMed MEDLINE was also used.

\section{Search strategy for EMBASE.com}

\section{\# 1 (atrial OR 'atrium'/exp OR auricular) AND fibrillat*}

\# 2 'anti-arrhythmic' OR antiarrhythmi* OR 'procainamide'/exp OR 'disopyramide'/exp OR 'quinidine'/exp OR 'mexiletine'/exp OR 'flecainide'/exp OR 'propafenone'/exp OR 'bisoprolol'/exp OR 'esmolol'/exp OR 'amiodarone'/exp OR 'dofetilide'/exp OR 'sotalol'/exp OR 'ibutilide'/exp OR 'azimilide'/exp OR 'dronedarone'/exp OR 'moricizine'/exp OR 'cibenzoline'/exp

\# 3 'randomized controlled trial'/exp OR 'controlled clinical trial'/exp OR 'randomized controlled trials'/exp OR 'random allocation'/exp OR 'double-blind method'/exp OR 'singleblind method'/exp OR 'clinical trial'/exp OR 'clinical trials'/exp OR ((singl* OR doubl* OR trebl* OR tripl*) AND (mask* OR blind*)) OR ('placebos'/exp OR placebo* OR random* OR 'comparative study'/exp OR 'evaluation studies'/exp OR 'follow-up studies'/exp OR 'prospective studies'/exp OR control* OR prospectiv* OR volunteer*)

\# 4 \#1 AND \#2 AND \#3

Note: The "related articles" feature was also used. 


\section{Search strategies 2010}

\section{CENTRAL in The Cochrane Library}

\#1 MeSH descriptor Atrial Fibrillation this term only

\#2 (atrial in All Text near/3 fibrillat* in All Text)

\#3 (auricular* in All Text near/3 fibrillat* in All Text)

\#4 (atrium in All Text near/3 fibrillat* in All Text)

\#5 atrial next arrhythmi* in All Text

\#6 (\#1 or \#2 or \#3 or \#4 or \#5)

\#7 MeSH descriptor Anti-Arrhythmia Agents explode all trees

\#8 antiarrhythmi* in All Text

\#9 anti-arrhythmi* in All Text

\#10 dronedarone in All Text

\#11 amiodarone in All Text

\#12 bisoprolol in All Text

\#13 disopyramide in All Text

\#14 dofetilide in All Text

\#15 azimilide in All Text

\#16 ibutilide in All Text

\#17 flecainide in All Text

\#18 propafenone in All Text

\#19 quinidine in All Text

\#20 cibenzoline in All Text

\#21 moricizine in All Text

\#22 mexiletine in All Text

\#23 procainamide in All Text

\#24 sotalol in All Text

\#25 esmolol in All Text

$\# 26$ (\#7 or \#8 or \#9 or \#10 or \#11 or \#12 or \#13 or \#14 or \#15 or \#16)

$\# 27$ (\#17 or \#18 or \#19 or \#20 or \#21 or \#22 or \#23 or \#24 or \#25)

\#28 (\#26 or \#27)

\#29 (\#6 and \#28)

\section{MEDLINE on Ovid}

1 Atrial Fibrillation/

2 atrial fibrillation.tw.

3 atrium fibrillation.tw.

4 auricular fibrillation.tw.

5 or/1-4

6 exp Anti-Arrhythmia Agents/

7 antiarrhythmi\$.tw.

8 anti-arrhythmi\$.tw.

9 dronedarone.tw.

10 amiodarone.tw.

11 bisoprolol.tw.

12 disopyramide.tw.

13 dofetilide.tw. 
14 azimilide.tw.

15 ibutilide.tw.

16 flecainide.tw.

17 propafenone.tw.

18 quinidine.tw.

19 cibenzoline.tw.

20 moricizine.tw.

21 mexiletine.tw.

22 procainamide.tw.

23 sotalol.tw.

24 esmolol.tw.

25 or/6-24

265 and 25

27 randomized controlled trial.pt.

28 controlled clinical trial.pt.

29 Randomized controlled trials/

30 random allocation/

31 double blind method/

32 single-blind method/

33 or/27-32

34 exp animal/ not humans/

3533 not 34

36 clinical trial.pt.

37 exp Clinical Trials as Topic/

38 (clin\$ adj25 trial\$).ti,ab.

39 ((singl\$ or doubl\$ or trebl\$ or tripl\$) adj (blind\$ or mask\$)).ti,ab.

40 placebos/

41 placebo\$.ti,ab.

42 random\$.ti,ab.

43 research design/

44 or/36-43

4544 not 34

4635 or 45

4726 and 46

48 limit 47 to $y r=" 2005$ - 2010"

\section{EMBASE on Ovid to 2010 Week 06}

1 heart atrium fibrillation/

2 atrial fibrillation.tw.

3 atrium fibrillation.tw.

4 auricular fibrillation.tw.

5 or/1-4

6 exp antiarrhythmic agent/

7 antiarrhythmi\$.tw.

8 anti-arrhythmi\$.tw.

9 dronedarone.tw.

10 amiodarone.tw.

11 bisoprolol.tw.

12 disopyramide.tw. 
13 dofetilide.tw.

14 azimilide.tw.

15 ibutilide.tw.

16 flecainide.tw.

17 propafenone.tw.

18 quinidine.tw.

19 cibenzoline.tw.

20 moricizine.tw.

21 mexiletine.tw.

22 procainamide.tw.

23 sotalol.tw.

24 esmolol.tw.

25 or/6-24

265 and 25

27 random\$.tw.

28 factorial\$.tw.

29 (crossover\$ or cross-over\$).tw.

30 placebo\$.tw.

31 (doubl\$ adj blind\$).tw.

32 (singl\$ adj blind\$).tw.

33 assign $\$$.tw.

34 allocat\$.tw.

35 volunteer\$.tw.

36 Crossover Procedure/

37 Double-blind Procedure/

38 Randomized Controlled Trial/

39 Single-blind Procedure/

40 or/27-39

41 (animal/ or nonhuman/) not human/

4240 not 41

4326 and 42

44 limit 43 to $y r=" 2005-2010 "$

\section{Search strategies 2014}

Note: The RCT filter for MEDLINE was updated. The RCT filter for MEDLINE is now the Cochrane sensitivity-maximising RCT filter, and for EMBASE, terms as recommended in the Cochrane Handbook have been applied. (Lefebvre C, Manheimer E, Glanville J. Chapter 6: Searching for studies. In: Higgins JPT, Green S (editors). Cochrane Handbook for Systematic Reviews of Interventions Version 5.1.0 (updated March 2011). The Cochrane Collaboration, 2011. Available from www.cochrane-handbook.org.)

\section{CENTRAL}

\#1 MeSH descriptor Atrial Fibrillation this term only \#2 (atrial in All Text near/3 fibrillat* in All Text)

\#3 (auricular* in All Text near/3 fibrillat* in All Text) \#4 (atrium in All Text near/3 fibrillat* in All Text) \#5 atrial next arrhythmi* in All Text 
\#6 (\#1 or \#2 or \#3 or \#4 or \#5)

\#7 MeSH descriptor Anti-Arrhythmia Agents explode all trees

\#8 antiarrhythmi* in All Text

\#9 anti-arrhythmi* in All Text

\#10 dronedarone in All Text

\#11 amiodarone in All Text

\#12 bisoprolol in All; Text

\#13 disopyramide in All Text

\#14 dofetilide in All Text

\#15 azimilide in All Text

\#16 ibutilide in All Text

\#17 flecainide in All Text

\#18 propafenone in All Text

\#19 quinidine in All Text

\#20 cibenzoline in All Text

\#21 moricizine in All Text

\#22 mexiletine in All Text

\#23 procainamide in All Text

\#24 sotalol in All Text

\#25 esmolol in All Text

$\# 26$ (\#7 or \#8 or \#9 or \#10 or \#11 or \#12 or \#13 or \#14 or \#15 or \#16)

$\# 27$ (\#17 or \#18 or \#19 or \#20 or \#21 or \#22 or \#23 or \#24 or \#25)

\#28 (\#26 or \#27)

\#29 (\#6 and \#28)

\section{MEDLINE Ovid (up to October 2013)}

1 Atrial Fibrillation/

2 atrial fibrillation.tw.

3 atrium fibrillation.tw.

4 auricular fibrillation.tw.

5 or/1-4

6 exp Anti-Arrhythmia Agents/

7 antiarrhythmi\$.tw.

8 anti-arrhythmi\$.tw.

9 dronedarone.tw.

10 amiodarone.tw.

11 bisoprolol.tw.

12 disopyramide.tw.

13 dofetilide.tw.

14 azimilide.tw.

15 ibutilide.tw.

16 flecainide.tw.

17 propafenone.tw.

18 quinidine.tw.

19 cibenzoline.tw.

20 moricizine.tw.

21 mexiletine.tw.

22 procainamide.tw.

23 sotalol.tw. 
24 esmolol.tw.

25 or/6-24

265 and 25

27 randomized controlled trial.pt.

28 controlled clinical trial.pt.

29 randomized.ab.

30 placebo.ab.

31 drug therapy.fs.

32 randomly.ab.

33 trial.ab.

34 groups.ab.

3527 or 28 or 29 or 30 or 31 or 32 or 33 or 34

36 exp animals/ not humans.sh.

3735 not 36

3826 and 37(6063)

$39\left(201002^{*}\right.$ or $201003^{*}$ or $201004^{*}$ or $201005^{*}$ or $201006^{*}$ or $201007^{*}$ or $201008^{*}$ or

$201009^{*}$ or $201010^{*}$ or $201011^{*}$ or $201012^{*}$ or $2011^{*}$ or $2012^{*}$ or $\left.2013^{*}\right)$.ed.

4038 and 39

\section{MEDLINE PubMed (October 2013 to January 2014)}

("Atrial Fibrillation" (mh) OR ((atrial OR atrium OR auricular) AND fibrillat*)) AND

("Anti-Arrhythmia Agents" (mh) OR antiarrhythmi* (tw) OR anti-arrhythmi* (tw) OR procainamide (tw) OR disopyramide (tw) OR quinidine (tw) OR mexiletine (tw) OR

flecainide (tw) propafenone (tw) OR bisoprolol (tw) OR esmolol (tw) OR amiodarone (tw) OR dofetilide (tw) OR sotalol (tw) OR ibutilide (tw) OR azimilide (tw) OR moricizine (tw) OR cibenzoline (tw))

AND

("randomized controlled trial" (pt) OR "controlled clinical trial" (pt) OR randomized (tiab) OR placebo (tiab) OR "drug therapy" (sh) OR randomly (tiab) OR trial (tiab) OR groups (tiab)) NOT (animal (mh) NOT human (mh)))

\section{EMBASE Ovid (up to October 2013)}

1 exp heart atrium fibrillation/

2 atrial fibrillation.tw.

3 atrium fibrillation.tw.

4 auricular fibrillation.tw.

5 or/1-4

6 exp antiarrhythmic agent/

7 antiarrhythmi $\$ . t w$.

8 anti-arrhythmi\$.tw.

9 dronedarone.tw.

10 amiodarone.tw.

11 bisoprolol.tw.

12 disopyramide.tw.

13 dofetilide.tw.

14 azimilide.tw.

15 ibutilide.tw. 
16 flecainide.tw.

17 propafenone.tw.

18 quinidine.tw.

19 cibenzoline.tw.

20 moricizine.tw.

21 mexiletine.tw.

22 procainamide.tw.

23 sotalol.tw.

24 esmolol.tw.

25 or/6-24

265 and 25

27 random\$.tw.

28 factorial\$.tw.

29 crossover\$.tw.

30 cross over\$.tw.

31 cross-over $\$ . t w$.

32 placebo\$.tw.

33 (doubl\$ adj blind\$).tw.

34 (singl\$ adj blind $\$$ ).tw.

35 assign $\$$.tw.

36 allocat\$.tw.

37 volunteer\$.tw.

38 crossover procedure/

39 double blind procedure/

40 randomized controlled trial/

41 single blind procedure/

4227 or 28 or 29 or 30 or 31 or 32 or 33 or 34 or 35 or 36 or 37 or 38 or 39 or 40 or 41

43 (animal/ or nonhuman/) not human/

4442 not 43

4526 and 44

$46\left(2010 *\right.$ or $2011^{*}$ or $2012 *$ or $\left.2013 *\right)$.em.

$47\left(2010^{*}\right.$ or $2011^{*}$ or $2012^{*}$ or $\left.2013^{*}\right) . d d$.

4846 or 47

4945 and 48

\section{EMBASE.com (October 2013 to January 2014)}

("Atrial Fibrillation" (mh) OR ((atrial OR atrium OR auricular) AND fibrillat*))

\# 1 (atrial OR 'atrium'/exp OR auricular) AND fibrillat*

\# 2 'anti-arrhythmic' OR antiarrhythmi* OR 'procainamide'/exp OR 'disopyramide'/exp OR

'quinidine'/exp OR 'mexiletine'/exp OR 'flecainide'/exp OR 'propafenone'/exp OR

'bisoprolol'/exp OR 'esmolol'/exp OR 'amiodarone'/exp OR 'dofetilide'/exp OR 'sotalol'/exp

OR 'ibutilide'/exp OR 'azimilide'/exp OR 'dronedarone'/exp OR 'moricizine'/exp OR

'cibenzoline'/exp

\# 3 'randomized controlled trial'/exp OR 'randomized controlled trial' OR 'controlled clinical trial'/exp OR 'controlled clinical trial' OR randomized OR 'placebo'/exp OR placebo OR 'drug therapy'/exp OR 'drug therapy' OR randomly OR trial OR groups NOT ('animal'/exp OR animal NOT ('human'/exp OR human))

\# 4 \#1 AND \#2 AND \#3 


\section{Search strategies 2019}

CENTRAL

\#1 MeSH descriptor: [Atrial Fibrillation] this term only

\#2 atrial near/3 fibrillat*

\#3 auricular* near/3 fibrillat*

\#4 atrium near/3 fibrillat*

\#5 atrial next arrhythmi*

\#6 \#1 or \#2 or \#3 or \#4 or \#5

\#7 MeSH descriptor: [Anti-Arrhythmia Agents] explode all trees

\#8 antiarrhythmi*

\#9 anti-arrhythmi*

\#10 dronedarone

\#11 amiodarone

\#12 bisoprolol

\#13 disopyramide

\#14 dofetilide

\#15 azimilide

\#16 ibutilide

\#17 flecainide

\#18 propafenone

\#19 quinidine

\#20 cibenzoline

\#21 moricizine

\#22 mexiletine

\#23 procainamide 
\#24 sotalol

\#25 esmolol

$\# 26 \# 7$ or \#8 or \#9 or \#10 or \#11 or \#12 or \#13 or \#14 or \#15 or \#16

$\# 27 \# 17$ or \#18 or \#19 or \#20 or \#21 or \#22 or \#23 or \#24 or \#25

\#28 \#26 or \#27

\#29 \#6 and \#28 Publication Year from 2014 to 2019

MEDLINE Ovid

1 Atrial Fibrillation/

2 atrial fibrillat*.tw.

3 atrium fibrillat*.tw.

4 auricular fibrillat*.tw.

5 or/1-4

6 exp Anti-Arrhythmia Agents/

7 antiarrhythmi $\$ . t w$.

8 anti-arrhythmi\$.tw.

9 dronedarone.tw.

10 amiodarone.tw.

11 bisoprolol.tw.

12 disopyramide.tw.

13 dofetilide.tw.

14 azimilide.tw.

15 ibutilide.tw.

16 flecainide.tw.

17 propafenone.tw.

18 quinidine.tw. 
19 cibenzoline.tw.

20 moricizine.tw.

21 mexiletine.tw.

22 procainamide.tw.

23 sotalol.tw.

24 esmolol.tw.

25 or/6-24

265 and 25

27 randomized controlled trial.pt.

28 controlled clinical trial.pt.

29 randomized.ab.

30 placebo.ab.

31 drug therapy.fs.

32 randomly.ab.

33 trial.ab.

34 groups.ab.

3527 or 28 or 29 or 30 or 31 or 32 or 33 or 34

36 exp animals/ not humans.sh.

3735 not 36

3826 and 37

$39\left(2014^{*}\right.$ or $2015^{*}$ or $2016^{*}$ or $2017^{*}$ or $2018^{*}$ or $\left.2019^{*}\right) . e d$.

4038 and 39

$4138 \operatorname{not}\left(1^{*}\right.$ or $\left.2^{*}\right)$. ed.

4240 or 41

\section{Embase Ovid}


1 exp heart atrium fibrillation/

2 atrial fibrillation.tw.

3 atrium fibrillation.tw.

4 auricular fibrillation.tw.

5 or/1-4

6 exp antiarrhythmic agent/

7 antiarrhythmi\$.tw.

8 anti-arrhythmi\$.tw.

9 dronedarone.tw.

10 amiodarone.tw.

11 bisoprolol.tw.

12 disopyramide.tw.

13 dofetilide.tw.

14 azimilide.tw.

15 ibutilide.tw.

16 flecainide.tw.

17 propafenone.tw.

18 quinidine.tw.

19 cibenzoline.tw.

20 moricizine.tw.

21 mexiletine.tw.

22 procainamide.tw.

23 sotalol.tw.

24 esmolol.tw.

25 or/6-24 
265 and 25

27 random\$.tw.

28 factorial\$.tw.

29 crossover\$.tw.

30 cross over\$.tw.

31 cross-over\$.tw.

32 placebo\$.tw.

33 (doubl\$ adj blind\$).tw.

34 (singl\$ adj blind\$).tw.

35 assign $\$ . t w$.

36 allocat\$.tw.

37 volunteer\$.tw.

38 crossover procedure/

39 double blind procedure/

40 randomized controlled trial/

41 single blind procedure/

4227 or 28 or 29 or 30 or 31 or 32 or 33 or 34 or 35 or 36 or 37 or 38 or 39 or 40 or 41

43 (animal/ or nonhuman/) not human/

4442 not 43

4526 and 44

$46\left(2014^{*}\right.$ or $2015^{*}$ or $2016^{*}$ or $2017^{*}$ or $2018^{*}$ or $\left.2019^{*}\right) . e m$.

$47\left(2014^{*}\right.$ or $2015^{*}$ or $2016^{*}$ or $2017^{*}$ or $2018^{*}$ or $\left.2019 *\right)$.dd.

4846 or 47

4945 and 48

ClinicalTrials.gov

Condition or disease: 
Atrial Fibrillation OR atrial fibrillat* OR atrium fibrillat* OR auricular fibrillat* Other terms:

antiarrhythmi* OR anti-arrhythmi* OR dronedarone OR amiodarone OR bisoprolol OR disopyramide OR dofetilide OR azimilide OR ibutilide OR flecainide OR propafenone OR quinidine OR cibenzoline OR moricizine OR mexiletine OR procainamide OR sotalol Filters: Recruiting: All ; Country: All

\section{WHO ICTRP}

Advanced Search:

title: atrial fibrillation

Condition:

Atrial Fibrillation OR atrial fibrillat* OR atrium fibrillat* OR auricular fibrillat* Intervention:

antiarrhythmi $*$ OR anti-arrhythmi* OR dronedarone OR amiodarone OR bisoprolol OR disopyramide OR dofetilide OR azimilide OR ibutilide OR flecainide OR propafenone OR quinidine OR cibenzoline OR moricizine OR mexiletine OR procainamide OR sotalol Filters: Recruiting: All ; Country: All ; Phases: All 